\title{
Microbial growth yield estimates from thermodynamics and its importance for degradation of pesticides and formation of biogenic non-extractable residues
}

\author{
Brock, Andreas Libonati; Kästner, M.; Trapp, Stefan
}

Published in:

SAR and QSAR in Environmental Research

Link to article, DOI:

10.1080/1062936X.2017.1365762

Publication date:

2017

Document Version

Peer reviewed version

Link back to DTU Orbit

Citation (APA):

Brock, A. L., Kästner, M., \& Trapp, S. (2017). Microbial growth yield estimates from thermodynamics and its importance for degradation of pesticides and formation of biogenic non-extractable residues. SAR and QSAR in Environmental Research, 28(8), 629-650. https://doi.org/10.1080/1062936X.2017.1365762

\section{General rights}

Copyright and moral rights for the publications made accessible in the public portal are retained by the authors and/or other copyright owners and it is a condition of accessing publications that users recognise and abide by the legal requirements associated with these rights.

- Users may download and print one copy of any publication from the public portal for the purpose of private study or research.

- You may not further distribute the material or use it for any profit-making activity or commercial gain

- You may freely distribute the URL identifying the publication in the public portal 


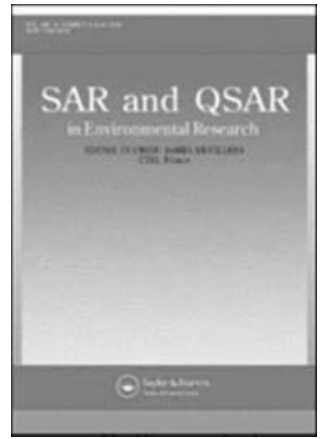

\section{Microbial growth yield estimates from thermodynamics and its importance for degradation of pesticides and formation of biogenic non-extractable residues}

\begin{tabular}{|r|l|}
\hline Journal: & SAR and QSAR in Environmental Research \\
\hline Manuscript ID & SQER-2017-0051.R2 \\
\hline Danuscript Type: & Special Issue Articles \\
\hline Complete List of Authors: & $\begin{array}{l}\text { Brock, Andreas; Danmarks Tekniske Universitet Institut for Vand og } \\
\text { Miljoteknologi } \\
\text { Kästner, Matthias; Helmholtz-Zentrum fur Umweltforschung UFZ, } \\
\text { Department of Environmental Biotechnology } \\
\text { Trapp, Stefan; Danmarks Tekniske Universitet Institut for Vand og } \\
\text { Miljoteknologi }\end{array}$ \\
\hline Keywords: & $\begin{array}{l}\text { xenobiotics, biodegradation, microbial biomass, turnover modelling, bound } \\
\text { residues, organic chemicals of environmental concern }\end{array}$ \\
\hline & \\
\hline
\end{tabular}

\section{SCHOLARONE}

Manuscripts 
1 Microbial growth yield estimates from thermodynamics and its

2 importance for degradation of pesticides and formation of biogenic

3 non-extractable residues

4 Andreas Libonati Brock ${ }^{\mathrm{a},{ }^{*}}$, Matthias Kästner ${ }^{\mathrm{b}}$, Stefan Trapp ${ }^{\mathrm{a}}$,

$5 \quad{ }^{a}$ Department of Environmental Engineering, Technical University of Denmark, Kgs.

6 Lyngby, Denmark

$7 \quad{ }^{b}$ UFZ_Helmholtz Centre for Environmental Research, Department of Environmental

8 Biotechnology, Leipzig, Germany

9 *alib@env.dtu.dk, Phone: +45 45251408

10

11 
12 Microbial growth yield estimates from thermodynamics and its

13 importance for degradation of pesticides and formation of biogenic bound residues, organic chemicals of environmental concern

In biodegradation studies with isotope-labelled pesticides fractions of nonextractable residues (NER) remains, but their nature and composition is rarely known, leading to uncertainty about their risk. Microbial growth leads to incorporation of carbon into the microbial mass, resulting in biogenic NER. Formation of microbial mass can be estimated from the microbial growth yield but experimental data is rare. Instead, we suggest using prediction methods for the theoretical yield based on thermodynamics. Recently, we suggested the Microbial Turnover to Biomass (MTB) method that needs minimum input data. We have estimated the growth yield on 40 organic chemicals (31 pesticides) using the MTB and two existing methods. The results were compared to experimental values, and the sensitivity of the methods was assessed. The MTB method performed best for pesticides. Having the theoretical yield and using the released $\mathrm{CO}_{2}$ as a measure for microbial activity, we predicted a range for the formation of biogenic NER. For the majority of the pesticides, a considerable fraction of the NER was estimated to be biogenic. This novel approach provides a theoretical foundation applicable to evaluate and predict biogenic NER formation during pesticide degradation experiments and may also be employed to interpret NER data from regulatory studies. 


\section{Introduction}

The evaluation of biodegradation of organic chemicals of environmental concern is a big challenge for risk assessment and is subject to legislation and regulation. In the European Union (EU) chemicals that are traded have to be approved by the REACH legislation if produced and sold in amounts greater than one ton per year [1-3]. The assessment of biodegradability under environmental conditions is standardised by OECD testing guidelines, such as OECD Tests Nos. 306-309 used for the assessment of biodegradation in sea water, soil, fresh water, and fresh-water-sediment systems [4-7]. Transformation and biodegradation is mostly tested with ${ }^{14} \mathrm{C}$ or ${ }^{13} \mathrm{C}$ labelled parent compounds. Isotopes are particularly needed for assessment of non-extractable residues (NER; also called "bound residues") and tracing of unknown metabolites [8]. Assessment of biodegradation is well established but may still have some pitfalls for various compounds [9-12]. Although there are several approaches for the reliable prospective assessment of chemical properties and behaviour from quantitativestructure-activity-relationship (QSAR) modelling available [13], much less is available for the assessment of biodegradation [14]. The assessment of residue formation is still in its infancy and and is not yet predictable.

\section{Recently, a novel approach was suggested for modelling the formation of} biogenic residues [15] which can also elucidate the black box of NER. NER may be formed by sequestration or entrapment of parent compounds or metabolites in soils and sediments (type I NER), and also by covalent bonding to soil organic matter (type II

NER). Another type of residues is formed after incorporation of carbon into microbial biomass after microbial productive degradation of the parent compound (type III = biogenic NER) [8]. Apparently, NER are mostly comprised of all types of residues and 
thus the assessment of the biogenic NER formation will also provide information about the amounts of the other types of NER formed.

Compounds that are poor growth substrates and do not provide sufficient energy, carbon or nutrients to the degrader microbes give no incentive for degradation and can be expected to be more stable under environmental conditions. Thus, the usability of the molecule, its energy content and suitability for anabolic processes has a profound impact on the evolutionary pressure to develop degradation pathways. Thermodynamic analysis can be applied to determine the feasibility and direction of chemical reactions under a given set of conditions (see, e.g., [16]). In addition, thermodynamics can also be used to describe the potential growth of bacteria [17]. Essentially, bacterial growth is simplified and split into anabolic processes (energy demanding) and catabolic processes (energy producing) [18]. The catabolic processes describe the energy released from the oxidation of a chemical or a substrate. In aerobic metabolism the oxidation product is usually $\mathrm{CO}_{2}$ and $\mathrm{H}_{2} \mathrm{O}$. The electrons derived from the oxidation are partly transferred to the synthesis of microbial biomass (anabolism) or transferred to the terminal electron acceptors via the respiration chains (catabolism) in the membranes of the organisms resulting in the release of energy, predominately from the formation of $\mathrm{CO}_{2}$ and $\mathrm{H}_{2} \mathrm{O}$ [19].

The anabolic processes describe the substrate and energy use for the synthesis of new cell biomass. Element, electron and energy balances are used to describe the processes related to the oxidation and reduction half-reactions of the catabolism and to the energy and electron gain used for cell synthesis (see, e.g., [17, 20-22]).

The bacterial growth yield is defined as the mass of bacteria formed per mass of substrate consumed ( $\mathrm{g}$ cells per g substrate, often also g C per g C) [19]. Thermodynamic growth-yield estimation methods were developed in order to model 
metabolic processes and to estimate the amounts of biomass that can be derived from metabolism (e.g. [15, 17, 20-25]). These estimates have previously been used for biotechnological purposes and for the estimation of activated sludge formation in waste water treatment processes, e.g. [26]. The different growth yield estimation methods are based on a similar set of considerations [26, 27]. The Thermodynamic Electron Equivalent Model (TEEM2) developed by Perry L. McCarty $[17,23]$ and Expanded Thermodynamic True Yield Prediction Model (ETTYM) of Xiao and VanBriesen $[22,24]$ or their variations have been applied [28, 29] for the estimation of bacterial growth yield on xenobiotics. Both models have evolved towards an increased need of knowledge regarding the transformation pathways, metabolic processes and the electron and energy losses associated hereto in order to model specific growth of various organisms. Recently, the Microbial Turnover to Biomass (MTB) method was developed by Trapp et al. [15] in order to provide a less complex method for the estimation of biomass formation during metabolism of any organic compound. In MTB we proposed a simple method to predict just the minimum bacterial growth yield potential without the need for information on the pathways, as this is rarely known for the majority of chemicals of environmental concern.

Furthermore, microbial growth and decline are coupled to the formation of soil organic matter (SOM) [30-33]. Therefore, yield estimation provides a tool for the assessment and prediction of biogenic NER formation in the degradation assessment of chemicals for regulatory purposes.

The objectives of the present study are i) to thoroughly compare the recently introduced MTB method with other yield estimation methods; ii) to extend the MTB approach for electron acceptors other than oxygen (e.g. nitrate and sulphate); iii) to predict the biomass yields during pesticide degradation and eventually the potential for 
113 biogenic NER formation; and iv) to determine the sensitive parameters in the yield

114 prediction methods. The estimates were compared to experimentally determined growth

115 yields. Finally, we contrast measured NER formation of pesticides and xenobiotics with

116 the predicted formation of SOM due to bacterial growth and decline.

\section{2. Materials and Methods}

118 The bacterial growth yield prediction methods chosen for this study have a common

119 basic approach: a stoichiometrically balanced redox reaction and the associated change

120 of Gibbs free energy. This means that one can set up half-reactions describing the

121 reduction of the targeted compound (be it xenobiotic or not), calculate the associated

122 Gibbs free energy [34], and combine it with half-reactions of an appropriate electron

123 acceptor (e.g. $\mathrm{O}_{2}, \mathrm{NO}_{3}^{-}, \mathrm{SO}_{4}{ }^{2-}, \mathrm{Fe}^{3+}, \mathrm{Mn}^{4+}$, or even $\mathrm{CO}_{2}$ etc.) allowing for assessment of

124 the bacterial growth yield under a multitude of redox conditions. Here we only look at

$125 \mathrm{O}_{2}, \mathrm{NO}_{3}^{-}$, and $\mathrm{SO}_{4}^{2-}$. This approach has been shown for ETTYM and TEEM2 and here

126 we will show that the procedure of half-reactions is applicable also for the MTB

127 method.

balances differ between the methods, thus a brief outline of the methods will be given in

131 Table 1, in which the final equations used to calculate the growth yield are shown.

\subsection{Microbial Turnover to Biomass (MTB)}

The Microbial Turnover to Biomass (MTB) method is presented in detail in

Trapp et al. [15]. The method is based on the work of Diekert [18]. The maximum bacterial yield is determined from the nutritional value of the substrate $(\mathrm{N})$ combined with the determination of bio-available electrons from the reaction. The nutritional 
137 value is the inverse of the yield and describes how much substrate is needed for the

138 growth of bacteria $\left[\mathrm{g}\right.$ substrate $\left.(\mathrm{g} \text { biomass })^{-1}\right]$. This is subdivided into a biomass

139 yielding (anabolic) and energy yielding (catabolic) part. The catabolic yield is

140 determined from calculation of the Gibbs free energy released from the oxidation of the

141 compound, the storage of this energy in ATP, and the bacterial growth yield on ATP.

\section{Microbes cannot use all electrons to generate energy and thus the} concept of bio-available electrons was introduced. [15]. Thus, energy and electron balances are implicitly considered. The anabolic yield is calculated from the carbon content in the compound (the carbon source) and in the bacterial cell [18], i.e. how many grams of cell can be produced from the carbon in the compound (only carbon availability is assumed to limit growth). Further details and examples can be found in SI 1.1 and Trapp et al. [15].

\subsection{Thermodynamic Electron Equivalent Model 2 (TEEM2)}

In 1965 P. L. McCarty presented a thermodynamic model to estimate the maximal bacterial yield from a single substrate [17]. The method determines the yield on a given substrate from the Gibbs free energy released in the redox process. Since its inception it has been modified and expanded [34]. It was recently modified to better capture the observed lower yields associated with $\mathrm{C} 1$ compounds (i.e. methanol) and reactions involving oxygenases $[22,23]$. It is based on electron and energy balances. The electron balance considers that the electrons provided by the substrate are used either in the synthesis of cell material (anabolism) or in energy generation (catabolism), and the energy balance states that the energy captured with a specific efficiency $(\varepsilon)$ by the organism is used for bacterial growth. The energy capture efficiency, $\varepsilon$, is a key 
161 parameter and is estimated from experimental data. Further details and examples are

162 found in SI 1.2 and McCarty [23] and Rittmann and McCarty [34].

163

1642.3 Expanded Thermodynamic True Yield Prediction Model (ETTYM)

165 The Expanded Thermodynamic True Yield Model is based on the work by McCarty and

166 was presented in [22] and expanded in [24]. To increase the accuracy for the yield

167 prediction on $\mathrm{C} 1$ compounds and substrates with low degrees of reduction, the authors

168 proposed to include a carbon and a nitrogen balance and as a result reformulated the

169 electron and energy balance originally proposed by McCarty. The carbon balance

170 describes the carbon as either invested in cell synthesis or into other carbonaceous

171 products. The nitrogen balance can be ignored if nitrogen is not limiting [24], hence, the

172 yield can be calculated from an energy balance, carbon balance, and electron balance.

173 For further details, see SI 1.3 and Xiao and VanBriesen [22, 24].

174

175

176

177

178

179

180

$<$ Table $1>$

\subsection{Conditions for comparison}

In all calculations the chemical was assumed to be the sole source of both energy and carbon. Ammonia was taken as the sole nitrogen source so electrons for the assimilatory reduction of $\mathrm{NO}_{3}{ }^{-}$was not considered, and the carbon was assumed to be used only for cell synthesis or oxidised to $\mathrm{CO}_{2}$, hence, no other carbonaceous products are formed. Gibbs energy of reaction is calculated using activities of the reactants and products assumed to be $1 \mathrm{M}$, except for $\mathrm{H}^{+}$which is assumed to be $10^{-7} \mathrm{M}(\mathrm{pH}$ 7). The Gibbs free energy of reaction for non-standard conditions can be calculated as

$\Delta G_{r}^{\prime}=\Delta G_{r}^{o^{\prime}}+R T \ln Q=\Delta G_{r}^{o^{\prime}}+R T \ln \left(\frac{\prod_{i=1}^{n}[\text { product }]_{i}^{p}}{\prod_{i=1}^{n}[\text { reactant }]_{i}^{r}}\right)$ 
186

187

where $R$ is the ideal gas constant $\left[8.314 \mathrm{~J}(\mathrm{~K} \mathrm{~mol})^{-1}\right], T$ is the absolute temperature $[\mathrm{K}]$, $Q$ is the reaction quotient, [product $]$ and $[$ reactant $]$ are the activities of products and reactants, and $p$ and $r$ are their respective stoichiometric coefficients. From the equation itself it can be seen that when $\mathrm{Q}<1$ the term is negative and when $\mathrm{Q}>1$ the term is positive.

For aerobic growth, $\mathrm{O}_{2}$ was taken as the terminal electron acceptor. For anaerobic growth both nitrate-reducing conditions $\left(\mathrm{NO}_{3}{ }^{-}\right.$as the terminal electron acceptor) and sulphate-reducing conditions $\left(\mathrm{SO}_{4}{ }^{2-}\right.$ as the terminal electron acceptor) were investigated. The balanced half-reactions as reductions and their associated Gibbs free energy of reaction can be found in Table 2 (refer to Table S1, Supplementary Information for simple carbon substrates). In this table, the thermodynamic frame of reference can also be seen: $\mathrm{SO}_{4}{ }^{2-}$ is reduced to $\mathrm{H}_{2} \mathrm{~S}$ and $\mathrm{HS}^{-}, \mathrm{NO}_{3}{ }^{-}$to $\mathrm{N}_{2}, \mathrm{O}_{2}$ to $\mathrm{H}_{2} \mathrm{O}, \mathrm{C}$ to $\mathrm{CO}_{2} . \mathrm{Cl}$ is released as $\mathrm{HCl}$, and $\mathrm{P}_{\text {as }} \mathrm{PO}_{4}{ }^{2-}$. The $\mathrm{pH}$ was assumed to be 7 and any change of Gibbs free energy due to speciation was disregarded. For TEEM2, the number of (putative) oxygenase reactions was explicitly taken into account. However, for ETTYM this was not done. This means that the results presented in this study differ from those presented in [24]. To assess the accuracy and precision of the model predictions, the relative error $(E(\%))$ and the mean average absolute error (MAE) were calculated. 
210 To assess the sensitivity of the different parameters on the predicted growth yield, key

211 input parameters were varied including $Y_{A T P}$, the assumption of biological standard state

212 conditions (i.e., chemical activities), Gibbs free energy of formation of the compound,

213 and the default bacterial cell formula (and thus the degree of reduction and cellular

214 carbon content). The sensitivity analysis was done changing one-factor-at-a-time, and

215 the parameter sensitivity was evaluated based on the ratio of change in output to the

216 change in input

$217 S_{i}=\frac{\Delta Y}{\Delta X_{i}}$

where $\Delta Y$ is the change in the observed output, $\Delta X_{i}$ is the change in input $i$, and $S_{i}$ is the sensitivity of $i$.

221

\subsection{Chemicals of environmental concern; data}

Thirty-one pesticides were selected for the present study because they are commercially available and widely applied [35] and have fate data (mineralisation and formation of non-extractable residues NER) available in the EU Pesticide Database [36, 37].

Bacterial growth yields have been experimentally assessed only for very few of the selected compounds. Where such data was available, it was used for comparing the performance of the prediction methods. Moreover, ibuprofen and some polycyclic aromatic hydrocarbons $(\mathrm{PAH})$ were also included as the bacterial growth yield has been experimentally determined for these. In total 40 chemicals were selected.

Due to the scarcity of experimentally determined bacterial growth yields on xenobiotics, the methods were also evaluated using the growth yield determined for simple carbon substrates used in biotechnology. The compounds selected for comparison are based on the review and evaluation made by Xiao and VanBriesen [24]. 
Information regarding the Gibbs free energies of formation, number of carbonhydrogen bonds, $Y_{A T P}$, number of (putative) oxygenase reactions, and degree of reductance are shown along with the name of the compound and reference of Gibbs energy of formation in Table 3 (for simple carbon substrates refer to Table S2).

$$
<\text { Table } 3>
$$

\subsection{Calculation of biogenic non-extractable residues}

Chemicals labelled with carbon isotopes $\left({ }^{14} \mathrm{C}\right.$ or $\left.{ }^{13} \mathrm{C}\right)$ allowed the flow of carbon

to be tracked in the experimental system [38-41]. If the compound provides carbon to anabolism and cell synthesis, the labelled carbon will end up in microbial biomass and finally in the biogenic NER. Biogenic NER is not posing a risk to neither the environment nor human health [8]. When a substrate $S$ is mineralized, the amount of biomass formed is yield times substrate, $Y \times S$, and the evolved $\mathrm{CO}_{2}$ is $(1-Y) \times S$ [15]. After the growth phase has stopped, the maximum ratio between biomass and $\mathrm{CO}_{2}$ and is thus

$\frac{\left[X_{\text {biogenic } N E R}\right]}{\left[\mathrm{CO}_{2}\right]}=\frac{Y S}{(1-Y) S}$ or $\left[X_{\text {biogenic NER }}\right]=\frac{Y}{1-Y}\left[\mathrm{CO}_{2}\right]$

where $X_{\text {biogenic NER }}$ is the biomass making up the living biogenic NER. After the cessation of the growth phase, the microorganisms start to decay. The dead microorganisms are turned over in the microbial food chain and form new biomass, $\mathrm{CO}_{2}$ and soil organic matter (SOM) [30-33]. Then, the ratio between biogenic NER and ${ }^{13 / 14} \mathrm{CO}_{2}$ becomes [15]

$\frac{\left[\text { SOM }_{\text {biogenic NER }}\right]}{\left[\mathrm{CO}_{2}\right]}=\frac{f \times Y}{(1-Y)+(1-f) \times Y}$ or $\left[\mathrm{SOM}_{\text {biogenic NER }}\right]=\frac{f \times Y}{(1-Y)+(1-f) \times Y}\left[\mathrm{CO}_{2}\right]$ 
where $S O M_{\text {biogenic }}$ NER is the non-living biogenic NER, $f$ is the fraction of decaying

260 biomass turned over into both living biomass and non-living $\operatorname{SOM}(0.5,[33])$, and $1-f$ is

261 the fraction of label released as $\mathrm{CO}_{2}$. Eq. (3) can be used to estimate NER formation

262 during short-term experiments, whereas Eq. (4) holds for long-term experiments. It can

263 be seen that a high mineralization and $\mathrm{CO}_{2}$ formation together with a high bacterial

264 growth yield leads to a high formation of biogenic NER.

\section{3. Results}

$266 \quad 3.1$ Comparison of predicted bacterial growth yields

267 Pesticides and chemicals of environmental concern

268 In Table 4, the predicted bacterial growth yields under aerobic conditions are shown and 269 compared to experimentally determined growth yields. In Table 5, the predicted growth 270 yields under anaerobic conditions are shown.

272 Aerobic conditions. With oxygen as the terminal electron acceptor, only chlorothalonil

273 was predicted to have a bacterial growth yield of zero and only by the MTB method.

274 The reason being the absence of carbon-hydrogen bonds. All other compounds except

275 pyrene were predicted to have a bacterial growth yield of $>0.3 \mathrm{~g}$ cell carbon (g substrate 276 carbon $)^{-1}$ by all methods. The yield predictions from ETTYM were higher than for 277 TEEM2 which in turn were higher than the predictions by MTB (except for NTA, 278 where TEEM2 adjusts for energy lost due to one oxygenase reaction). Experimental 279 yields were found for 13 of the 40 compounds selected. The mean absolute error was 280 found to be $49 \%$ for MTB, $82 \%$ for TEEM2, and $111 \%$ for ETTYM (Table 4 ).

281 Moreover, a strong positive and highly significant $(\mathrm{p}<0.01)$ linear correlation between 282 degree of reductance and predicted yield was found for ETTYM $\left(Y=0.093 \gamma_{s}+0.14\right.$,

URL: http://mc.manuscriptcentral.com/sqer 
$\left.R^{2}=0.70\right)$. A weaker but still highly significant $(\mathrm{p}<0.01)$ correlation was found for TEEM2 $\left(Y=0.09 \gamma_{s}+0.15, R^{2}=0.53\right)$, and a significant $(\mathrm{p}<0.05)$ but rather weak correlation was found for MTB $\left(R^{2}=0.14\right)$.

For 2,4-D and carbofuran, MTB predicted the yields with an absolute error of $4.7 \%$ and $1.4 \%$, respectively, whereas TEEM 2 overestimated them by $51 \%$ and $16 \%$, respectively, and ETTYM overestimated by $56 \%$ and $25 \%$, respectively. For glyphosate and anthracene, the predicted growth yields by all three methods deviate greatly from the observed value (more than $180 \%$ overestimation).

Anaerobic conditions. With nitrate as the electron acceptor, the predicted yields decrease $2-5 \%$ for all methods (Table 5). All 40 chemicals are predicted to be degradable under nitrate-reducing conditions when considering their energy and carbon content (the only exception still being chlorothalonil for MTB). The linear correlation between yield and degree of reduction was similar to the aerobic case. Again, ETTYM predictions were higher than TEEM2 predictions, which in turn are higher than the MTB predictions.

With sulphate as the terminal electron acceptor, the predicted yields decrease $54-93 \%$ for MTB, $50-118 \%$ for TEEM2, and $47-91 \%$ for ETTYM, compared to the yields found under aerobic conditions (Table 5). For both aerobic and nitrate-reducing conditions, the ranking of the estimated yields was close. Under sulphate-reducing conditions this was not the case. In fact, TEEM2 predicted negative yields for benzene, benzoate, and EDTA (highlighted in bold), while they were positive (albeit low) for ETTYM and MTB. MTB predicted 20 chemicals to have a yield of $<0.1 \mathrm{~g}$ cell carbon (g substrate carbon) $)^{-1}$, while ten were predicted using TEEM2, and only four using 
307 ETTYM. No linear correlation between the predicted yield and the degree of reductance could be found for any of the methods.

The lack of experimental observations under a multitude of redox conditions makes assessment of the prediction accuracy unachievable.

\section{Simple carbon substrates}

More experimental data are available for simple carbon substrates, and the result of the growth yield predictions are shown in Table 6 . The lowest MAE between experimental and predicted growth yield was observed for TEEM2 (MAE $=15 \%)$. MTB showed the highest MAE of $23 \%$. It should be noted, that while TEEM2 took energy losses due to oxygenase reactions into account, the implemented ETTYM method did not.

Subsequently, the work presented in [24] resulted in an even lower MAE when both the $\mathrm{pH}$ and related speciation, and oxygenase reactions were taken into account.

All three methods predict oxalate to have the lowest yield. Additionally, the TEEM2 and ETTYM predictions showed similar ranking of the chemicals.

Generally, the highest deviations from the experimental yields were similar for all methods. For MTB, these were formate, oxalate, and glycine; for TEEM2, these were oxalate, glycine, and formate; and for ETTYM, these were oxalate, phenol, and formate.

Excluding oxalate, formate, and glycine from the results, all three methods predicted the experimental growth yield with a MAE below 15\%, with TEEM2 still giving the lowest MAE (9\%). These three compounds all have a degree of reductance below that of the assumed cell formula for either method. 
332
$<$ Table $5>$

$<$ Table $6>$

\subsection{Sensitivity Analysis}

The calculated average sensitivity $\overline{S_{l}}$ towards the varied parameters can be found in Table 7.

$Y_{A T P}$

All methods are relatively sensitive to changes in $Y_{A T P}$, especially MTB. $Y_{A T P}$ is an uncertain parameter because no such values have ever been determined with pesticides or other xenobiotics as substrate. The chosen default value for xenobiotics of $5 \mathrm{~g}$ cell $\mathrm{dw}\left(\right.$ mol ATP) ${ }^{-1}$ ([18], for methanol) used in the MTB method does not lead to large errors (cf. Table 4).

Gibbs free energy of formation $\left(\Delta G_{f}^{\circ}\right)$

If $\Delta G_{f}{ }^{\circ}$ ' is positive (e.g. benzene) then an increase in this value would lead to an increase in the predicted yield. Conversely, a negative $\Delta G_{f}^{\circ}$ ' which is made more negative leads to a decrease in the predicted yield (e.g., EDTA). All three methods show a low sensitivity towards changes of the Gibbs energy of the substrate $\left(\overline{S_{l}}<0.1\right)$. While TEEM2 and ETTYM also both have low $\overline{S_{l}}$ values for changes in $\Delta G_{f}^{\circ}$, the standard deviation is high. Yield estimates for chemicals with few carbon atoms (and thus low formation of $\mathrm{CO}_{2}$ ) and high negative $\Delta G_{f}^{\circ}$ ' (e.g. glyphosate) are especially sensitive to changes. 
Standard state conditions

359 The deviation from standard state conditions was found to have only a very small effect

360 on the predicted yields. The relation between $R T \ln Q$ and $\Delta G_{r}{ }^{\prime}$ in Eq. (1) is logarithmic.

361 Setting $\Delta G_{r}{ }^{0}$ ' to zero shows that varying $Q$ from $10^{-25}$ to $10^{25}$ leads to a change in Gibbs

362 free energy of only $\pm 143 \mathrm{~kJ} \mathrm{~mol}^{-1}$ (at standard pressure and temperature).

\section{Cell formula}

365 While all methods are sensitive to the cell formula used (Table 7), MTB is the method

366 least affected. The effect of the cell formula in TEEM2 and ETTYM is not only on the

367 energy costs related to synthesis [24], but also on the conversion to g cell carbon ( $\mathrm{g}$

368 substrate carbon $)^{-1}$ in TEEM2. This is due to the degree of reduction of the cell $\left(\gamma_{s}\right)$ used

369 in converting the units. For MTB, the predicted yield is only affected by changes in the

370 assumed cellular carbon content $\left(\sigma_{C}\right)$. For MTB, a higher carbon content per mass of

371 cell leads to a higher yield in $\mathrm{g}$ cell carbon ( $\mathrm{g}$ substrate carbon $)^{-1}$ but lower yield in gram

372 bacteria (gram substrate) $)^{-1}$ (Figure S1).

\subsection{Prediction of biogenic NER formation based on the predicted growth yields}

375 The growth yields predicted with the MTB method were used to estimate the biogenic

376 NER formation from the $\mathrm{CO}_{2}$ produced during degradation experiments (Table 8). The

377 formation of biogenic NER was predicted to make up a considerable fraction of the

378 experimentally determined NER for most of the chemicals. Except for one compound

379 (glyphosate, caused by the production of the metabolite aminomethylphosphonic acid

380 (AMPA)), the predicted biogenic NER was smaller than the measured total NER. For

381 daminozide, almost all of the formed NER is suggested to be made up of biogenic NER 
382 (94\%). For MCPA and MCPB, approximately $50 \%$ of the NER is biogenic. For bifenzate, iprodione, pendimethalin, phenmedipham, and pymetrozine the biogenic NER is suggested to make up less than $10 \%$ of the formed NER. This then suggests that for these chemicals, type I and II NER make up the majority of the formed NER. The experimental period for ibuprofen and 2,4-D (64 days) [38, 39], and glyphosate and metamitron (80 days) $[42,43]$ was shorter than the experiments reported in [36]. Eq. (3), which calculates living biomass $\mathrm{X}$ as biogenic NER, was additionally used to interpret these experiments. In these four studies, the carbon label found in amino acids was reported. For living microbes, about half of the carbon is in proteins. This fraction increases during decay and turnover of microbial biomass because proteins are the most stable fraction of the cells $[30,33,15]$. Except for glyphosate, the measured label in amino acids is within the range of biogenic NER predicted by Eqs. (3) and (4), and the measured total NER is greater.

$$
<\text { Table } 8>
$$

\section{Discussion}

\subsection{Comparison of predicted bacterial growth yields}

For the pesticides and chemicals of environmental concern, the lack of experimental data for the bacterial growth yield under different redox conditions made it difficult to assess the error associated with the predicted growth yields. Only 14 yield values could be used in the comparison, with some of them used earlier in [15]. Although MTB performs better than TEEM2 and ETTYM, the MAE was still found to be $\sim 50 \%$. The bacterial growth yield estimation methods are all developed to predict the true yield at optimal growth conditions for microorganisms. The observed value is typically a net yield accounting only for the formation of new cell mass and removal of 
407 the parent compound $[15,23,24,44]$. The difference between the two is that for the

408

409

410

411

412

413

414 observed yield energy and carbon expenditure, due to non-growth purposes, are not captured (e.g. energy spent on maintenance, formation of metabolites or soluble microbial products and extracellular polymeric substances), unless a dynamic model was used for fit. Hence, the observed yield is typically lower than the true yield. Additionally, the prediction methods assume a complete degradation of the compound. If hardly degradable or insoluble metabolites are formed and rendered not bioavailable (as NER I or II), the observed yield will be lower than the predicted true yield. Compounds which have a known toxic effect (e.g. phenolic compounds [45]) can also result in a higher amount of energy being spent on maintenance leading to an observed yield lower than the predicted true yield.

The bacterial yields for anthracene and glyphosate are by all methods overestimated by $>100 \%$. Anthracene is readily adsorbed and is scarcely soluble in water [46]. In the experiments with glyphosate [42], the intermediate AMPA accumulated, resulting in an observed yield much that was lower than the predicted yield (Table 4). If these two are removed from the calculations, the MAE is reduced to $20 \%$ for MTB, $40 \%$ for TEEM2, and $58 \%$ for ETTYM.

The presence of other sources of carbon or energy (mixed substrate use) also adds uncertainty to the observed value. Interestingly, in the experiments with 2,4-D and carbofuran $[29,47]$, great care was taken in the experimental setup to minimise confounding factors due to other carbon sources, and here the MTB predicted yields are very close to the experimentally determined values. The observed differences might also be attributed to their high hydrophobicity and limited bioavailability $[8,48-50]$, which means that truly dissolved concentrations are low. Under these conditions, microbes use most of the growth substrate just for 
432

maintenance [51]. Despite the explicit consideration of energy losses related to (putative) oxygenase reactions for PAHs in TEEM2, its errors were higher than for MTB. Helbling et al. [29] successfully matched the predicted bacterial yield with the measured bacterial yield on carbofuran by taking oxygenase reactions into account as suggested in [28]. Under sulphate-reducing conditions the predicted bacterial yields were much lower than the predicted yields under aerobic conditions, which can be expected considering the lower energy associated with the reduction of sulphate in comparison to oxygen reduction. An interesting observation was that the decrease in yield is similar across all three methods. This shows that the half-reaction approach using various electron acceptors used in ETTYM and TEEM2 can also be used with MTB, which has not been shown before.

Under anaerobic conditions, the energy released from the majority of redox reactions might not be sufficient to fuel bacterial growth. This suggests that there would not be an evolutionary incentive to develop metabolic pathways for anaerobic degradation where the chemical is the electron donor (unless the chemical can provide other macro- or micronutrients, e.g. nitrogen and carbon). For all methods, the predicted growth yield is so small that there is no relationship between degree of reductance and bacterial growth yield.

For the simple carbon substrates, both TEEM2 and ETTYM perform better than MTB (lower MAE). However, one has to consider the fact that the efficiency parameter in the TEEM2 method was calibrated to the data in order to produce yield estimates close to experimentally determined growth yields [23]; and experimental yields were converted to $g$ cell carbon (g substrate carbon) ${ }^{-1}$ using the cell formula $\left(\mathrm{CH}_{2} \mathrm{O}_{0.6} \mathrm{~N}_{0.2}\right)$ proposed for the ETTYM method [24]. 
While ETTYM and TEEM2 both overestimated the yield for oxalate, MTB estimated it as zero due to the absence of $\mathrm{C}-\mathrm{H}$ bonds (which points to the need for a model modification as bacteria are able to grow on this substrate).

\subsection{Sensitivity analysis}

All the methods were shown to be sensitive to the choice of cell formula but exhibited low sensitivity to variations of the formation energy, $\Delta G_{f}{ }^{\circ}$, of the chemical of interest.

All methods are based on the Gibbs energy of reaction and knowledge of the Gibbs energy of formation of the chemical of interest is needed. If the value has not been determined experimentally (e.g. [52]), it can be estimated using group contribution methods [53-58] (method [53] is implemented in the freely available ChemProp [59]), or by component contribution methods [60] (implemented in the free accessible database eQuilibrator [61]), or calculated using quantum mechanics [62]. For xenobiotics, the applicability of these estimation methods may be limited. Consequently, we also tested the sensitivity of Gibbs energy of formation of the xenobiotic substrate by setting this value to $0 \mathrm{~kJ} \mathrm{~mol}^{-1}$ (Table S3). The MTB method has surprisingly low sensitivity. Compounds having a large negative Gibbs energy of formation (e.g. NTA, EDTA, and glyphosate) and few carbon-hydrogen bonds $(6,8$, and 4 , respectively) show a maximum deviation of around 20\% from the predictions done with correct Gibbs energy of formation. Overall, the average deviation is only $6 \%$. In comparison, TEEM2 and ETTYM have considerably higher average deviation (14\% and $11 \%$, respectively).

While deviation from the standard state conditions might be needed to render a reaction step thermodynamically feasible [16], the effect on the overall yield prediction would only be seen for reactions where the Gibbs free energy of reaction is low, either 
482

due to the low energy associated with the oxidation of substrate (e.g. formate or

483

484 formaldehyde), or the low energy associated with the reduction of the electron acceptor (e.g. $\mathrm{SO}_{4}{ }^{2-}$ ). This means that the true concentrations or activities during the reaction can be neglected without significant error.

The effect of $\mathrm{pH}$ on Gibbs energy of reaction was not investigated in this study as this was recently done in [24]. At $\mathrm{pH} 7$, taking the distribution of the inorganic carbon species into account only changed the predicted yield approximately $1 \%$. However, speciation of the substrate also has an effect on its Gibbs energy of formation. Similarly, the sensitivity of the energy capture efficiency parameter $\varepsilon$ (or variations thereof) has been assessed elsewhere [22, 23].

\subsection{Prediction of biogenic NER formation and implication for degradation in the} environment

The experiments cited from [36] in Table 8 were run for more than 100 days. The peak in living biomass is usually after a few days to weeks $[38,39]$, and therefore we expect that Eq. (4) $\left(S O M_{\text {biogenic } N E R}\right)$ is more appropriate for these experiments than Eq. (3) ( $X_{\text {biogenic NER }}$ ) as the majority of the living biomass has decayed and been incorporated into SOM after 100 days. Results obtained by Eq. (4) are smaller than the measured

NER, which confirms the results of this equation. The only exception is glyphosate. For daminozide, the chemical with the highest predicted yield, the calculated biogenic NER and measured NER are almost equal.

The examination of Table 8 gives no significant correlation between measured total NER and predicted $X_{\text {biogenic }}$ NER or $S O M_{\text {biogenic NER. }}$ Such a correlation should not be expected since the processes leading to NER I, II and III are competing. If a pesticide is not degraded it can undergo aging and irreversible sorption (type I NER) and covalent 
binding of the parent compound or its metabolites (type II NER) [8]. The estimation of the various fractions of NER can be rebuilt in a dynamic simulation model. We suggested such a model in [8] and used it successfully for the prediction of the NER formation from 2,4-D and ibuprofen with pre-estimated yield data [15].

The data compiled by [36] give no hints into which form the NER are present, and thus cannot serve to validate the estimation equation. However, it is likely that high true yields are connected to high experimental yields, which stimulate bacterial growth and thus microbial degradation. Of course, the enzymatic pathways to facilitate the degradation and energy exploitation of the molecule also need to be present. In degradation experiments with metamitron [43], glyphosate [42], ibuprofen $[39,63]$ and 2,4-D [38, 63], the formation of biogenic NER was investigated by tracking the distribution of stable carbon or nitrogen isotope $\left({ }^{13} \mathrm{C}\right.$ or $\left.{ }^{15} \mathrm{~N}\right)$ in $\mathrm{CO}_{2}$, amino acids, fatty acids, metabolites, and parent compounds. Experiments of this kind are very helpful to discriminate between the various types of NER and to validate our biogenic NER estimation approach. Shrestha et al. [11] observed that the formation of NER occurred simultaneously with the degradation and release of $\mathrm{CO}_{2}$. This shows the coupling of the formation of NER to microbial activity, and to the growth and decay of biomass. Mamy et al. [13] observed a lack of QSAR approaches to predict the formation of NER. The method applied in this study provides process-based theoretical background that may be used to interpret NER data derived in degradation experiments. Before routine application though, further confirmation by targeted experiments is still needed. 
1

2

3

4

5

6

7

8

9
530

531

\section{Conclusions}

The MTB method was compared with two widely used bacterial growth yield estimation methods, TEEM2 and ETTYM. The results showed that TEEM2 and ETTYM methods performed better than MTB in estimating the yield on simple substrates, while MTB performed better when estimating the yield on organic chemicals of environmental concern in general and in particular on pesticides. It was also shown that the MTB approach can be expanded to electron acceptors other than oxygen, like sulphate and nitrate.

The sensitivity analysis revealed that all three methods are relatively sensitive to changes in $Y_{A T P}$, an uncertain parameter. TEEM2 and ETTYM are also sensitive to changes in the cell formula due to the change in the degree of reductance. All methods showed low sensitivity to variations in the Gibbs energy of formation of the organic chemicals because most of the Gibbs energy of reaction stems from the formation of the oxidation products carbon dioxide and water. The growth yield estimates were then successfully used to estimate the formation of biogenic non-extractable residues. The approach applied in this study provides a theoretical foundation that can be used to predict biogenic NER formation during pesticide degradation experiments. It can also be employed to interpret NER data derived during regulatory studies.

\section{Acknowledgements}

This research project was financially supported by the Technical University of Denmark and the Helmholtz Centre for Environmental Research UFZ. We thank Fabio Polesel, Carson Odell Lee, and Ulrich Bay Gosewinkel for valuable suggestions and discussions. We also wish to acknowledge the comments and 
554 suggestions provided by the anonymous reviewers which helped to improve the

555 manuscript.

556 The MTB theoretical yield tool is available both in spreadsheet and Python code

557 on request from the first author.

\section{Disclosure statement}

559 The authors declare no financial interest.

560 


\section{References}

[1] EU. Regulation (EC) No 1907/2006 of the European Parliament and the Council of 18 December 2006 concerning Registration, Evaluation, Authorisation and Restriction of Chemicals (REACH), Official Journal of the European Union (2006), L 136.

[2] EU. Regulation (EC) No 1107/2009 of the European Parliament and the council of 21 October 2009 concerning the placing of plant protection products on the market and repealing Council Directives 79/117/EEC and 91/414/EEC, Official Journal of the European Union (2009), L 309/1.

[3] EU. Commission regulation (EU) No 283/2013 setting out the data requirements for active substances, in accordance with Regulation (EC) No 1107/2009 of the European Parliament and the Council concerning the placing of plant protection products on the market. Official Journal of the European Union (2013), L 93/1.

[4] OECD. Test No. 306: Biodegradability in Seawater. OECD Publishing, Paris, 1992. DOI 10.1787/9789264070486-en

[5] OECD. Test No. 307: Aerobic and Anaerobic Transformation in Soil. OECD Publishing, Paris, 2002a. DOI 10.1787/9789264070509-en

[6] OECD. Test No. 308: Aerobic and Anaerobic Transformation in Aquatic Sediment Systems. OECD Publishing, Paris, 2002b. DOI 10.1787/9789264070523-en

[7] OECD. Test No. 309: Aerobic Mineralisation in Surface Water - Simulation Biodegradation Test. OECD Publishing, Paris, 2004. DOI 10.1787/9789264070547-en

[8] M. Kästner, K. M. Nowak, A. Miltne, S. Trapp, and A. Schäffer, Classification and Modelling of Nonextractable Residue (NER) Formation of Xenobiotics in Soil - A Synthesis, Crit. Rev. Env. Sci. Technol. 44 (2014), pp. 2107-2171.

[9] K. Fenner, S. Canonica, L.P. Wackett, and M. Elsner, M., Evaluating Pesticide Degradation in the Environment: Blind Spots and Emerging Opportunities, Science 341 (2013), pp. 752-758.

[10] M. Honti, and K. Fenner, Deriving persistence indicators from regulatory watersediment studies - Opportunities and limitations in OECD 308 data, Environ. Sci. Technol. 49 (2015), pp. 5879-5886

[11] P. Shrestha, T. Junker, K. Fenner, S. Hahn, M. Honti, R. Bakkour, C. Diaz, and D. Hennecke, Simulation Studies to Explore Biodegradation in Water-Sediment Systems: From OECD 308 to OECD 309, Environ. Sci. Technol. 50 (2016), pp. 6856-6864.

[12] M. Honti, S. Hahn, D. Hennecke, T. Junker, P. Shrestha, and K. Fenner,Bridging across OECD 308 and 309 Data in Search of a Robust Biotransformation Indicator, Environ. Sci. Technol. 50 (2016), pp. 6865-6872. 
[13] L. Mamy, D. Patureau, E. Barriuso, C. Bedos, F. Bessac, X. Louchart, F. MartinLaurent, C. Miege, and P. Benoit, Prediction of the Fate of Organic Compounds in the Environment From Their Molecular Properties: A Review, Crit. Rev. Env. Sci. Tec. 45 (2015), pp. 1277-1377.

[14] A. Sabljic and Y. Nakagawa, Biodegradation and quantitative structure-activity relationship (QSAR), in Non-First Order Degradation and Time-Dependent Sorption of Organic Chemicals in Soil, W. Chen, A. Sabljic, S.A. Cryer and R.S. Kookana, eds, Book Series: ACS Symposium Series, American Chemical Society, Washington (DC), Volume 1174, 2014, pp. 57-84.

[15] S. Trapp, A. Libonati Brock, K. Nowak and M. Kästner, Prediction of the formation of biogenic non-extractable residues during degradation of environmental chemicals from biomass yields, Environ. Sci. Technol. (2017), Submitted for publication

[16] T. Maskow, and U. von Stockar, How reliable are thermodynamic feasibility statements of biochemical pathways?, Biotecnol. Bioeng. 92 (2005), pp. 223-230.

[17] P.L. McCarty, Thermodynamics of biological synthesis and growth, Intl. J. Air Water Poll. 9 (1965), pp. 621-639.

[18] G. Diekert, Grundmechanismen des Stoffwechsels und der Energiegewinnung, in Umweltbiotechnologie, J.C.G. Ottow and W. Bidlingmaier, eds., Fischer Verlag, Stuttgart, Germany, 1997; pp. 1-38.

[19] M.T. Madigan, J. Martinki, and J. Parker, Biology of Microorganisms. International Student Edition, Pearson Inc, 2011.

[20] J.J. Heijnen, A new thermodynamically based correlation of chemotrophic biomass yields, Anton. Leeuw. Int. J. G. 60 (1991), pp. 235-256.

[21] J.J. Heijnen, and J.P. Dijken, In search of a thermodynamic description of biomass yields for the chemotrophic growth of microorgansims, Biotechnol Bioeng 39 (1992), pp. 833-852

[22] J. Xiao, and J.M. VanBriesen, Expanded thermodynamic model for microbial true yield prediction, Biotechnol. Bioeng 93 (2006), pp. 110-121.

[23] P.L. McCarty, Thermodynamic Electron Equivalents Model for bacterial yield prediction: Modifications and comparative evaluations, Biotechnol. Bioeng 97 (2007), pp. 377-388.

[24] J. Xiao, and J.M. VanBriesen, Expanded thermodynamic true yield prediction model: adjustments and limitations, Biodegradation 19 (2008), pp. 99-127.

[25] R. Kleerebezem, and M.C.M. Van Loosdrecht, A Generalized Method for Thermodynamic State Analysis of Environmental Systems, Crit. Rev. Env. Sci. Tec. 40 (2010), pp. 1-54. 
[26] G. Tchobanoglous, F.L. Burton, and H.D. Stensel, Wastewater Engineering, Treatment and Reuse, 4th ed. McGraw-Hill: Boston, USA, 2004.

[27] J.M. VanBriesen, Evaluation of methods to predict bacterial yield using thermodynamics, Biodegradation 13 (2002), pp. 171-190.

[28] J.M. VanBriesen, Thermodynamic yield predictions for biodegradation through oxygenase activation reactions, Biodegradation 12 (2001), pp. 265-281.

[29] D.E. Helbling, F. Hammes, T. Egli, and H.-P.E. Kohler, Kinetics and yields of pesticide biodegradation at low substrate concentrations and under conditions restricting assimilable organic carbon, Appl. Environ. Microbiol. 80 (2014), pp. 1306-1313.

[30] R. Kindler, A. Miltner, H.H. Richnow, and M. Kästner, Fate of gram-negative bacterial biomass in soil - Mineralization and contribution to SOM, Soil Biol. Biochem. 38 (2006), pp. 2860-2870.

[31] R. Kindler, A. Miltner, M. Thullner, H.H. Richnow, and M. Kästner, Fate of bacterial biomass derived fatty acids in soil and their contribution to soil organic matter, Org. Geochem. 40 (2009), pp. 29-37.

[32] A. Miltner, R. Kindler, H. Knicker, H.H. Richnow, and M. Kästner, Fate of microbial biomass-derived amino acids in soil and their contribution to soil organic matter. Org. Geochem. 40 (2009), pp. 978-985.

[33] A. Miltner, P. Bombach, B. Schmidt-Brücken, and M. Kästner, SOM genesis: Microbial biomass as a significant source, Biogeochemistry 111 (2012), pp. 4155.

[34] B.E. Rittmann, P.L. McCarty, Environmental biotechnology: principles and applications. McGraw-Hill: New York, NY, 2001.

[35] J. E. Ørum, and H. Hossy, Bekcempelsesmiddel-statistik 2014. Behandlingshyppighed og pesticidbelastning, baseret på salgsstatistik og sprøjtejournaldata. Orientering fra Miljøstyrelsen nr. 13, 2015. Miljøstyrelsen (Danish EPA), 2015.

[36] E. Barriuso, P. Benoit, and I. G. Dubus, Formation of pesticide nonextractable (bound) residues in soil: Magnitude, controlling factors and reversibility, Environ. Sci. Technol. 42 (2008), pp. 1845-1854.

[37] EU. EU Pesticides Database. Available at http://ec.europa.eu/food/plant/pesticides/eu-pesticides-database/public/ (visited 2017-04-07).

[38] K. M. Nowak, A. Miltner, M. Gehre, A. Schäffer, and M. Kästner, Formation and fate of bound residues from microbial biomass during 2, 4-D degradation in soil, Environ. Sci. Technol. 45 (2011), pp. 999-1006. 
677

678

679

680

681

682

683

684

685

686

687

688

689

690

691

692

693

694

695

696

697

698

699

700

701

702

703

704

705

706

707

708

709

710

711

712

713

[39] K. M. Nowak, C. Girardi, A. Miltner, M. Gehre, A. Schäffer, and. M. Kästner, Contribution of microorganisms to non-extractable residue formation during biodegradation of ibuprofen in soil, Sci. Total Environ. 445-446 (2013), pp. 377384.

[40] C. Poßberg, B. Schmidt, K.M. Nowak, M. Telscher, A. Lagojda, and A. Schaeffer, Quantitative Identification of Biogenic Nonextractable Pesticide Residues in Soil by 14C-Analysis Environ. Sci. Technol. 50 (2016), pp. 6415-6422.

[41] M. Kästner, K.M. Nowak, A. Miltner, and A. Schäffer, (Multiple) Isotope probing approaches to trace the fate of environmental chemicals and the formation of nonextractable "bound" residues. Curr. Opin. Biotech 41 (2016), pp. 73-82

[42] S. Wang, B. Seiwert, M. Kästner, A, Miltner, A. Schäffer, T. Reemtsma, Q. Yang, and K.M. Nowak, (Bio)degradation of glyphosate in water-sediment microcosms - A stable isotope co-labeling approach, Water Res 99 (2016), pp. 91-100.

[43] S. Wang, A. Miltner, and K.M. Nowak, Identification of degradation routes of metamitron in soil microcosms using 13C-isotope labeling, Environ. Pollut. 220 (2017), pp. 927-935.

[44] D. W. Tempest and O.M. Neijssel, The Status of $Y_{\text {atp }}$ and Maintenance Energy as Biologically Interpretable Phenomena. Ann. Rev. Microbiol., 38 (1984), pp. 459486.

[45] B.I. Escher, R.W. Hunziker, and R.P. Schwarzenbach, Interaction of phenolic uncouplers in binary mixtures: concentration-additive and synergistic effects. Environ Sci Technol 35 (2001), pp. 3905-14.

[46] R.P. Schwarzenbach, P.M Gschwend, and D.M. Imboden, Environmental Organic Chemistry, 1st ed., John Wiley \& Sons, Inc., New York, NY, 1993.

[47] N.M. Chong, S.C. Tsai, and T.N. Le, The biomass yielding process of xenobiotic degradation, Bioresource Technol. 101 (2010), pp. 4337-4342.

[48] T.N. Bosma, P.J.M. Middeldorp, G. Schraa, and A.J.B. Zehnder, Mass transfer limitation of biotransformation: Quantifying bioavailability, Environ. Sci. Technol. 31 (1997), pp. 248-252.

[49] L.Y. Wick, T. Colangelo, and H. Harms, Kinetics of mass transfer-limited bacterial growth on solid PAHs, Environ. Sci. Technol. 35 (2001), pp. 354-361.

[50] A. Katayama, R. Bhula, G.R. Burns, E. Carazo, A. Felsot, D. Hamilton, C. Harris, Y.H. Kim, G. Kleter, W. Koerdel, J. Linders, J.G.M.W. Peijnenburg, A. Sabljic, R.G. Stephenson, D.K. Racke, B. Rubin, K. Tanaka, J. Unsworth and R.D. Wauchope, Bioavailability of xenobiotics in the soil environment, Rev. Environ. Contam. Toxicol 203 (2010), pp. 1-86.

URL: http://mc.manuscriptcentral.com/sqer 
[51] A. Rein, I.K.U. Adam, A. Miltner, K. Brumme, M. Kästner, and S. Trapp, Impact of bacterial activity on turnover of insoluble hydrophobic substrates (phenanthrene and pyrene) - Model simulations for prediction of bioremediation success, J.

716 Hazard. Mater. 306 (2016), pp. 105-114.

[52] R.K. Thauer, K. Jungermann, and K. Decker, Energy conservation in chemotrophic anaerobic bacteria, Bacteriol. Rev. 41 (1977), pp. 100-180.

[53] K. G. Joback, and R.C. Reid, Estimation of pure-component properties from group-contributions, Chem. Eng. Comm. 57 (1987), pp. 233-243.

[54] M.L. Mavrovouniotis, Group contributions for estimating standard Gibbs energies of formation of biochemical compounds in aqueous solution, Biotech. Bioeng. 36 (1990), pp. 1070-1082.

[55] M. L. Mavrovouniotis, Estimation of standard Gibbs energy changes of biotransformations, J. Biol. Chem. 266 (1991), pp. 14440-14445.

[56] M.L. Mavrovouniotis, S. Prickett, and L. Constantinou, Object-oriented estimation of properties from molecular structure, Comput. Chem. Eng. 16 (1992), pp. 353360.

[57] J. Marrero, and R. Gani, Group-contribution based estimation of pure component properties, Fluid Phase Equilibr. 183-184 (2001), pp. 183-208.

[58] A. S. Hukkerikar, B. Sarup, A. Ten Kate, J. Abildskov, G. Sin, and R. Gani, Group-contribution $+(G C+)$ based estimation of properties of pure components: Improved property estimation and uncertainty analysis, Fluid Phase Equilibr. 321 (2012), pp. 25-43.

[59] G. Schüürmann, R. Kühne, F. Kleint, R.-U. Ebert, C. Rothenbacher, and P. Herth, A software system for automatic chemical property estimation from molecular structure. in Quantitative Structure-Activity Relationships in Environmental Sciences - VII, F. Chen and G. Schüürmann G, eds, SETAC Press, Pensacola (FL), USA, 1996, pp. 93-114.

[60] E. Noor, H.S. Haraldsdóttir, R. Milo, R.M.T. Fleming, Consistent Estimation of Gibbs Energy Using Component Contributions, PLoS Comput. Biol. 9 (2013).

[61] A. Flamholz, E. Noor, A. Bar-Even, and R. Milo, eQuilibrator - the biochemical thermodynamics calculator, Nucleic Acids Res. 40 (2012), pp. 770-775.

[62] Mol-Instincts, A Fundamental Chemical Database based on Quantum Mechanics $\& Q S P R$, Copyright by ChemEssen, Inc. 2017; software available at http://www.mol-in.com

[63] C. Girardi, K.M. Nowak, O. Carranza-Diaz, B. Lewkow, A. Miltner, M. Gehre, A. Schäffer, M. Kästner, Microbial degradation of the pharmaceutical ibuprofen and the herbicide 2,4-D in water and soil - Use and limits of data obtained from 
753

754

755

756

757

758

759

760

761

762

763

764

765

766

767

768

769

770

771

772

aqueous systems for predicting their fate in soil, Sci. Total Environ. 444 (2013), pp. $32-42$.

[64] S.L. Trabue, X. Feng, A.V. Ogram, and L.T. Ou, Carbofuran degradation in soil profiles, J. Environ. Sci. Heal. B 32 (19976), pp. 861-878.

[65] Z. Yuan and J. M. VanBriesen, Yield prediction and stoichiometry of multi-step biodegradation reactions involving oxygenation, Biotecnol. Bioeng. 80 (2002), pp. $100-113$

[66] C.N Sawyer, P.L. McCarty, and G.F. Parkin, Chemistry for environmental engineering and science, 5th Edn., McGraw-Hill: New York, USA, 752 p., 2003.

[67] P.W. Atkins, and J. de Paula, Physical Chemistry for the Life Sciences. 1st ed. Oxford University Press: Oxford, UK. 2006.

[68] L. Toräng, N. Nyholm, H.-J. Albrechtsen, Shifts in biodegradation kinetics of the herbicides MCPP and 2,4-D at low concentrations in aerobic aquifer materials, Environ. Sci. Technol 37 (2003), pp. 3095-3103.

[69] Z. Yuan, The role of oxygenation and intermediates in biodegradation of chelating agents, Ph.D. diss., Carnegie Mellon University, US, 2004.

[70] J.D. Linton and R.J. Stephenson, A preliminary study on growth yields in relation to the carbon and energy content of various organic growth substrates, FEMS Microbiol. Lett. 3 (1978), pp. 95-98

URL: http://mc.manuscriptcentral.com/sqer 
2

3

4

5

7

8

9

10

11

12

13

14

15

16

17

18

19

20

21
773

\section{Tables:}

774 Table 1. Comparison of equations used to estimate the bacterial yield on a given substrate serving as both electron donor and carbon source in $g$ cell carbon (g substrate carbon) $)^{-1}$. The nitrogen source is assumed to be $\mathrm{NH}_{4}{ }^{+}$. Carbon is assumed to be incorporated into biomass or evolved as $\mathrm{CO}_{2}$.

\begin{tabular}{|c|c|}
\hline Method & Equation \\
\hline $\begin{array}{l}\text { Minimum } \\
\text { Turnover to } \\
\text { Biomass } \\
\text { (MTB) }\end{array}$ & $Y_{\bar{C}}=\left(\frac{\frac{n_{\text {bio }}}{n} \frac{\Delta G_{r}^{0^{\prime}}}{\Delta G_{A T P}} \times Y_{A T P}}{\frac{M_{c}}{\sigma_{c}} \times n_{C}+\frac{n_{\text {bio }}}{n} \frac{\Delta G_{r}^{0^{\prime}}}{\Delta G_{A T P}} \times Y_{A T P}}\right)$ \\
\hline $\begin{array}{l}\text { Thermodynam } \\
\text { ic Electron } \\
\text { Equivalent } \\
\text { Model } 2 \\
\text { (TEEM2) }\end{array}$ & $Y_{\bar{c}}=\left(\frac{\gamma_{S}}{\gamma_{c}}\right)\left(\frac{\Delta G_{a}^{0^{\prime}}-\Delta G_{d}^{0^{\prime}}-\frac{q}{p} \Delta G_{x y}^{0{ }^{\prime}}}{\Delta G_{a}^{0^{\prime}}-\Delta G_{d}^{0 \prime}-\frac{q}{p} \Delta G_{x y}^{0 \prime}-\frac{\frac{\Delta G_{f a}^{0}{ }^{\prime}-\Delta G_{d}^{0^{\prime}}}{\epsilon^{m}}+\frac{\Delta G_{i n}^{0 \prime}-\Delta G_{f a}^{0 \prime}}{\epsilon^{\prime}}+\frac{\Delta \mathrm{G}_{\mathrm{ATP}}}{\epsilon} \times \frac{M_{C}}{\gamma_{c} \sigma_{c}}}{\epsilon}}\right.$ \\
\hline $\begin{array}{l}\text { Expanded } \\
\text { thermodynami } \\
\text { c true yield } \\
\text { model } \\
\text { (ETTYM) }\end{array}$ & $Y_{\frac{C}{C}}=f_{\text {cell }}=\frac{-K\left(\gamma_{s} \Delta G_{e-O_{2}}-\Delta G_{d}\right)}{\frac{\Delta G_{\text {acetate }}-\Delta G_{d}}{K^{m}}+\frac{\frac{\Delta G_{A T P} \times M_{\text {cell }}}{Y_{\text {ATP }} \times 0.9}}{K}-K\left(\gamma_{c} \Delta G_{e-O_{2}}-\Delta G_{d}\right)}$ \\
\hline
\end{tabular}

the redox reaction; $\triangle G_{A T P}$ : Gibbs free energy of hydrolysis with $\sim 40 \%$ efficiency taken into account $\left[80 \mathrm{~kJ}\right.$ mol $\left.{ }^{-1}\right] ; Y_{A T P}$ : bacterial yield on ATP [ $\mathrm{g}$ cell dw (mol ATP $\left.)^{-1}\right]$, which is assumed to be dependent on the chemical structure; $M_{c}$ : molar mass of carbon $\left[12.01 \mathrm{~g} \mathrm{~mol}^{-1}\right] ; \sigma_{c}$ : fraction of carbon in dry cell $\left[\mathrm{g} \mathrm{C}(\mathrm{g} \text { cell dw })^{-1}\right] ; n_{c}:$ number of carbon atoms in the substrate.

TEEM2: $\gamma_{s}$ : degree of reductance of the substrate; $\gamma_{\mathrm{c}}$ : degree of reductance of the cell; $\Delta G_{a}{ }^{\circ}:$ Gibbs free energy of reduction of the electron acceptor $\left[\mathrm{kJ} \mathrm{eeq}^{-1}\right] ; \Delta G_{d}{ }^{\circ}$ : Gibbs free energy of reduction of the electron donor $\left[\mathrm{kJ} \mathrm{eeq}^{-1}\right] ; q$ : number of oxygenase reactions [oxygenase reactions $\left.\mathrm{mol}^{-1}\right] ; p$ : number of electron equivalents per mole substrate $\left[\mathrm{eeq} \mathrm{mol}^{-1}\right] ; \Delta G_{x y}$ : reduction potential of $\mathrm{NADH} / \mathrm{NAD}^{+}$oxidation $\left[=-219.2 \mathrm{~kJ} \mathrm{~mol}^{-1}\right]^{;} \Delta G_{f a}{ }^{\circ}:$ Gibbs free energy of reduction of formaldehyde [ $=46.53 \mathrm{~kJ}$ eeq $\left.^{-1}\right] ; \Delta G_{i n}{ }^{\circ}$ : Gibbs free energy of reduction of acetyl-CoA $\left[=30.9 \mathrm{~kJ} \mathrm{eeq}^{-1}\right] ; \varepsilon$ : energy capture efficiency $[=0.37] ; \Delta G_{A T P}$ : hydrolysis of ATP at standard biological conditions $\left[=30.53 \mathrm{~kJ} \mathrm{~mol}^{-1}\right] ; Y_{A T P}$ : the bacterial yield on ATP $\left[=10.5 \mathrm{~g}\right.$ cell dw $\left.(\mathrm{mol} \mathrm{ATP})^{-1}\right] ; \sigma_{c}$ : fraction of carbon in the cell; $M_{c}$ : molar mass of carbon $\left[12.01 \mathrm{~g} \mathrm{~mol}^{-1}\right] ; m:+1$ if $\Delta G_{f a}{ }^{\circ}>0$, else $=n ; n:+1$ if $\Delta G_{i n}{ }^{\circ}-\Delta G_{d}{ }^{\circ}>0$, else $n=-1$.

URL: http://mc.manuscriptcentral.com/sqer 
1

2

3

4

5

6

7

8

9

10

11

12

13

14

15

16

17

18

19

20

21

22

23

24

25

26

27

28

29

30

31

32

33

34

35

36

37

38

39

40

41

42

43

44

45

46

47

48

49

50

51

52

53

54

55

56

57

58

59

60
789 ETTYM: $K$ : efficiency parameter $[=0.41]$; $\gamma_{s}$ : degree of reductance of the substrate; $\Delta G_{e-02}$ : Gibbs free energy of reduction of

790 oxygen $\left[\mathrm{kJ} \mathrm{eeq}^{-1}\right] ; \gamma_{c}$ : degree of reductance of the cell; $\Delta G_{d}$ : Gibbs free energy of the carbon source $\left[\mathrm{kJ}(\mathrm{mol} \mathrm{C})^{-1}\right] ; \Delta G_{\text {acetate: }}$ Gibbs

791 free energy of acetate reduction $\left(=106.3 \mathrm{~kJ}\left(\mathrm{~mol} \mathrm{C}^{-1}\right) ; \Delta G_{A T P}\right.$ : hydrolysis of ATP at standard biological conditions $[=30.53 \mathrm{~kJ}$ mol

$\left.792{ }^{\mathrm{I}}\right] ; Y_{\text {ATP }}$ : bacterial yield on ATP $\left[=10.5 \mathrm{~g}\right.$ cell dw $\left.(\mathrm{mol} \mathrm{ATP})^{-1}\right] ; M_{\text {cell: }}$ : cell mass per mol carbon $\left(=26.4 \mathrm{~g}\left(\mathrm{molC}^{-1}\right)\right.$ with cell formula

$\left.793 \mathrm{C}_{5} \mathrm{H}_{10} \mathrm{O}_{3} \mathrm{~N}\right) ; m: m$ is +1 if $\left(\Delta \mathrm{G}_{\text {acetate }}-\Delta G_{C S}\right)>0$ else $m$ is $=-1$.

794

URL: http://mc.manuscriptcentral.com/sqer 
1

2

4

5

8

9

10

11

12

13

14

15

16

17

18

19

20

21
795

Table 2. Balanced half-reactions as reductions of the three different terminal electron acceptors and pesticides and xenobiotics and their associated Gibbs free energy of the half-reaction $\left(\Delta G_{r}{ }^{\circ} \text { ) in } \mathrm{kJ} \mathrm{mol}^{-1} \text { and } \mathrm{kJ} \text { (electron equivalent (eeq)) }\right)^{-1}$ at standard state conditions, except for $\mathrm{H}^{+}\left(=10^{-7} \mathrm{M}\right)$

\begin{tabular}{|c|c|c|c|}
\hline & Half-reaction & \multicolumn{2}{|c|}{$\Delta G_{r}{ }^{\circ}$} \\
\hline Terminal electron acceptor & & $\begin{array}{l}{\left[\mathrm{kJ} \mathrm{mol}^{-}\right.} \\
\left.{ }^{1}\right]\end{array}$ & $\begin{array}{l}{[\mathrm{kJ}} \\
\left.\text { eeq }^{-1}\right]\end{array}$ \\
\hline Oxygen, $\mathrm{O}_{2}$ & $\mathrm{O}_{2}+4 \mathrm{H}^{+}+4 \mathrm{e}^{-} \rightleftharpoons 2 \mathrm{H}_{2} \mathrm{O}$ & -314.88 & -78.72 \\
\hline Nitrate, $\mathrm{NO}_{3}^{-}$ & $\mathrm{NO}_{3}^{-}+6 \mathrm{H}^{+}+5 \mathrm{e}^{-} \rightleftharpoons \frac{1}{2} \mathrm{~N}_{2}+3 \mathrm{H}_{2} \mathrm{O}$ & -358.8 & -71.76 \\
\hline Sulphate, $\mathrm{SO}_{4}{ }^{2-}$ & $\begin{aligned} \mathrm{SO}_{4}^{2-}+9.5 \mathrm{H}^{+}+ & 8 \mathrm{e}^{-} \\
& \rightleftharpoons \frac{1}{2} \mathrm{HS}^{-}+\frac{1}{2} \mathrm{H}_{2} \mathrm{~S} \\
& +4 \mathrm{H}_{2} \mathrm{O}\end{aligned}$ & 170.16 & 21.27 \\
\hline $\begin{array}{l}\text { Electron donor, Pesticides } \\
\text { xenobiotics }\end{array}$ & & & \\
\hline $2,4-\mathrm{D}$ & $\begin{array}{r}8 \mathrm{CO}_{2}+2 \mathrm{HCl}+30 \mathrm{H}^{+}+30 \mathrm{e}^{-} \\
\rightleftharpoons \mathrm{C}_{8} \mathrm{H}_{6} \mathrm{Cl}_{2} \mathrm{O}_{3} \\
+13 \mathrm{H}_{2} \mathrm{O}\end{array}$ & 1286 & 42.9 \\
\hline $2,4-\mathrm{DB}$ & $\begin{aligned} 10 \mathrm{CO}_{2}+2 \mathrm{HCl}+ & 42 \mathrm{H}^{+}+42 \mathrm{e}^{-} \\
& \rightleftharpoons \mathrm{C}_{10} \mathrm{H}_{10} \mathrm{Cl}_{2} \mathrm{O}_{3} \\
& +17 \mathrm{H}_{2} \mathrm{O}\end{aligned}$ & 1778 & 42.3 \\
\hline Acetamiprid & $\begin{aligned} 10 \mathrm{CO}_{2}+\mathrm{HCl}+ & 4 \mathrm{NH}_{3}+38 \mathrm{H}^{+}+38 \mathrm{e}^{-} \\
& \rightleftharpoons \mathrm{C}_{10} \mathrm{H}_{11} \mathrm{ClN}_{4} \\
& +20 \mathrm{H}_{2} \mathrm{O}\end{aligned}$ & 1695 & 44.6 \\
\hline Acetochlor & $\begin{array}{c}14 \mathrm{CO}_{2}+\mathrm{HCl}+\mathrm{NH}_{3}+68 \mathrm{H}^{+}+68 \mathrm{e}^{-} \\
\rightleftharpoons \mathrm{C}_{14} \mathrm{H}_{20} \mathrm{ClNO}_{2} \\
+26 \mathrm{H}_{2} \mathrm{O}\end{array}$ & 2091 & 30.8 \\
\hline Alachlor & $14 \mathrm{CO}_{2}+68 \mathrm{H}^{+}+68 \mathrm{e}^{-}+\mathrm{HCl}+$ & 2890 & 42.5 \\
\hline
\end{tabular}

URL: http://mc.manuscriptcentral.com/sqer 


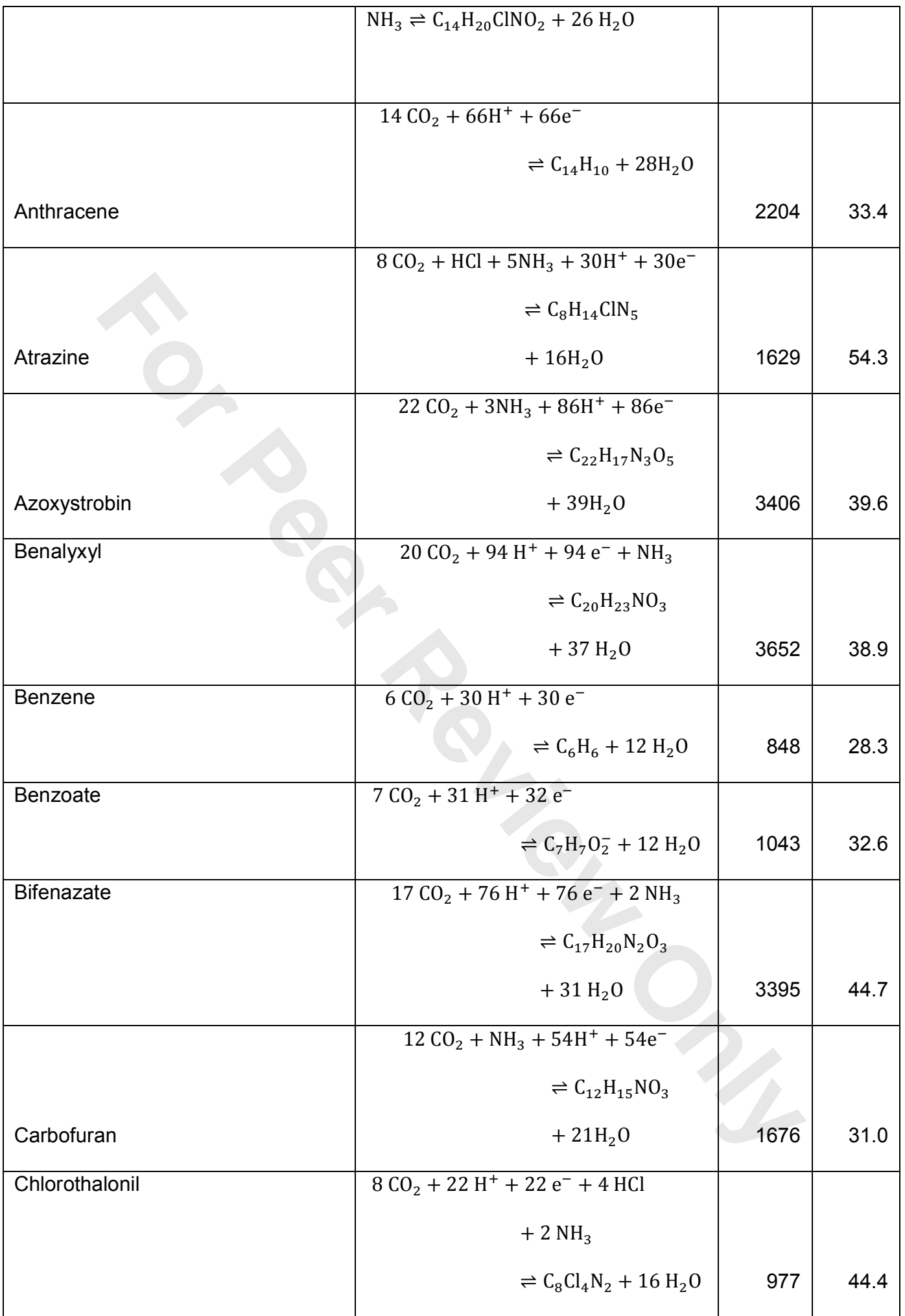

URL: http://mc.manuscriptcentral.com/sqer 


\begin{tabular}{|c|c|c|c|}
\hline Chlorpropham & $\begin{aligned} 10 \mathrm{CO}_{2}+44 \mathrm{H}^{+} & +44 \mathrm{e}^{-}+\mathrm{HCl}+\mathrm{NH}_{3} \\
& \rightleftharpoons \mathrm{C}_{10} \mathrm{H}_{12} \mathrm{ClNO}_{2} \\
& +18 \mathrm{H}_{2} \mathrm{O}\end{aligned}$ & 2223 & 50.5 \\
\hline Cypermethrin & $\begin{aligned} 22 \mathrm{CO}_{2}+96 \mathrm{H}^{+} & +96 \mathrm{e}^{-}+2 \mathrm{HCl} \\
& +\mathrm{NH}_{3} \\
& \rightleftharpoons \mathrm{C}_{22} \mathrm{H}_{19} \mathrm{Cl}_{2} \mathrm{NO}_{3} \\
& +41 \mathrm{H}_{2} \mathrm{O}\end{aligned}$ & 3762 & 39.2 \\
\hline Daminozide & $\begin{aligned} 6 \mathrm{CO}_{2}+2 \mathrm{NH}_{3}+ & 24 \mathrm{H}^{+}+24 \mathrm{e}^{-} \\
& \rightleftharpoons \mathrm{C}_{6} \mathrm{H}_{12} \mathrm{~N}_{2} \mathrm{O}_{3} \\
& +9 \mathrm{H}_{2} \mathrm{O}\end{aligned}$ & 1251 & 52.1 \\
\hline DDT & $\begin{aligned} 14 \mathrm{CO}_{2}+60 \mathrm{H}^{+} & +60 \mathrm{e}^{-}+5 \mathrm{HCl} \\
& \rightleftharpoons \mathrm{C}_{14} \mathrm{H}_{9} \mathrm{Cl}_{5}+28 \mathrm{H}_{2} \mathrm{O}\end{aligned}$ & 2508 & 41.8 \\
\hline Desmedipham & $\begin{aligned} 16 \mathrm{CO}_{2}+2 \mathrm{NH}_{3}+ & 66 \mathrm{H}^{+}+66 \mathrm{e}^{-} \\
& \rightleftharpoons \mathrm{C}_{16} \mathrm{H}_{16} \mathrm{~N}_{2} \mathrm{O}_{4} \\
& +28 \mathrm{H}_{2} \mathrm{O}\end{aligned}$ & 3342 & 50.6 \\
\hline Dicamba & $\begin{array}{l}8 \mathrm{CO}_{2}+30 \mathrm{H}^{+}+30 \mathrm{e}^{-}+2 \mathrm{HCl} \rightleftharpoons \\
\mathrm{C}_{8} \mathrm{H}_{6} \mathrm{Cl}_{2} \mathrm{O}_{3}+13 \mathrm{H}_{2} \mathrm{O}\end{array}$ & 1278 & 42.6 \\
\hline $\begin{array}{l}\text { Ethylenediaminetetraacetate } \\
\text { (EDTA) }\end{array}$ & $\begin{array}{r}10 \mathrm{CO}_{2}+2 \mathrm{NH}_{3}+34 \mathrm{H}^{+}+34 \mathrm{e}^{-} \\
\rightleftharpoons \mathrm{C}_{10} \mathrm{H}_{16} \mathrm{~N}_{2} \mathrm{O}_{8} \\
+12 \mathrm{H}_{2} \mathrm{O}\end{array}$ & 1294 & 38.1 \\
\hline Famoxadone & $\begin{aligned} 22 \mathrm{CO}_{2}+2 \mathrm{NH}_{3} & +92 \mathrm{H}^{+}+92 \mathrm{e}^{-} \\
& \rightleftharpoons \mathrm{C}_{22} \mathrm{H}_{18} \mathrm{~N}_{2} \mathrm{O}_{4} \\
& +40 \mathrm{H}_{2} \mathrm{O}\end{aligned}$ & 3840 & 41.7 \\
\hline Glyphosate & $\begin{array}{r}3 \mathrm{CO}_{2}+15 \mathrm{H}^{+}+12 \mathrm{e}^{-}+\mathrm{PO}_{4}^{3-}+\mathrm{NH}_{3} \\
\rightleftharpoons \mathrm{C}_{3} \mathrm{H}_{8} \mathrm{NO}_{5} \mathrm{P}+5 \mathrm{H}_{2} \mathrm{O}\end{array}$ & 756 & 63.0 \\
\hline Ibuprofen & $\begin{aligned} 13 \mathrm{CO}_{2}+66 \mathrm{H}^{+} & +66 \mathrm{e}^{-}+ \\
& \rightleftharpoons \mathrm{C}_{13} \mathrm{H}_{18} \mathrm{O}_{2} \\
& +24 \mathrm{H}_{2} \mathrm{O}\end{aligned}$ & 2566 & 38.9 \\
\hline
\end{tabular}

URL: http://mc.manuscriptcentral.com/sqer 


\begin{tabular}{|c|c|c|c|}
\hline Iprodione & $\begin{aligned} 13 \mathrm{CO}_{2}+2 \mathrm{HCl}+ & 3 \mathrm{NH}_{3}+48 \mathrm{H}^{+} \\
& +48 \mathrm{e}^{-} \\
& \rightleftharpoons \mathrm{C}_{13} \mathrm{H}_{13} \mathrm{Cl}_{2} \mathrm{~N}_{3} \mathrm{O}_{3} \\
& +23 \mathrm{H}_{2} \mathrm{O}\end{aligned}$ & 2358 & 49.1 \\
\hline MCPA & $\begin{aligned} \mathrm{CO}_{2}+38 \mathrm{H}^{+}+ & 38 \mathrm{e}^{-}+\mathrm{HCl} \\
& \rightleftharpoons \mathrm{C}_{9} \mathrm{H}_{9} \mathrm{ClO}_{3} \\
& +15 \mathrm{H}_{2} \mathrm{O}\end{aligned}$ & 1530 & 40.3 \\
\hline MCPB & $\begin{aligned} 11 \mathrm{CO}_{2}+\mathrm{HCl}+ & 50 \mathrm{H}^{+}+50 \mathrm{e}^{-} \\
& \rightleftharpoons \mathrm{C}_{11} \mathrm{H}_{13} \mathrm{ClO}_{3} \\
& +19 \mathrm{H}_{2} \mathrm{O}\end{aligned}$ & 1964 & 39.3 \\
\hline Mecoprop (MCPP) & $\begin{aligned} 10 \mathrm{CO}_{2}+44 \mathrm{H}^{+} & +44 \mathrm{e}^{-}+\mathrm{HCl} \\
& \rightleftharpoons \mathrm{C}_{10} \mathrm{H}_{11} \mathrm{ClO}_{3} \\
& +17 \mathrm{H}_{2} \mathrm{O}\end{aligned}$ & 1779 & 40.4 \\
\hline Metalaxyl-M & $\begin{aligned} 15 \mathrm{CO}_{2}+\mathrm{NH}_{3}+ & 70 \mathrm{H}^{+}+70 \mathrm{e}^{-} \\
& \rightleftharpoons \mathrm{C}_{15} \mathrm{H}_{21} \mathrm{NO}_{4} \\
& +26 \mathrm{H}_{2} \mathrm{O}\end{aligned}$ & 2997 & 42.8 \\
\hline Metamitron & $\begin{aligned} 10 \mathrm{CO}_{2}+36 \mathrm{H}^{+} & +36 \mathrm{e}^{-}+4 \mathrm{NH}_{3} \\
& \rightleftharpoons \mathrm{C}_{10} \mathrm{H}_{10} \mathrm{~N}_{4} \mathrm{O} \\
& +19 \mathrm{H}_{2} \mathrm{O}\end{aligned}$ & 1391 & 38.6 \\
\hline Milbemectin & $\begin{aligned} 31 \mathrm{CO}_{2}+154 \mathrm{H}^{+} & +154 \mathrm{e}^{-} \\
& \rightleftharpoons \mathrm{C}_{31} \mathrm{H}_{44} \mathrm{O}_{7}+55 \mathrm{H}_{2} \mathrm{O}\end{aligned}$ & 6402 & 41.6 \\
\hline Naphthalene & $\begin{aligned} 10 \mathrm{CO}_{2}+48 \mathrm{H}^{+} & +48 \mathrm{e}^{-} \\
& \rightleftharpoons \mathrm{C}_{10} \mathrm{H}_{8}+20 \mathrm{H}_{2} \mathrm{O}\end{aligned}$ & 1638 & 34.1 \\
\hline Nitrilotriacetate (NTA) & $\begin{aligned} & 6 \mathrm{CO}_{2}+\mathrm{NH}_{3}+18 \mathrm{H}^{+}+18 \mathrm{e}^{-} \\
& \rightleftharpoons \mathrm{C}_{6} \mathrm{H}_{9} \mathrm{NO}_{6}+6 \mathrm{H}_{2} \mathrm{O}\end{aligned}$ & 731 & 40.6 \\
\hline Paraquat & $\begin{aligned} 12 \mathrm{CO}_{2}+2 \mathrm{NH}_{3}+ & 56 \mathrm{H}^{+}+56 \mathrm{e}^{-} \\
& \rightleftharpoons \mathrm{C}_{12} \mathrm{H}_{14} \mathrm{~N}_{2}+24 \mathrm{H}_{2} \mathrm{O}\end{aligned}$ & 2229 & 39.8 \\
\hline
\end{tabular}

URL: http://mc.manuscriptcentral.com/sqer 


\begin{tabular}{|c|c|c|c|}
\hline Pendimethalin & $\begin{array}{c}13 \mathrm{CO}_{2}+54 \mathrm{H}^{+}+54 \mathrm{e}^{-}+3 \mathrm{NH}_{3} \\
\rightleftharpoons \mathrm{C}_{13} \mathrm{H}_{19} \mathrm{~N}_{3} \mathrm{O}_{4} \\
+22 \mathrm{H}_{2} \mathrm{O}\end{array}$ & 3082 & 57.1 \\
\hline Phenanthrene & $\begin{aligned} 14 \mathrm{CO}_{2}+66 \mathrm{H}^{+} & +66 \mathrm{e}^{-} \\
& \rightleftharpoons \mathrm{C}_{14} \mathrm{H}_{10}+28 \mathrm{H}_{2} \mathrm{O}\end{aligned}$ & 2204 & 33.4 \\
\hline Phenmedipham & $\begin{aligned} 16 \mathrm{CO}_{2}+66 \mathrm{H}^{+} & +66 \mathrm{e}^{-}+2 \mathrm{NH}_{3} \\
& \rightleftharpoons \mathrm{C}_{16} \mathrm{H}_{16} \mathrm{~N}_{2} \mathrm{O}_{4} \\
& +28 \mathrm{H}_{2} \mathrm{O}\end{aligned}$ & 3336 & 50.5 \\
\hline Propyzamid & $\begin{aligned} 12 \mathrm{CO}_{2}+52 \mathrm{H}^{+} & +52 \mathrm{e}^{-}+2 \mathrm{HCl} \\
& +\mathrm{NH}_{3} \\
& \rightleftharpoons \mathrm{C}_{12} \mathrm{H}_{11} \mathrm{Cl}_{2} \mathrm{NO} \\
& +23 \mathrm{H}_{2} \mathrm{O}\end{aligned}$ & 2036 & 39.2 \\
\hline Pymetrozine & $\begin{aligned} 11 \mathrm{CO}_{2}+5 \mathrm{NH}_{3} & +38 \mathrm{H}^{+}+38 \mathrm{e}^{-} \\
& \rightleftharpoons \mathrm{C}_{11} \mathrm{H}_{11} \mathrm{~N}_{5} \mathrm{O} \\
& +21 \mathrm{H}_{2} \mathrm{O}\end{aligned}$ & 1880 & 49.5 \\
\hline Pyrene & $\begin{aligned} 16 \mathrm{CO}_{2}+74 \mathrm{H}^{+} & +74 \mathrm{e}^{-} \\
& \rightleftharpoons \mathrm{C}_{16} \mathrm{H}_{10}+32 \mathrm{H}_{2} \mathrm{O}\end{aligned}$ & 1968 & 26.6 \\
\hline
\end{tabular}


801 Table 3. Gibbs free energy of formation in $\mathrm{kJ} \mathrm{mol}^{-1}\left(\Delta G_{f}^{\circ}\right)$, number of carbon-hydrogen bonds,

$802 Y_{A T P}$ in g dry weight (mol ATP $)^{-1}$, number of oxygenase reactions $\left(t_{\text {oxy }}\right)$, chemical structure, and

803 degree of reducatance $\left(\gamma_{s}\right)$ of the pesticides and xenobiotics used in the comparison.

\begin{tabular}{|c|c|c|c|c|c|c|c|}
\hline Name & Structure & $\Delta G_{f}^{\circ}$ & C-H bonds & $Y_{A T P}$ & $t_{\text {oxy }}$ & $\gamma_{s}$ & Reference \\
\hline $2,4-D$ & $\mathrm{C}_{8} \mathrm{H}_{6} \mathrm{Cl}_{2} \mathrm{O}_{3}$ & -241.5 & 5 & 5 & 0 & 3.75 & [61] \\
\hline $2,4-\mathrm{DB}$ & $\mathrm{C}_{10} \mathrm{H}_{10} \mathrm{Cl}_{2} \mathrm{O}_{3}$ & -67.8 & 9 & 5 & 0 & 4.20 & [61] \\
\hline Acetamiprid & $\mathrm{C}_{10} \mathrm{H}_{11} \mathrm{CIN}_{4}$ & 745.6 & 11 & 5 & 0 & 3.80 & [61] \\
\hline Acetochlor & $\mathrm{C}_{14} \mathrm{H}_{20} \mathrm{CINO}_{2}$ & -128.1 & 20 & 5 & 0 & 4.86 & [61] \\
\hline Alachlor & $\mathrm{C}_{14} \mathrm{H}_{20} \mathrm{CINO}_{2}$ & 670.8 & 20 & 5 & 0 & 4.86 & [61] \\
\hline Anthracene & $\mathrm{C}_{14} \mathrm{H}_{10}$ & 695.8 & 10 & 5 & 1 & 4.71 & [61] \\
\hline Atrazine & $\mathrm{C}_{8} \mathrm{H}_{14} \mathrm{CIN}_{5}$ & 811.3 & 12 & 5 & 0 & 3.75 & [61] \\
\hline Azoxystrobin & $\mathrm{C}_{22} \mathrm{H}_{17} \mathrm{~N}_{3} \mathrm{O}_{5}$ & 478.1 & 17 & 5 & 0 & 3.91 & [61] \\
\hline Benalaxyl & $\mathrm{C}_{20} \mathrm{H}_{23} \mathrm{NO}_{3}$ & 771.4 & 23 & 5 & 0 & 4.70 & [61] \\
\hline Benzene & $\mathrm{C}_{6} \mathrm{H}_{6}$ & 133.9 & 6 & 5 & 2 & 5.00 & $\begin{array}{l}\text { [66] cited } \\
\text { in [23] }\end{array}$ \\
\hline Benzoate & $\mathrm{C}_{7} \mathrm{H}_{7} \mathrm{O} 2-$ & -105.4 & 6 & 5 & 2 & 4.57 & [62] \\
\hline Bifenazate & $\mathrm{C}_{17} \mathrm{H}_{20} \mathrm{~N}_{2} \mathrm{O}_{3}$ & 965.2 & 18 & 5 & 0 & 4.47 & [61] \\
\hline Carbofuran & $\mathrm{C}_{12} \mathrm{H}_{15} \mathrm{NO}_{3}$ & -251.6 & 14 & 5 & 2 & 4.50 & [61] \\
\hline Chlorothalonil & $\mathrm{C}_{8} \mathrm{Cl}_{4} \mathrm{~N}_{2}$ & 163.8 & 0 & 5 & 0 & 2.75 & [61] \\
\hline Chlorpropham & $\mathrm{C}_{10} \mathrm{H}_{12} \mathrm{CINO}_{2}$ & 639.1 & 11 & 5 & 0 & 4.40 & [61] \\
\hline Cypermethrin & $\mathrm{C}_{22} \mathrm{H}_{19} \mathrm{Cl}_{2} \mathrm{NO}_{3}$ & 700 & 19 & 5 & 0 & 4.36 & [61] \\
\hline Daminozide & $\mathrm{C}_{6} \mathrm{H}_{12} \mathrm{~N}_{2} \mathrm{O}_{3}$ & 11.2 & 11 & 5 & 0 & 4.00 & [61] \\
\hline DDT & $\mathrm{C}_{14} \mathrm{H}_{9} \mathrm{Cl}_{5}$ & 583 & 9 & 5 & 0 & 4.29 & [61] \\
\hline Desmedipham & $\mathrm{C}_{16} \mathrm{H}_{16} \mathrm{~N}_{2} \mathrm{O}_{4}$ & 993 & 14 & 5 & 0 & 4.13 & [61] \\
\hline Dicamba & $\mathrm{C}_{8} \mathrm{H}_{6} \mathrm{Cl}_{2} \mathrm{O}_{3}$ & -249.8 & 5 & 5 & 0 & 3.75 & [61] \\
\hline Ethylenediaminetetraacetate (EDTA) & $\mathrm{C}_{10} \mathrm{H}_{16} \mathrm{~N}_{2} \mathrm{O}_{8}$ & -1209.2 & 8 & 5 & 4 & 3.40 & [65] \\
\hline Famoxadone & $\mathrm{C}_{22} \mathrm{H}_{18} \mathrm{~N}_{2} \mathrm{O}_{4}$ & 935.9 & 17 & 5 & 0 & 4.18 & [61] \\
\hline Glyphosate & $\mathrm{C}_{3} \mathrm{H}_{8} \mathrm{NO}_{5} \mathrm{P}$ & -883.5 & 4 & 5 & 0 & 4.00 & [61] \\
\hline Iprodione & $\mathrm{C}_{13} \mathrm{H}_{13} \mathrm{Cl}_{2} \mathrm{~N}_{3} \mathrm{O}_{3}$ & 434 & 12 & 5 & 0 & 5.08 & [61] \\
\hline
\end{tabular}

URL: http://mc.manuscriptcentral.com/sqer 


\begin{tabular}{|c|c|c|c|c|c|c|c|}
\hline Ibuprofen & $\mathrm{C}_{13} \mathrm{H}_{18} \mathrm{O}_{2}$ & 504 & 17 & 5 & 0 & 3.69 & [61] \\
\hline MCPA & $\mathrm{C}_{9} \mathrm{H}_{9} \mathrm{ClO}_{3}$ & -105.2 & 8 & 5 & 0 & 4.22 & [61] \\
\hline MCPB & $\mathrm{C}_{11} \mathrm{H}_{13} \mathrm{ClO}_{3}$ & 11.2 & 12 & 5 & 0 & 4.55 & [61] \\
\hline Mecoprop (MCPP) & $\mathrm{C}_{10} \mathrm{H}_{11} \mathrm{ClO}_{3}$ & -15.7 & 10 & 5 & 0 & 4.40 & [61] \\
\hline Metalaxyl-M & $\mathrm{C}_{15} \mathrm{H}_{21} \mathrm{NO}_{4}$ & 434.8 & 21 & 5 & 0 & 4.67 & [61] \\
\hline Metamitron & $\mathrm{C}_{10} \mathrm{H}_{10} \mathrm{~N}_{4} \mathrm{O}$ & 414.8 & 8 & 5 & 0 & 3.60 & [62] \\
\hline Milbemectin & $\mathrm{C}_{31} \mathrm{H}_{44} \mathrm{O}_{7}$ & 1090 & 42 & 5 & 0 & 4.97 & [61] \\
\hline Naphthalene & $\mathrm{C}_{10} \mathrm{H}_{8}$ & 527.1 & 10 & 5 & 1 & 4.80 & [61] \\
\hline Nitrilotriacetate (NTA) & $\mathrm{C}_{6} \mathrm{H}_{9} \mathrm{NO}_{6}$ & -954.8 & 6 & 5 & 1 & 3.00 & [65] \\
\hline Paraquat & $\mathrm{C}_{12} \mathrm{H}_{14} \mathrm{~N}_{2}$ & 906.4 & 14 & 5 & 0 & 4.67 & [61] \\
\hline Pendimethalin & $\mathrm{C}_{13} \mathrm{H}_{19} \mathrm{~N}_{3} \mathrm{O}_{4}$ & 944.3 & 18 & 5 & 0 & 4.15 & [61] \\
\hline Phenanthrene & $\mathrm{C}_{14} \mathrm{H}_{10}$ & 695.8 & 10 & 5 & 1 & 4.71 & [61] \\
\hline Phenmedipham & $\mathrm{C}_{16} \mathrm{H}_{16} \mathrm{~N}_{2} \mathrm{O}_{4}$ & 986.9 & 14 & 5 & 0 & 4.13 & [61] \\
\hline Propyzamide & $\mathrm{C}_{12} \mathrm{H}_{11} \mathrm{Cl}_{2} \mathrm{NO}$ & 399.9 & 10 & 5 & 0 & 4.33 & [61] \\
\hline Pymetrozine & $\mathrm{C}_{11} \mathrm{H}_{11} \mathrm{~N}_{5} \mathrm{O}$ & 878 & 10 & 5 & 0 & 3.45 & [61] \\
\hline Pyrene & $\mathrm{C}_{16} \mathrm{H}_{10}$ & 301.3 & 10 & 5 & 1 & 4.63 & [62] \\
\hline Ammonia & $\mathrm{NH}_{3}$ & -26.6 & & & & & [52] \\
\hline Carbon dioxide & $\mathrm{CO}_{2}$ & -394.4 & & & & 0 & [52] \\
\hline Nitrate & $\mathrm{NO}_{3}^{-}$ & -108.7 & & & & & [67] \\
\hline Hydrogen ion (proton) (pH 7) & $\mathrm{H}^{+}$ & -39.9 & & & & & [52] \\
\hline Water & $\mathrm{H}_{2} \mathrm{O}$ & -237.2 & & & & & [52] \\
\hline Oxygen & $\mathrm{O}_{2}$ & 0 & & & & & [67] \\
\hline Hydrogen sulphide anion & $\mathrm{HS}^{-}$ & 12.1 & 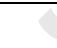 & & & & [52] \\
\hline Hydrogen sulphide & $\mathrm{H}_{2} \mathrm{~S}$ & -27.8 & & & & & [67] \\
\hline Sulphate & $\mathrm{SO}_{4}{ }^{2-}$ & -744.4 & & & & & [52] \\
\hline Nitrogen & $\mathrm{N}_{2}$ & 0 & & & & & [67] \\
\hline Hydrogen chloride & $\mathrm{HCl}$ & -131.2 & & & & & [67] \\
\hline
\end{tabular}

URL: http://mc.manuscriptcentral.com/sqer 
805 Table 4. Bacterial growth yields on organic chemicals of environmental concern under aerobic

806 conditions in $\mathrm{g}$ cell carbon ( $\mathrm{g}$ substrate carbon) ${ }^{-1}$ predicted using MTB, TEEM2, and MTB.

807 Predictions are evaluated using available experimental data. The error and mean absolute error

808 are shown. The observed experimental bacterial growth yields $\left(\mathrm{Y}^{\mathrm{OBS}}\right)$ with reference are shown.

809 The cell formulation for MTB and TEEM2 was taken to be $\mathrm{C}_{5} \mathrm{H}_{7} \mathrm{O}_{2} \mathrm{~N}$ with a degree of

810 reductance of 4.0. For ETTYM it was taken to be $\mathrm{C}_{5} \mathrm{H}_{10} \mathrm{O}_{3} \mathrm{~N}$ with a degree of reductance of 4.2.

811 The predictions were made under standard state conditions $(\mathrm{pH}=7)$. The entries are sorted from

812 low to high predicted yield of MTB. For TEEM2 a weak positive correlation and for ETTYM a

813 strong positive correlation exists between the degree of reductance of the compound and

814 predicted yield ( $R^{2}$ is shown).

\begin{tabular}{|c|c|c|c|c|c|c|c|c|}
\hline Compound & $Y^{O B S}$ & $\begin{array}{l}Y^{\text {pred }} \\
\text { MTB }\end{array}$ & Error & $\begin{array}{l}Y^{\text {pred }} \\
\text { TEEM2 }\end{array}$ & Error & $\begin{array}{l}Y^{\text {pred }} \\
\text { ETTYM }\end{array}$ & Error & Reference \\
\hline Unit & $\begin{array}{c}\text { g cell } \\
\text { carbon } \\
\text { (g } \\
\text { substrate } \\
\text { carbon) } \\
1\end{array}$ & $\begin{array}{c}\text { g cell } \\
\text { carbon } \\
\text { substrate } \\
\text { carbon) } \\
1\end{array}$ & [\%] & $\begin{array}{l}\text { g cell } \\
\text { carbon } \\
\text { (g } \\
\text { substrate } \\
\text { carbon)- } \\
1\end{array}$ & [\%] & $\begin{array}{l}\text { g cell } \\
\text { carbon } \\
\text { (g } \\
\text { substrate } \\
\text { carbon)- } \\
1\end{array}$ & {$[\%]$} & \\
\hline Chlorothalonil & & 0.00 & & 0.35 & & 0.36 & & \\
\hline Pyrene & $\begin{array}{r}0.21- \\
0.31\end{array}$ & 0.27 & $\begin{array}{r}-13 \\
\text { to } 27\end{array}$ & 0.44 & $\begin{array}{r}45 \text { to } \\
111\end{array}$ & 0.52 & 145 & {$[51]$} \\
\hline $2,4-D$ & 0.31 & 0.30 & -4.7 & 0.47 & 51 & 0.48 & 56 & [47] \\
\hline Dicamba & & 0.30 & & 0.47 & & 0.48 & & \\
\hline DDT & & 0.30 & & 0.53 & & 0.55 & & \\
\hline Anthracene & $\begin{array}{r}0.11- \\
0.13\end{array}$ & 0.31 & $\begin{array}{r}128 \\
\text { to } \\
183\end{array}$ & 0.54 & $\begin{array}{r}182 \\
\text { to } \\
341\end{array}$ & 0.56 & $\begin{array}{r}316 \\
\text { to } \\
416\end{array}$ & [49] \\
\hline Phenanthrene & 0.32 & 0.31 & -4.1 & 0.54 & 67.3 & 0.56 & 75 & [23] \\
\hline
\end{tabular}




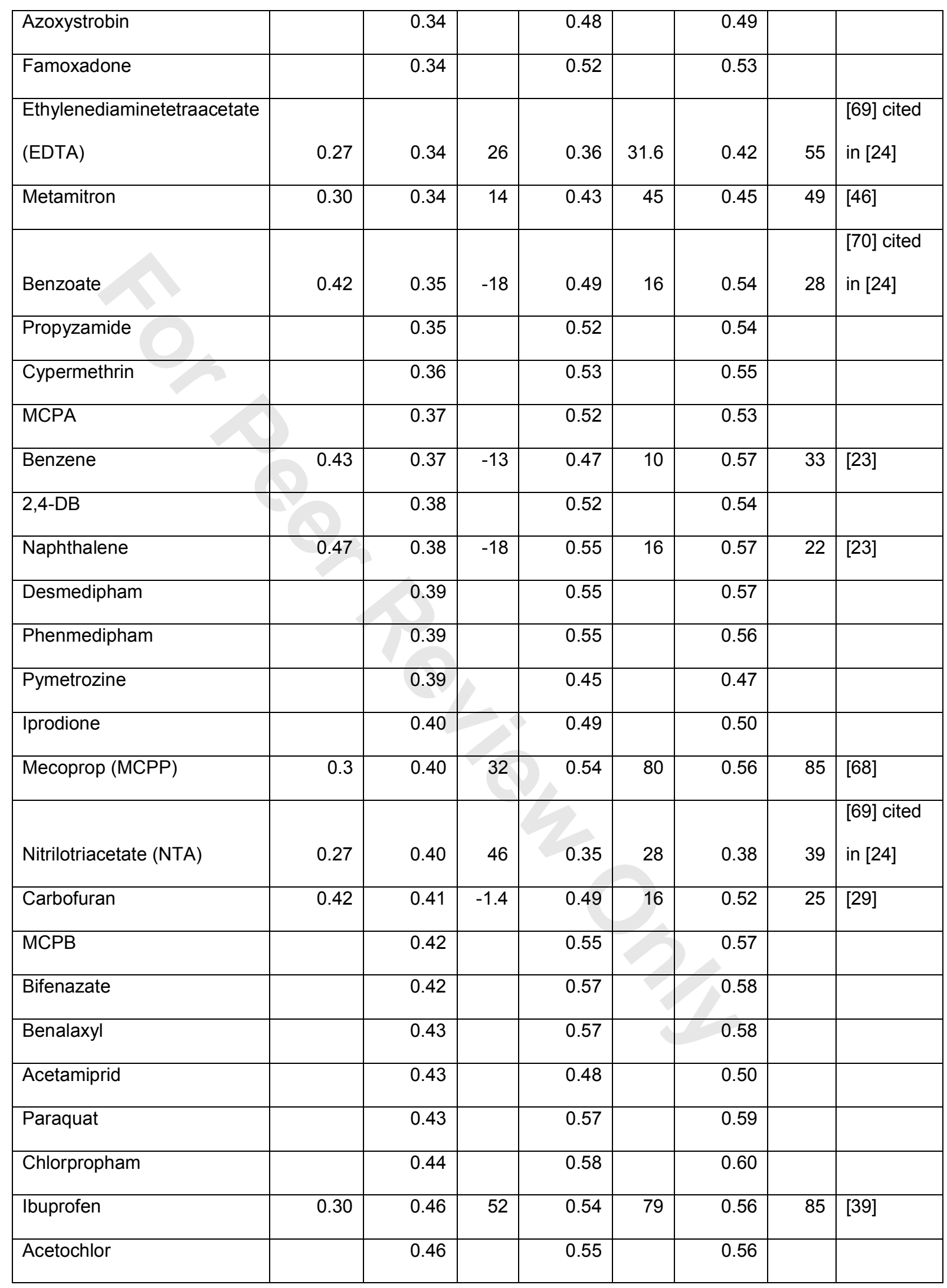

URL: http://mc.manuscriptcentral.com/sqer 


\begin{tabular}{|c|c|c|c|c|c|c|c|c|}
\hline Milbemectin & & 0.47 & & 0.62 & & 0.63 & & \\
\hline Metalaxyl-M & & 0.48 & & 0.58 & & 0.60 & & \\
\hline Alachlor & & 0.49 & & 0.61 & & 0.62 & & \\
\hline Pendimethalin & & 0.51 & & 0.58 & & 0.60 & & \\
\hline Glyphosate & 0.18 & 0.51 & 183 & 0.58 & 224 & 0.60 & 234 & [42] \\
\hline Atrazine & & 0.52 & & 0.51 & & 0.53 & & \\
\hline Daminozide & & 0.57 & & 0.54 & & 0.55 & & \\
\hline $\begin{array}{l}\text { Linear correlation to degree } \\
\text { of reductance }\left(R^{2}\right)\end{array}$ & & 0.14 & & 0.53 & & 0.70 & & \\
\hline Mean absolute error (MAE) & & & $49 \%$ & & $82 \%$ & & $111 \%$ & \\
\hline
\end{tabular}


1

5

817 Table 5. Comparison of bacterial growth yields of organic chemicals of environmental concern

818 under anaerobic conditions in $\mathrm{g}$ cell carbon (g substrate carbon) ${ }^{-1}$. Predictions were made using

819 MTB, TEEM2, and MTB. The cell formulation for MTB and TEEM2 was taken to be $\mathrm{C}_{5} \mathrm{H}_{7} \mathrm{O}_{2} \mathrm{~N}$

820 with a degree of reductance of 4.0. For ETTYM it was taken to be $\mathrm{C}_{5} \mathrm{H}_{10} \mathrm{O}_{3} \mathrm{~N}$ with a degree of

821 reductance of 4.2. The predictions were made under standard biochemical conditions $(\mathrm{pH}=7)$.

822 The entries are sorted from low to high predicted yield of MTB under nitrate-reducing

823 conditions. For TEEM2 a weak positive correlation and for ETTYM and strong positive

824 correlation exists between the degree of reductance of the compound and predicted yield $\left(R^{2}\right.$ is

825 shown). Values highlighted in bold are negative and thus not meaningful.

\begin{tabular}{|c|c|c|c|c|c|c|}
\hline Compound & MTB & TEEM2 & ETTYM & MTB & TEEM2 & ETTYM \\
\hline Unit & \multicolumn{6}{|c|}{ g cell carbon (g substrate carbon) $)^{-1}$} \\
\hline Electron acceptor & \multicolumn{3}{|c|}{$\mathrm{NO}_{3}^{-}$} & \multicolumn{3}{|c|}{$\mathrm{SO}_{4}^{2-}$} \\
\hline Chlorothalonil & 0.00 & 0.34 & 0.35 & 0.00 & 0.11 & 0.12 \\
\hline Pyrene & 0.25 & 0.42 & 0.50 & 0.02 & 0.02 & 0.05 \\
\hline $2,4-\mathrm{D}$ & 0.28 & 0.46 & 0.47 & 0.07 & 0.14 & 0.15 \\
\hline Dicamba & 0.28 & 0.45 & 0.47 & 0.07 & 0.14 & 0.15 \\
\hline DDT & 0.29 & 0.51 & 0.53 & 0.07 & 0.15 & 0.17 \\
\hline Anthracene & 0.29 & 0.52 & 0.54 & 0.05 & 0.07 & 0.11 \\
\hline Phenanthrene & 0.29 & 0.52 & 0.54 & 0.05 & 0.07 & 0.11 \\
\hline Azoxystrobin & 0.32 & 0.46 & 0.47 & 0.07 & 0.12 & 0.14 \\
\hline Famoxadone & 0.33 & 0.50 & 0.52 & 0.08 & 0.15 & 0.16 \\
\hline Ethylenediaminetetraacetate (EDTA) & 0.33 & 0.34 & 0.41 & 0.07 & -0.06 & 0.11 \\
\hline Metamitron & 0.33 & 0.42 & 0.43 & 0.07 & 0.11 & 0.12 \\
\hline Benzoate & 0.33 & 0.47 & 0.52 & 0.05 & -0.02 & 0.10 \\
\hline Propyzamide & 0.34 & 0.51 & 0.52 & 0.08 & 0.13 & 0.15 \\
\hline Cypermethrin & 0.35 & 0.51 & 0.53 & 0.08 & 0.14 & 0.15 \\
\hline MCPA & 0.35 & 0.50 & 0.52 & 0.09 & 0.14 & 0.15 \\
\hline Benzene & 0.36 & 0.45 & 0.55 & 0.04 & -0.07 & 0.07 \\
\hline
\end{tabular}

URL: http://mc.manuscriptcentral.com/sqer 


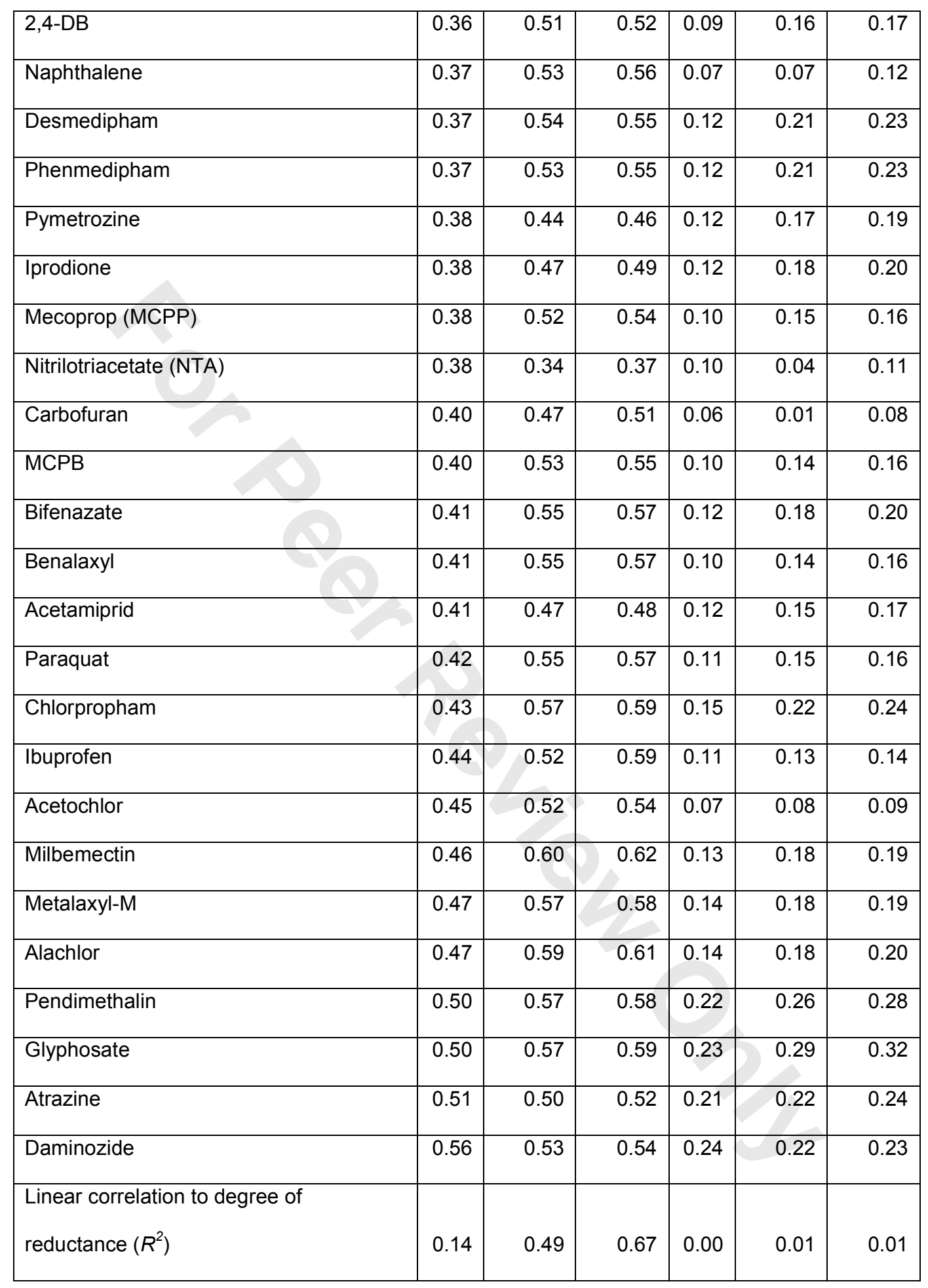

URL: http://mc.manuscriptcentral.com/sqer 
1

5

8

10

11

828 Table 6. Bacterial growth yields on simple carbon substrates under aerobic conditions predicted

829 using MTB, TEEM2 and ETTYM in $\mathrm{g}$ cell carbon ( $\mathrm{g}$ substrate carbon) $)^{-1}$. Where experimental

830 data have been available, the predictions are evaluated with respect to these. The error and mean

831 absolute error are shown. The experimental bacterial growth yields $\left(\mathrm{Y}^{\mathrm{EXP}}\right)$ were taken from

832 Xiao and VanBriesen [24]. The predictions were done under standard biochemical conditions

$833(\mathrm{pH}=7)$. For ETTYM the cell formulation is $\mathrm{CH}_{10} \mathrm{O}_{3} \mathrm{~N}$ with a degree of reductance of 4.2. For

834 TEEM2 and MTB it is $\mathrm{C}_{5} \mathrm{H}_{7} \mathrm{O}_{2} \mathrm{~N}$ with a degree of reductance of 4.0. The entries are sorted

835 based on the highest absolute error calculated for MTB.

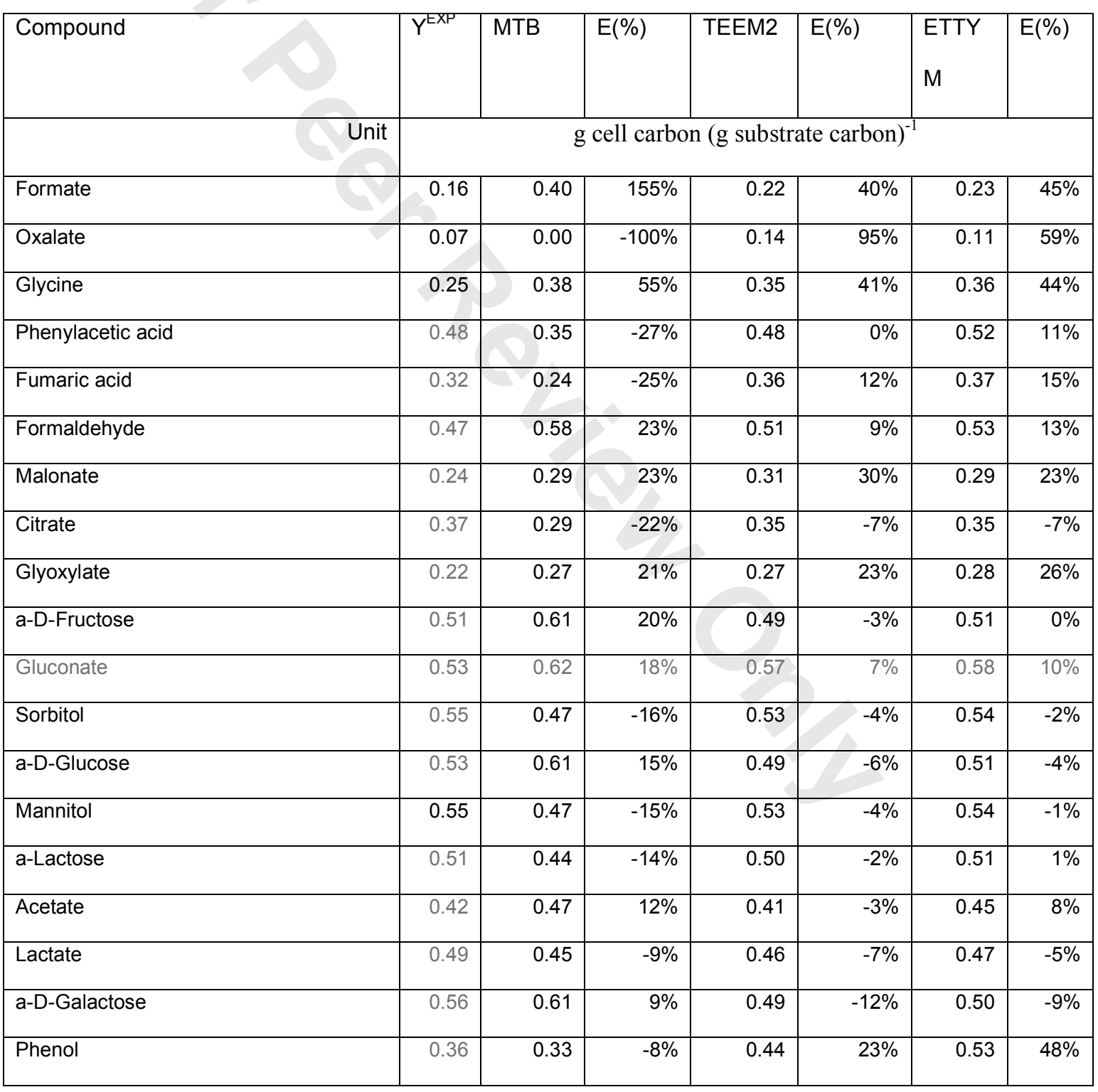


1

2

3

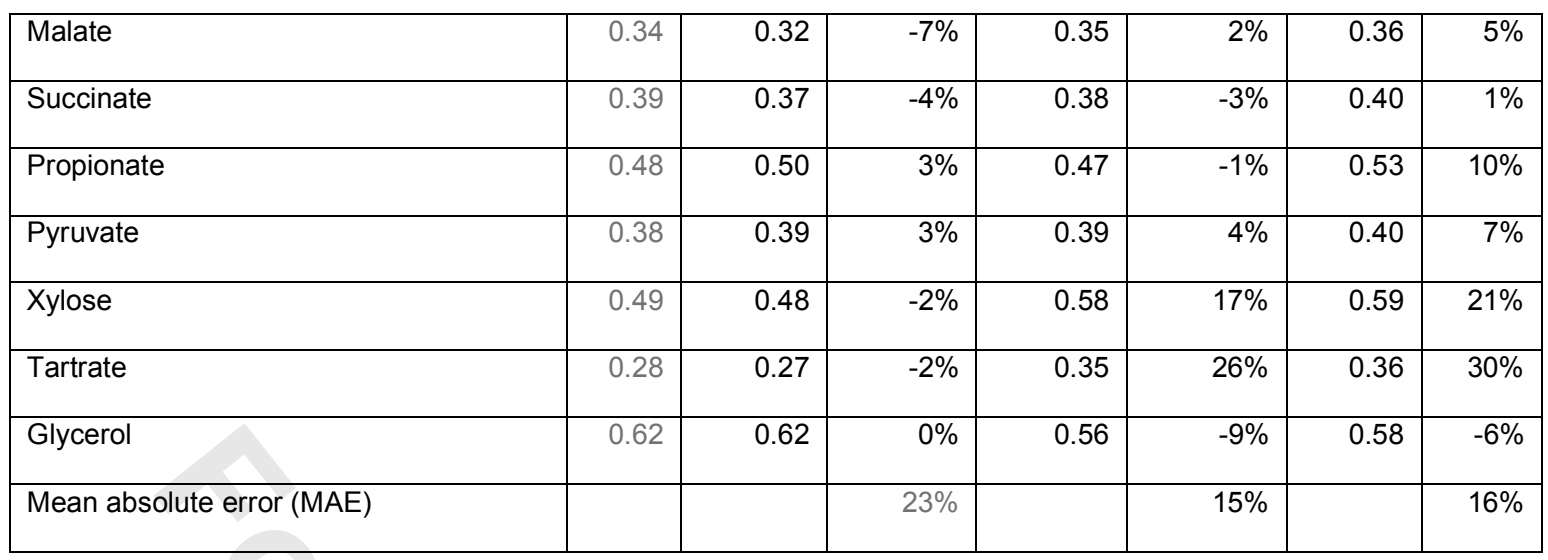

836

837

838

839

840

841

842

843

844

URL: http://mc.manuscriptcentral.com/sqer 
1

2

3

4

5

6

7

8

9

10

11
845 Table 7 . Sensitivity analysis of all three methods. The average sensitivity, $\bar{S}_{l}$, and standard

846 deviation shown in brackets. The degree of reductance does not affect the predictions of MTB.

847 The standard cell formula for ETTYM is $\mathrm{C}_{5} \mathrm{H}_{10} \mathrm{O}_{3} \mathrm{~N}\left(\gamma_{s}=4.2, \sigma_{\mathrm{c}}=0.45 \mathrm{gC}(\mathrm{g} \mathrm{cell} \mathrm{dw})^{-1}\right)$ and for

848 MTB and TEEM2 it is $\mathrm{C}_{5} \mathrm{H}_{7} \mathrm{O}_{2} \mathrm{~N}\left(\gamma_{s}=4, \sigma_{\mathrm{c}}=0.53 \mathrm{~g}\right.$ cell carbon $\left.(\mathrm{g} \text { cell dw })^{-1}\right)$. The alternative 849 cell formulae used were: $\mathrm{C}_{5} \mathrm{H}_{8.33} \mathrm{O}_{0.8} \mathrm{~N}\left(\gamma_{s}=4.74, \sigma_{\mathrm{c}}=0.63 \mathrm{~g}\right.$ cell carbon $\left.(\mathrm{g} \text { cell dw })^{-1}\right)$,

$850 \quad \mathrm{C}_{4.1} \mathrm{H}_{6.8} \mathrm{O}_{2.2} \mathrm{~N}\left(\gamma_{s}=3.85, \sigma_{\mathrm{c}}=0.47 \mathrm{~g}\right.$ cell carbon $\left.(\mathrm{g} \text { cell dw })^{-1}\right)$.

\begin{tabular}{|c|c|c|c|}
\hline Parameter & Method & $\begin{array}{l}\text { Relative change in } \\
\text { parameter value }\end{array}$ & $\begin{array}{c}\text { Average sensitivity, } \bar{S}_{l} \text { (standard } \\
\text { deviation) }\end{array}$ \\
\hline \multirow[t]{6}{*}{$Y_{A T P}$} & MTB & \multirow{3}{*}{$+20 \%$} & $0.56(0.073)$ \\
\hline & TEEM2 & & $0.51(0.016)$ \\
\hline & ETTYM & & $0.49(0.006)$ \\
\hline & MTB & \multirow{3}{*}{$-20 \%$} & $0.66(0.068)$ \\
\hline & TEEM2 & & $0.61(0.016)$ \\
\hline & ETTYM & & $0.59(0.0046)$ \\
\hline \multirow[t]{6}{*}{$\Delta G_{f}^{\circ}$} & MTB & \multirow{3}{*}{$+50 \%$} & $0.010(0.090)$ \\
\hline & TEEM2 & & $-0.004(0.25)$ \\
\hline & ETTYM & & $0.006(0.21)$ \\
\hline & MTB & \multirow{3}{*}{$-50 \%$} & $0.015(0.080)$ \\
\hline & TEEM2 & & $0.035(0.17)$ \\
\hline & ETTYM & & $0.024(0.15)$ \\
\hline \multicolumn{4}{|c|}{$\mathrm{C}_{5} \mathrm{H}_{10} \mathrm{O}_{3} \mathrm{~N}$} \\
\hline \multirow[t]{2}{*}{ Carbon content } & MTB & $-14 \%$ & $0.59(0.12)$ \\
\hline & TEEM2 & $-14 \%$ & $0.71(0.02)$ \\
\hline \multicolumn{4}{|l|}{ Degree of } \\
\hline reductance & TEEM2 & $5 \%$ & $-2.05(0.05)$ \\
\hline \multicolumn{4}{|c|}{$\mathrm{C}_{5} \mathrm{H}_{7} \mathrm{O}_{2} \mathrm{~N}$} \\
\hline Carbon content & ETTYM & $17 \%$ & $0.61(0.03)$ \\
\hline Degree of & ETTYM & $-5 \%$ & $-2.14(0.12)$ \\
\hline
\end{tabular}




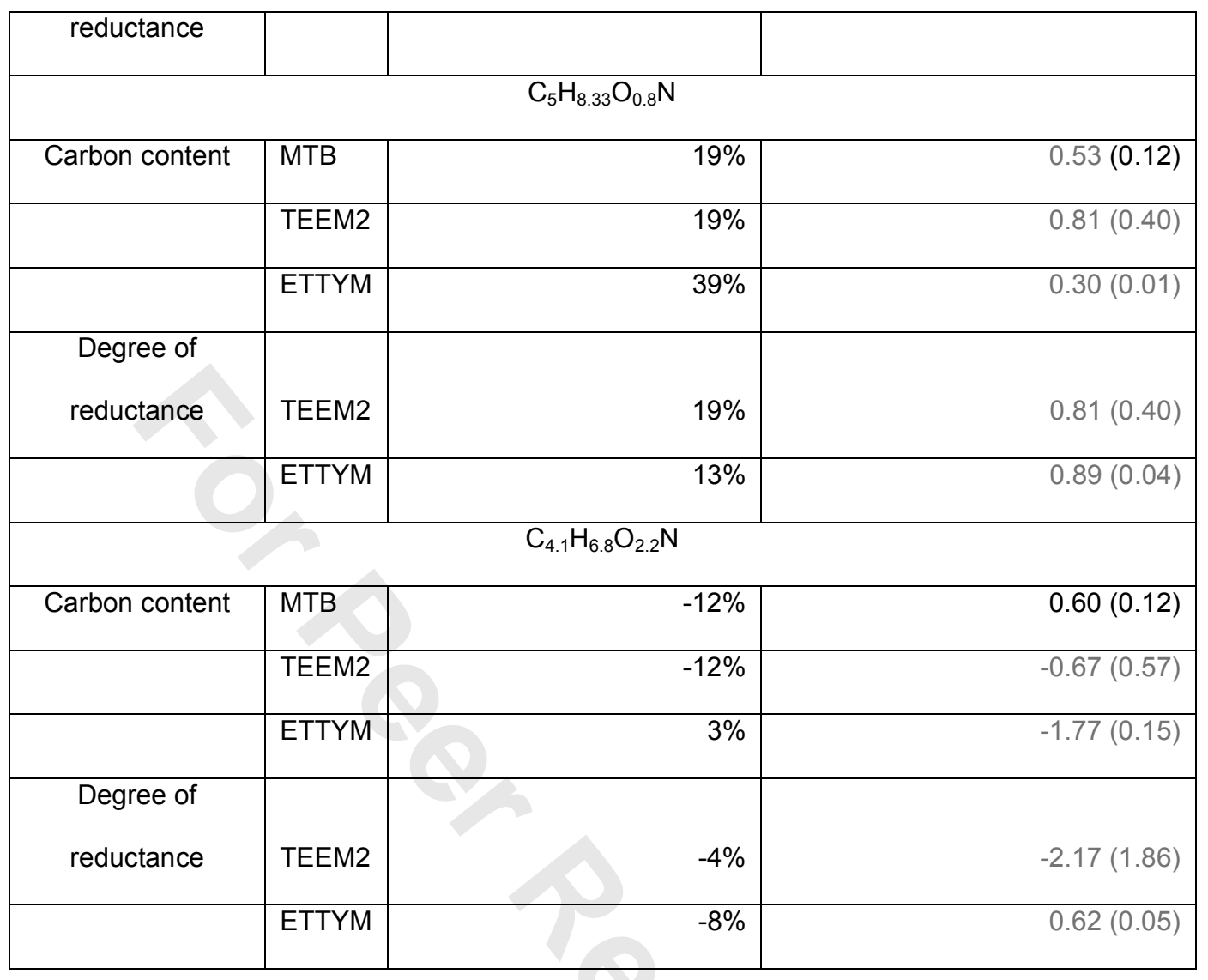

851

852

853

854 
1

2

3

4

5

8

9

10

11

855 Table 8. Predicted yields, measured $\mathrm{CO}_{2}$, non-extractable residues (NER), amino-acids, and

856 predicted formation of soil organic matter (SOM) (biogenic NER) from Eq. (4) (SOM biogenic NER)

857 (in brackets: result of Eq. (3), short-term experiments only). The data on measured $\mathrm{CO}_{2}$ and

858 NER formation were taken from Barriuso et al. [36] except where indicated otherwise. The data

859 points are the maximum values reported for the experiments with the longest duration, if more

860 than one experiment was reported. The entries are sorted from high to low predicted biogenic

861 NER formation.

\begin{tabular}{|c|c|c|c|c|c|}
\hline Compound & $\mathrm{Y}_{\mathrm{MTB}}^{\mathrm{EST}}$ & $\begin{array}{l}\text { Measured } \\
\mathrm{CO}_{2}\end{array}$ & $\begin{array}{l}\text { Measured } \\
\text { NER }\end{array}$ & $\begin{array}{l}\text { Measured } \\
\text { carbon label in } \\
\text { amino acids }\end{array}$ & $\begin{array}{l}\text { Predicted SOM } \text { biogenic }_{\text {NER }} \\
\text { NEsing Eq. (4) } \\
\left(X_{\text {biomass NER }} \text { using Eq. }\right. \\
(3))\end{array}$ \\
\hline Unit & $\begin{array}{c}\text { mol }_{\text {bacteria }} \\
\text { (mol } \\
\left.\mathrm{C}_{\text {substrate }}\right)^{-1}\end{array}$ & 8 & of app & lied labelled com & ound \\
\hline Glyphosate & 0.51 & 80.1 & 8.8 & & 28 \\
\hline Daminozide & 0.57 & 59 & 25 & 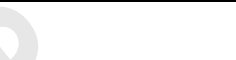 & 24 \\
\hline Glyphosate $^{1}$ & 0.51 & 50 & 30.4 & $11-12$ & $17(52)$ \\
\hline MCPB & 0.43 & 58 & 30 & & 15 \\
\hline MCPA & 0.38 & 67 & 30 & & 15 \\
\hline Ibuprofen $^{2}$ & 0.46 & 45 & 29.6 & 28 & $13(38)$ \\
\hline $\begin{array}{l}\text { Mecoprop } \\
\text { (MCPP) }\end{array}$ & 0.41 & 52 & 47 & & ren \\
\hline Desmedipham & 0.39 & 46.4 & 55 & & 11 \\
\hline Milbemectin & 0.49 & 35 & 40 & & 11 \\
\hline Metalaxyl-M & 0.5 & 33 & 73 & & 11 \\
\hline Cypermethrin & 0.36 & 48 & 26 & & 11 \\
\hline
\end{tabular}

URL: http://mc.manuscriptcentral.com/sqer 


\begin{tabular}{|c|c|c|c|c|c|}
\hline Propyzamid & 0.36 & 48 & 27 & & 11 \\
\hline $2,4-D^{3}$ & 0.3 & 58 & 36 & 23 & $10(24)$ \\
\hline Metamitron $^{4}$ & 0.35 & 49 & 41 & 15 & $10(25)$ \\
\hline $2,4-D B$ & 0.38 & 42.1 & 33.2 & & 10 \\
\hline Benalaxyl & 0.43 & 25 & 18.8 & & 7 \\
\hline Famoxadone & 0.34 & 32.2 & 51.4 & & 7 \\
\hline Bifenazate & 0.43 & 23 & 67.3 & & 6 \\
\hline 2,4-D & 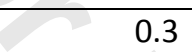 & 36 & 27.9 & & 6 \\
\hline Carbofuran $^{5}$ & 0.41 & 23.8 & 63 & & 6 \\
\hline Phenmedipham & 0.4 & 16.5 & 64.1 & & 4 \\
\hline Pymetrozine & 0.4 & 15 & 61 & & 4 \\
\hline Azoxystrobin & 0.34 & 14 & 24 & & 3 \\
\hline Acetamiprid & 0.43 & 9.6 & 32.3 & & 3 \\
\hline Iprodione & 0.41 & 5 & 40 & & 1 \\
\hline Pendimethalin & 0.5 & 2.4 & 10 & & 1 \\
\hline Chlorothalonil & 0 & 15 & 54 & 8 & 0 \\
\hline
\end{tabular}

URL: http://mc.manuscriptcentral.com/sqer 
Authors' response for

Microbial growth yield estimates from thermodynamics and its importance for degradation of pesticides and formation of biogenic non-extractable residues.

(Manuscript ID SQER-2017-0051)

\author{
Andreas Libonati Brock ${ }^{\mathrm{a},{ }^{*}, \text { Matthias Kästner }}{ }^{\mathrm{b}}$, Stefan Trapp ${ }^{\mathrm{a}}$, \\ ${ }^{a}$ Department of Environmental Engineering, Technical University of Denmark, Kgs. Lyngby, \\ Denmark \\ ${ }^{b}$ UFZ-Helmholtz Centre for Environmental Research, Department of Environmental \\ Biotechnology, Leipzig, Germany \\ *alib@env.dtu.dk, Phone: +45 45251408
}

\begin{abstract}
We greatly appreciate the feedback we received from the anonymous reviewers. In this document, we have addressed all the comments made (blue font colour) and we have listed the revisions made to the manuscript in quotation marks. The revisions made to sentences are marked in blue font colour. In the manuscript, the revisions are included in the same blue font colour.
\end{abstract}


Referee: 1

Comments to the Author

A thermodynamically based approach is presented for modelling the degradation of chemicals and the formation of non extractable residues. The manuscript extends an approach that is submitted to another journal and is still under review.

Although the authors complete their conclusions section on a positive note, it is difficult to see an added value of the approaches presented in this manuscript. Basically, the main conclusion is that other factors than thermodynamics are more important in modulating degradation and bound residue formation. It is especially surprising in this respect to see that at the end, setting a default value to the Gibbs freen energy of formation is concluded to be a suited approach as the final results are independent of this parameter. In addition to this key issue, there is the problem of the underlying conceptual manuscript still being under review. Thus, there is currently no real basis for the key model used in this contribution.

We thank the reviewer for the comment. We do agree with the reviewer that the conceptual manuscript should be accepted (and published online) before the publication of the present manuscript. Adding to this, we think that the reviewer has misunderstood the conclusion regarding the Gibbs free energy. Our finding was not that other factors than thermodynamics are important in modulating degradation and bound residue formation (although they surely are). The finding is that the Gibbs free energy of formation of the chemical of interest (i.e. pesticide) can be set to $0 \mathrm{~kJ} \mathrm{~mol}^{-1}$ if no reliable data is available without affecting the outcome of the MTB method more than a few percent. This is because the majority of energy in the reaction comes from the formation of $\mathrm{CO}_{2}$ and $\mathrm{H}_{2} \mathrm{O}$ - especially if the pesticide contains many $\mathrm{C}$ and $\mathrm{H}$ atoms.

To make this clearer we changed the sentence in the conclusions accordingly. It now reads (lines 541-543):

"All methods showed low sensitivity to variations in the Gibbs energy of formation of the organic chemicals because most of the Gibbs energy of reaction stems from the formation of the oxidation products carbon dioxide and water."

Referee: 2

Comments to the Author

Authors: Andreas Libonati Brock,* Matthias Kästner, Stefan Trapp

Article: Microbial growth yield estimates from thermodynamics and its importance for degradation of pesticides and formation of biogenic non-extractable residues

Journal: SAR and QSAR in Environmental Research

Manuscript: SQER-2017-0051

This is a valuable contribution on the evaluation and/or prediction of non-extractable residues formation during (bio)degradation of pesticides and I would like to see it published. However, this manuscript has several major problems, some of which is of a formal nature, and needs major revision before it will be suitable for publication. The detailed description of each critical point is given in the following section, complemented with the suggestion for possible improvement.

This is an outstanding review, helpful, detailed, and careful. We are very grateful to this reviewer for the efforts made to improve our manuscript. Thank you! The contribution has been duly noted in the acknowledgements. The critical points given in the following section are all addressed. 
Major problems:

1. This manuscript cannot and should not be published before reference 16 , manuscript submitted by the same authors to Environmental Science and Technology (ES\&T) journal, is accepted for publication and published on-line. Namely, manuscript submitted to ES\&T and its content is of critical importance for the main objective of this study, comparison of MTB method with the existing yield estimation methods. Reference 16 is cited 15 times in the text of this manuscript which clearly demonstrates its critical relevance for this manuscript.

We do agree with the reviewer that the conceptual manuscript should be accepted (and published online) before the publication of the present manuscript. Reference 16 (in the revised manuscript it is reference 15) was submitted several months before this manuscript, but we had been given more time for revision. We will resubmit ref 16 earlier so that it is published soon (but of course we cannot guarantee this :-))

2. Materials and Methods section should be significantly reduced since to a large extent it duplicates materials and results that are already published in the open literature.

Lines 118-123 now reads:

"The bacterial growth yield prediction methods chosen for this study have a common basic approach: a stoichiometrically balanced redox reaction and the associated change of Gibbs free energy. This means that one can set up half-reactions describing the reduction of the targeted compound (be it xenobiotic or not), calculate the associated Gibbs free energy [34], and combine it with half-reactions of an appropriate electron acceptor."

Line 125 now reads:

"This approach has been shown for ETTYM and TEEM2 and here"

Line 128-131 has been changed and now reads:

"A detailed summary of the methods can be found in the Supplementary Information (SI) and in the original references. The element, energy and electron balances differ between the methods, thus a brief outline of the methods will be given in Table 1, in which the final equations used to calculate the growth yield are shown."

The section has been significantly reduced (for details on each sub-section in the section see below). Table S1 showing the final equations used for the growth yield predictions has been moved from the Supplementary Information to the manuscript. The table is now listed as Table 1. Consequently, the numbering of tables has been updated throughout the manuscript. Additionally, the amount of equations has been reduced and their numbering has also been updated throughout the text.

Specifically:

(i) sub-section "Microbial Turnover to Biomass (MTB)" covering 3.5 pages should be either deleted or reduced to a minimum (half page). All this is already described in reference 16 and only points relevant for the main objective of this study may be briefly presented in this sub-section.

The sub-section has been significantly reduced and now contains the following (lines 132-148):

"The Microbial Turnover to Biomass (MTB) method is presented in detail in Trapp et al. [15]. The method is based on the work of Diekert [18]. The maximum bacterial yield is determined from the nutritional value of the substrate $(\mathrm{N})$ combined with the determination of bio-available electrons from the reaction. The nutritional value is the inverse of the yield and describes how much substrate is needed for the growth of bacteria [g substrate $\left(\mathrm{g}\right.$ biomass) ${ }^{-1}$ ]. This is subdivided into a biomass yielding (anabolic) and energy yielding 
(catabolic) part. The catabolic yield is determined from calculation of the Gibbs free energy released from the oxidation of the compound, the storage of this energy in ATP, and the bacterial growth yield on ATP. Microbes cannot use all electrons to generate energy and thus the concept of bio-available electrons was introduced. [15]. Thus, energy and electron balances are implicitly considered. The anabolic yield is calculated from the carbon content in the compound (the carbon source) and in the bacterial cell [18], i.e. how many grams of cell can be produced from the carbon in the compound (only carbon availability is assumed to limit growth).

Further details and examples can be found in SI 1.1 and Trapp et al. [15]. “

The paragraph

"Gibbs energy of reaction is calculated using activities of the reactants and products assumed to be $1 \mathrm{M}$, except for $\mathrm{H}^{+}$which is assumed to be $10^{-7} \mathrm{M}(\mathrm{pH}$ 7). The Gibbs free energy of reaction for non-standard conditions can be calculated as

$\Delta G_{r}^{\prime}=\Delta G_{r}^{o^{\prime}}+R T \ln Q=\Delta G_{r}^{o^{\prime}}+R T \ln \left(\frac{\prod_{i=1}^{n}[\text { product }]_{i}^{p}}{\prod_{i=1}^{n}[\text { reactant }]_{i}^{r}}\right)$

where $R$ is the ideal gas constant $\left[8.314 \mathrm{~J}\left(\mathrm{~K} \mathrm{~mol}^{-1}\right], T\right.$ is the absolute temperature $[\mathrm{K}], Q$ is the reaction quotient, and [product] and [reactant] are the activities of products and reactants, and $p$ and $r$ are their respective stoichiometric coefficients. From the equation itself it can be seen that when $Q<1$ the term is negative and when $\mathrm{Q}>1$ the term is positive."

has been moved to lines 182-191.

The bulk of the text has been moved to the supplementary information thus making it possible for the interested reader to easily locate a relevant summary of the method.

(ii) sub-section "Thermodynamic Electron Equivalent Model 2 (TEEM2)" covering 3 pages should be also either deleted or reduced to a minimum (half page). Content of this sub-section is covered in details in the original studies (references $18,23,24,35$ ) and there is no need for repetition here. Again, only a brief outline of points relevant for the main objective of this study may be given in this sub-section.

The sub-section has been significantly reduced and now contains the following (lines 151-162):

"In 1965 P. L. McCarty presented a thermodynamic model to estimate the maximal bacterial yield from a single substrate [17]. The method determines the yield on a given substrate from the Gibbs free energy released in the redox process. Since its inception it has been modified and expanded [34]. It was recently modified to better capture the observed lower yields associated with $\mathrm{C} 1$ compounds (i.e. methanol) and reactions involving oxygenases $[22,23]$. It is based on electron and energy balances. The electron balance considers that the electrons provided by the substrate are used either in the synthesis of cell material (anabolism) or in energy generation (catabolism), and the energy balance states that the energy captured with a specific efficiency $(\varepsilon)$ by the organism is used for bacterial growth. The energy capture efficiency, $\varepsilon$, is a key parameter and is estimated from experimental data. Further details and examples are found in SI 1.2 and McCarty [23] and Rittmann and McCarty [34]. “ 
The bulk of the text has been moved to the supplementary information thus making it possible for the interested reader to easily locate a relevant summary of the method.

(iii) sub-section "Expanded Thermodynamic True Yield Prediction Model (ETTYM)" covering 2.5 pages is also a waste of valuable journal space and should be reduced to a minimum. Its content is already published in references 23 and 25 . Outline briefly points relevant for the main objective of this study.

The sub-section has been significantly reduced and now contains the following (lines 165-173):

"The Expanded Thermodynamic True Yield Model is based on the work by McCarty and was presented in [22] and expanded in [24]. To increase the accuracy for the yield prediction on C1 compounds and substrates with low degrees of reduction, the authors proposed to include a carbon and a nitrogen balance and as a result thereof reformulate the electron and energy balance originally proposed by McCarty. The carbon balance describes that the carbon is either invested in cell synthesis or into other carbonaceous products. The nitrogen balance can be ignored if nitrogen is not limiting [24], hence, the yield can be calculated from an energy balance, carbon balance, and electron balance.

For further details, the reader is kindly referred to SI1.3 and [22, 24]."

The bulk of the text has been moved to the supplementary information thus making it possible for the interested reader to easily locate a relevant summary of the method.

3. It seems that the authors are not familiar with the mathematical concept of logarithms. Logarithms are only defined for positive numbers, those larger than zero. Thus, there are no logarithms for negative numbers. Consequently, the statement "when $Q<0$ the term is negative" on page 8 , line 172 is meaningless.

Thank you. This is an obvious oversight - what is meant is that when $Q<1 \Rightarrow \ln (Q)<0$. This has been corrected. Lines 190-191 now reads:

"when $Q<1$ the term is negative and when $Q>1$ the term is positive."

4. page 8 , lines 169 and 170 : There is no such unit as degree Kelvin ( $\left.{ }^{\circ} \mathrm{K}\right)$. The units of absolute temperatures are Kelvin (K).

Thank you for the comment. This has been corrected on line 187.

5. Another major drawback of this manuscript are numerous linguistic problems. A lot of sentences in this manuscript have awkward structure and are in contrast to the elementary principles of English language. This made the reading of this manuscript a demanding and time-consuming task. This manuscript should have been checked and corrected by someone proficient in English before it was submitted for a review. In a separate section "Some Linguistic Problems or Errors" I have listed some of those linguistic problems and have suggested possible corrections. However, in addition to those suggested corrections, a thorough inspection of the revised manuscript by someone proficient in English is still needed.

We sincerely thank the reviewer for taking time to meticulously go through the manuscript. The manuscript has undergone a thorough inspection with the aid from a proficient native speaker from the USA. The changes made are listed in the following. 
Lines 19-22: "Formation of microbial mass can be estimated from the microbial growth yield but experimental data is rare. Instead, we suggest using prediction methods for the theoretical yield based on thermodynamics."

Lines 23-24: "We have estimated the growth yield on 40 organic chemicals"

Lines 28-29: "Having the theoretical yield and using the released $\mathrm{CO}_{2}$ as a measure for microbial activity,"

Lines 40-41: "The evaluation of biodegradation of organic chemicals of environmental concern is a big challenge for risk assessment and is subject to legislation and regulation."

Lines 43-45: "The assessment of biodegradability under environmental conditions is standardised by OECD testing guidelines, such as OECD Tests Nos. 306-309 used for"

Lines 47-48: "Transformation and biodegradation is mostly tested with ${ }^{14} \mathrm{C}$ or ${ }^{13} \mathrm{C}$ labelled parent compounds."

Lines 48-49: "Isotopes are particularly needed for assessment of non-extractable residues (NER; also called "bound residues") and tracing of unknown metabolites [8]."

Line 51: "Although there are several approaches for the reliable prospective assessment"

Lines 50-51:"Assessment of biodegradation is well established but may still have some pitfalls for various compounds [9-12]."

Lines 54-55: "The assessment of residue formation is still in its infancy and is not yet predictable."

Line 62-64: "Apparently, NER are mostly comprised of all types of residues and thus the assessment of the biogenic NER formation will also provide information about the amounts of the other types of NER formed."

Lines 65-66: "Compounds that are poor growth substrates and do not provide sufficient energy"

Lines 67-69: "Thus, the usability of the molecule, its energy content and suitability for anabolic processes has a profound impact on the evolutionary pressure to develop degradation pathways."

Lines 71-73:"In addition, thermodynamics can also be used to describe the potential growth of bacteria [17]."

Lines 73-74: "Essentially, bacterial growth is simplified and split into anabolic processes (energy demanding) and catabolic processes (energy producing) [18]."

Line 74-77: "The catabolic processes describe the energy released from the oxidation of a chemical or a substrate. In aerobic metabolism the oxidation product is usually $\mathrm{CO}_{2}$ and $\mathrm{H}_{2} \mathrm{O}$. The electrons derived from the oxidation are partly transferred (...)"

Lines 79-80: ", predominately from the formation of $\mathrm{CO}_{2}$ and $\mathrm{H}_{2} \mathrm{O}$ [19]."

Lines 81-82: "The anabolic processes describe the substrate and energy use for the synthesis of new cell biomass." 
Lines 89-91: "These estimates have previously been used for biotechnological purposes and for the estimation of activated sludge formation in waste water treatment processes,"

Lines 91-9: "The different growth yield estimation methods are based on a similar set of considerations [26, 27]."

Lines 106-108: "Therefore, yield estimation provides a tool for the assessment and prediction of biogenic NER formation in the degradation assessment of chemicals for regulatory purposes."

Lines 179-180: "Ammonia was taken as the sole nitrogen source so electrons for the assimilatory reduction of $\mathrm{NO}_{3}{ }^{-}$was not considered,"

Lines 193-194: "nitrate-reducing conditions $\left(\mathrm{NO}_{3}{ }^{-}\right.$as the terminal electron acceptor) and sulphate-reducing conditions $\left(\mathrm{SO}_{4}{ }^{2-}\right.$ as the terminal electron acceptor)"

Line 202: “. However, for ETTYM this was not done"

Lines 210-211: "key input parameters were varied including $Y_{\text {ATP," }}$

Lines 226-227: "Bacterial growth yields have been experimentally assessed only for very few of the selected compounds."

Lines 229-231: "Moreover, ibuprofen and some polycyclic aromatic hydrocarbons (PAH) were also included as the bacterial growth yield has been experimentally determined for these."

Lines 232-233: "the methods were also evaluated using the growth yield determined for simple carbon substrates used in biotechnology."

Lines 233-234: "The compounds selected for comparison are based on the review and evaluation made by Xiao and VanBriesen [24]. "

Line 268: "In Table 4, the predicted bacterial growth yields under aerobic conditions are shown and"

Lines 274-276: “. The reason being the absence of carbon-hydrogen bonds. All other compounds except pyrene were predicted to have a bacterial growth yield of $>0.3 \mathrm{~g}$ cell carbon ( $\mathrm{g}$ substrate carbon) ${ }^{-1}$ by all methods."

Lines 283-285: ". A weaker but still highly significant $(p<0.01)$ correlation was found for TEEM2 $\left(Y=0.09 \gamma_{s}\right.$ $\left.+0.15, R^{2}=0.53\right)$, and a significant $(\mathrm{p}<0.05)$ but rather weak correlation was found for MTB $\left(R^{2}=0.14\right) . "$

Lines 288-289: "and ETTYM overestimated by $56 \%$ and $25 \%$, respectively. For glyphosate and anthracene,"

Line 299: "With sulphate as the terminal electron acceptor,"

Lines 300-301: "compared to the yields found under aerobic conditions (Table 5)"

Lines 301-302: "For both aerobic and nitrate-reducing conditions, the ranking of the estimated yields was close."

Lines 305-307: "MTB predicted 20 chemicals to have a yield of $<0.1 \mathrm{~g}$ cell carbon (g substrate carbon) ${ }^{-1}$, while ten were predicted using TEEM2, and only four using ETTYM." 
Lines 309-310: "The lack of experimental observations under a multitude of redox conditions makes assessment of the prediction accuracy unachievable."

Lines 318-319: "Subsequently, the work presented in [24] resulted in an even lower MAE when both the pH and related speciation, and oxygenase reactions were taken into account."

Lines (formerly) 320-322 were deleted: "(the ranking was identical from the lowest predicted yield and 12 places up; and the six substrates predicted to give the highest yield)"

Lines 323-325: "For MTB, these were formate, oxalate, and glycine; for TEEM2, these were oxalate, glycine, and formate; and for ETTYM, these were oxalate, phenol, and formate."

Lines 327-328: "with TEEM2 still giving the lowest MAE (9\%)"

Line 342: "All methods are relatively sensitive to changes in $Y_{\text {ATP, }}$ especially MTB."

Lines 344-446: "The chosen default value for xenobiotics of $5 \mathrm{~g}$ cell dw (mol ATP) ${ }^{-1}$ ([18], for methanol) used in the MTB method does not lead to large errors (cf. Table 4)."

Lines 350-351: ". Conversely, a negative $\Delta G_{f}{ }^{\circ}$ which is made more negative leads to a decrease in the predicted yield (e.g., EDTA)."

Line 354: "Yield estimates for chemicals with few carbon atoms"

Line 355: "are especially sensitive to changes"

Lines 366-369: “. The effect of the cell formula in TEEM2 and ETTYM is not only on the energy costs related to synthesis [24], but also on the conversion to $g$ cell carbon ( $g$ substrate carbon) ${ }^{-1}$ in TEEM2. This is due to the degree of reduction of the cell $\left(\gamma_{s}\right)$ used in converting the units."

Line 376: "NER formation from the $\mathrm{CO}_{2}$ produced during degradation experiments"

Lines 378-380: "Except for one compound (glyphosate, caused by the production of the metabolite aminomethylphosphonic acid (AMPA)), the predicted biogenic NER was smaller than the measured total NER."

Lines 383-384: "and pymetrozine the biogenic NER is suggested to make up less than $10 \%$ of the formed NER"

Line 402: "with some of them used earlier in [15]."

Lines 404-405: "The bacterial growth yield estimation methods are all developed to predict the true yield"

Lines 405-407: "The observed value is typically a net yield accounting only for the formation of new cell mass and removal of the parent compound"

Lines 407-409: "The difference between the two is that for the observed yield energy and carbon expenditure, due to non-growth purposes, are not captured"

Lines 409-410: "(e.g. energy spent on maintenance, formation of metabolites or soluble microbial products and extracellular polymeric substances)" 
Line 411: ", unless a dynamic model was used for fit. Hence,"

Line 413-414: "If hardly degradable or insoluble metabolites are formed and rendered not bioavailable (as NER I or II),"

Lines 415-417: "can also result in a higher amount of energy being spent on maintenance leading to an observed yield lower than the predicted true yield. "

Lines 420-422: ", the intermediate AMPA accumulated, resulting in an observed yield much that was lower than the predicted yield (Table 4)."

Lines 424-425: "The presence of other sources of carbon or energy (mixed substrate use) also adds uncertainty to the observed value."

Lines 431-432: "Under these conditions, microbes use most of the growth substrate just for maintenance [51]."

Lines 441-442: "This shows that the half-reaction approach using various electron acceptors used in ETTYM and TEEM2 can also be used with MTB"

Line 453: "the TEEM2 method was calibrated to the data in order to produce yield estimates"

Line 456: "proposed for the ETTYM method [24]."

Line 458: "estimated it as zero due to the absence of C-H bonds (which points to the need for a"

Line 489: ". However, speciation of the substrate also has an effect on its Gibbs energy of formation."

Line 490: "Similarly, the sensitivity of the energy capture efficiency parameter $\varepsilon$ "

Line 496: "The peak in living biomass is usually after a few days to weeks [38, 39],"

Lines 508-510: "We suggested such a model in [8] and used it successfully, for the prediction of the NER formation from 2,4-D and ibuprofen with pre-estimated yield data [15]."

Line 511: "The data compiled by [36] give no hints into which form the NER are present"

Line 516: "done" deleted: "In degradation experiments with metamitron [43], glyphosate [42]"

Lines 518-519: "amino acids, fatty acids, metabolites, and parent compounds."

Lines 525-526: "The method applied in this study provides process-based theoretical background that may be used to interpret NER data derived in degradation experiments."

Lines 534-535:" while MTB performed better when estimating the yield on organic chemicals of environmental concern in general and in particular on pesticides."

Line 808: "Predictions are evaluated using available experimental data."

Line 826: "Values highlighted in bold are negative and thus not meaningful."

6. lines 650-666 and 733-736: This extensive discussion and related conclusions are meaningless and should be deleted. Gibbs energy of formation can be easily calculated for any chemical by quantum-mechanical 
methods. Thus, any limitation of group contribution methods is irrelevant and it also does not make sense to set the Gibbs energy of formation to zero.

Please allow that at this one issue we disagree with the reviewer. It may be possible to get exact values of Gibbs energy of formation, but personally we had some difficulties to find the values of several organic chemicals and we also found many conflicting data of delta G. We expect other users to have similar experiences. It is therefore a relevant message that small error or even missing delta $\mathrm{G}$ does not inhibit good estimates of the microbial yield of xenobiotics. Nonetheless, we shortened this section in 4.2 so that it is less extensive, and we deleted the lines in the conclusions, except one, which now reads (lines 541-543):

"All methods showed low sensitivity to variations in the Gibbs energy of formation of the organic chemicals because most of the Gibbs energy of reaction stems from the formation of the oxidation products carbon dioxide and water.

Section 4.2 Sensitivity analysis now reads (lines 462-478):

"All the methods were shown to be sensitive to the choice of cell formula but exhibited low sensitivity to variations of the formation energy, $\Delta G_{f}^{\circ}$, of the chemical of interest. All methods are based on the Gibbs energy of reaction and knowledge of the Gibbs energy of formation of the chemical of interest is needed. If the value has not been determined experimentally (e.g. [52]), it can be estimated using group contribution methods [53-58] (method [53] is implemented in the freely available ChemProp [59]), or by component contribution methods [60] (implemented in the free accessible database eQuilibrator [61]), or calculated using quantum mechanics [62]. For xenobiotics, the applicability of these estimation methods may be limited. Consequently, we also tested the sensitivity of Gibbs energy of formation of the xenobiotic substrate by setting this value to $0 \mathrm{~kJ} \mathrm{~mol}^{-1}$ (Table S3). The MTB method has surprisingly low sensitivity. Compounds having a large negative Gibbs energy of formation (e.g. NTA, EDTA, and glyphosate) and few carbon-hydrogen bonds $(6,8$, and 4 , respectively) show a maximum deviation of around $20 \%$ from the predictions done with correct Gibbs energy of formation. Overall, the average deviation is only $6 \%$. In comparison, TEEM2 and ETTYM have considerably higher average deviation ( $14 \%$ and $11 \%$, respectively). "

\section{Specific Problems or Errors:}

1. line 54: References 13 and 15 are barely suitable to support the current status on modeling and assessment of biodegradation. Reference 13 is just a technical collection of published QSAR models without any critical evaluation of those models while reference 15 is only describing Biocatalysis/Biodegradation Database and the improved public access to this database. Thus, those references should be either replaced or, at least, amended by the recent critical review on the most relevant qualitative and quantitative models for estimating or evaluating biodegradation of organic chemicals and published in ACS Symposium Series:

A. Sabljic and Y. Nakagawa, Biodegradation and quantitative structure-activity relationship (QSAR), in NonFirst Order Degradation and Time-Dependent Sorption of Organic Chemicals in Soil, W. Chen, A. Sabljic, S.A. Cryer and R.S. Kookana, eds, Book Series: ACS Symposium Series, American Chemical Society, Washington (DC), Volume 1174, 2014, pp. 57-84.

We thank the reviewer for the comment. After reading the suggested literature, we have included it as a reference and removed reference 15 . 
2. lines 115-117: Delete this sentence since it only repeats previous statement.

The sentence was deleted.

3. line 193: It seems that variable YATP has not been defined.

Please note, that this sentence has been deleted from the manuscript and moved to the supplementary information. (Line SI 58)

Due to the changes made to the Material and Methods section, $Y_{\text {ATP }}$ is now defined in Table 1.

4. line 266: “(McCarty 2007)”, wrong format for this reference

The reference has been changed to the correct format:

"[23]"

Please note, that this sentence has been deleted from the manuscript and moved to the supplementary information.

5. line 352: From here the authors have started to number sections and sub-sections. Why? Previous sections and sub-sections are not numbered.

The un-numbered sections and subsections have now been numbered.

Line 39: "1. Introduction"

Line 117: "2. Materials and Methods"

Line 132: "2.1 Microbial Turnover to Biomass (MTB)"

Line 150: "2.2 Thermodynamic Electron Equivalent Model 2 (TEEM2)"

Line 164: "2.3 Expanded Thermodynamic True Yield Prediction Model (ETTYM)"

Line 177: "2.4 Conditions for comparison"

Line 222: "2.5 Chemicals of environmental concern; data"

Line 242: "2.6 Calculation of biogenic non-extractable residues"

6. lines 363-364: "SO42- is oxidised to H2S and HS-, NO3- to N2, $\mathrm{O} 2$ to H2O,"?! Do you mean reduced? Also "oxidized" is US spelling used in this manuscript.

Thank you for pointing this out. Yes, it is not oxidation but reduction as they are all electron acceptors.

"Oxidised" has been changed to "reduced" on line 198: ": $\mathrm{SO}_{4}{ }^{2-}$ is reduced to $\mathrm{H}_{2} \mathrm{~S}$ and $\mathrm{HS}, \mathrm{NO}_{3}{ }^{-}$to $\mathrm{N}_{2}, \mathrm{O}_{2}$ to $\mathrm{H}_{2} \mathrm{O}, \mathrm{C}$ to $\mathrm{CO}_{2}^{\prime \prime}$ 
7. lines 409-442: The content of sub-section "2.3 Calculation of biogenic non-extractable residues" is described in details in reference 16 and only points relevant for the main objective of this study should be briefly presented in this sub-section.

Thank you for the comment. The sub-section has been revised and reduced one third. It now reads (Lines 243-264):

"Chemicals labelled with carbon isotopes $\left({ }^{14} \mathrm{C}\right.$ or $\left.{ }^{13} \mathrm{C}\right)$ allowed the flow of carbon to be tracked in the experimental system [38-41]. If the compound provides carbon to anabolism and cell synthesis, the labelled carbon will end up in microbial biomass and finally in the biogenic NER. Biogenic NER is not posing a risk to neither the environment nor human health [8]. When a substrate $S$ is mineralized, the amount of biomass formed is yield times substrate, $Y \times S$, and the evolved $\mathrm{CO}_{2}$ is $(1-Y) \times S$ [15]. After the growth phase has stopped, the maximum ratio between biomass and $\mathrm{CO}_{2}$ and is thus

$\frac{\left[X_{\text {biogenic NER }}\right]}{\left[\mathrm{CO}_{2}\right]}=\frac{Y S}{(1-Y) S}$ or $\left[X_{\text {biogenic NER }}\right]=\frac{Y}{1-Y}\left[\mathrm{CO}_{2}\right]$

where $X_{\text {biogenic NER }}$ is the biomass making up the living biogenic NER. After the cessation of the growth phase, the microorganisms start to decay. The dead microorganisms are turned over in the microbial food chain and form new biomass, $\mathrm{CO}_{2}$ and soil organic matter (SOM) [30-33]. Then, the ratio between biogenic NER and ${ }^{13 / 14} \mathrm{CO}_{2}$ becomes [15]

$\frac{\left[\text { SOM }_{\text {biogenic NER }}\right]}{\left[\mathrm{CO}_{2}\right]}=\frac{f \times Y}{(1-Y)+(1-f) \times Y}$ or $\left[S O M_{\text {biogenic } N E R}\right]=\frac{f \times Y}{(1-Y)+(1-f) \times Y}\left[\mathrm{CO}_{2}\right]$

where SOM $M_{\text {biogenic NER }}$ is the non-living biogenic NER, $f$ is the fraction of decaying biomass turned over into both living biomass and non-living $\operatorname{SOM}(0.5,[33])$, and $1-f$ is the fraction of label released as $\mathrm{CO}_{2}$. Eq. (3) can be used to estimate NER formation during short-term experiments, whereas Eq. (4) holds for long-term experiments. It can be seen that a high mineralization and $\mathrm{CO}_{2}$ formation together with a high bacterial growth yield leads to a high formation of biogenic NER."

\section{8. lines 569-570: In Table 7 the predicted and measured biogenic NERs are not similar for 2,4-D. Clarify.}

This requires some explanation. In the four cases where biogenic NER was reported (Karolina Nowak and her co-workers), the authors took the measured label in amino acids and multiplied with factor 2 . This factor stems from the protein content (about 50\%) in living microbes. However, as seen from the NER equations (now Eq. (3) and Eq. (4)), the biogenic NER is comprised of living and dead biomass. And for dead biomass, the factor 2 is not valid because sugars and fatty acids are metabolized much faster than amino acids. It can even be seen from the author's data that the application of the factor 2 to the amino acid fraction leads to false results because for ibuprofen and 2,4-D the fraction of biogenic NER is larger than the total NER. We therefore deleted the column "Reported biogenic NER" in Table 8, refer to the measured amino acids and changed the manuscript accordingly. As can be seen, the measured label in amino acid is always within the range of biogenic NER given by Eq. 3 (living biomass) and Eq. 4 (decayed biomass).

\section{Now line 386-394:}

"The experimental period for ibuprofen and 2,4-D (64 days) [38, 39], and glyphosate and metamitron (80 days) [42,43] was shorter than the experiments reported in [36]. Eq. (3), which calculates living biomass $X$ as biogenic NER, was additionally used to interpret these experiments. In these four studies, the carbon label found in amino acids was reported. For living microbes, about half of the carbon is in proteins. This fraction increases during decay and turnover of microbial biomass because proteins are the most stable fraction of the cells $[30,33,15]$. Except for glyphosate, the measured label in amino acids is within the range of biogenic NER predicted by Eqs. (3) and (4), and the measured total NER is greater." 
9. line 613: I would suggest to cite here also the recent review on bioavailability of xenobiotica in the soils environment.

A. Katayama, R. Bhula, G.R. Burns, E. Carazo, A. Felsot, D. Hamilton, C. Harris, Y.H. Kim, G. Kleter, W. Koerdel, J. Linders, J.G.M.W. Peijnenburg, A. Sabljic, R.G. Stephenson, D.K. Racke, B. Rubin, K. Tanaka, J. Unsworth and R.D. Wauchope, Bioavailability of xenobiotics in the soil environment, Reviews of Environmental Contamination and Toxicology 203 (2010), pp. 1-86.

Thank you for the suggestion. After reading the publication we agree with the reviewer. It is an excellent review and is now cited as ref 50 on line 430 .

10. line 631: "any linearity"?! probably "there is no relationship"

Thank you for your comment. The sentence now reads (lines 448-450):

"For all methods, the predicted growth yield is so small that there is no relationship between degree of reductance and bacterial growth yield."

11. line 649: References 55-59 should be deleted since those are not references for ChemProp estimation software, only reference 14 is relevant.

Thank you for the comment. References 55-59 are references for group contribution based methods. Lines 466-469 now read:

"it can be estimated using group contribution methods [53-58] (method [53] is implemented in the freely available ChemProp [59]) or by component contribution methods [60] (implemented in the free accessible database eQuilibrator [61]) or calculated using quantum mechanics [62]."

12. line 650: Quantum mechanics is used to calculate and not to estimate the Gibbs energy of formation for chemicals.

Thank you for the comment. See above comment where 'calculated' has been added.

13. line 684: Reference 16 should be replaced by original reference(s) on "the peak in living biomass". Besides, reference 16 is not published jet.

Done. We cite here as example the experiments done with ibuprofen and 2,4-D (Refs 38, 39) (Line 496).

14. line 685: expression "is more likely applying to the data" is confusing and does not make sense

Thank you for the comment. The sentence has been revised and now reads (Lines 496-499):

"and therefore we expect that Eq. (4) $\left(S O M_{\text {biogenic NER }}\right)$ is more appropriate for these experiments than Eq. (3) $\left(X_{\text {biogenic NER }}\right)$ as the majority of the living biomass has decayed and been incorporated into SOM after 100 days."

15. lines 685-687: What is implied by "this view"? No view is described in previous sentences of this subsection.

Lines 499-500 have been revised and now read:

"Results obtained by Eq. (4) are smaller than the measured NER, which confirms the results of this equation." 
See also comment 14.

16. lines 690-693: confusing long sentence

In regards to comment 37, the sentence has been changed to (lines 504-507):

"Such a correlation should not be expected since the processes leading to NER I, II and III are competing. If a pesticide is not degraded it can undergo aging and irreversible sorption (type I NER) and covalent binding of the parent compound or its metabolites (type II NER) [8]."

17. lines 700-701: What is the meaning of this sentence? How do you exploit the structure and energy of molecule by enzymatic pathways?

Thank you for the comment. The sentence has been revised and now reads (lines 514-515):

"Of course, the enzymatic pathways to facilitate the degradation and energy exploitation of the molecule also need to be present."

18. lines 716-718: This statement is not correct since the MTB method is already presented in reference 16.

Thank you for the comment. Changed to "applied". It now reads (lines 525-526):

"The method applied in this study provides process-based theoretical background that may be used to interpret NER data derived in degradation experiments."

19. lines 738-740: This conclusion is not correct since the MTB method is already presented in reference 16.

Thank your pointing this out. Changed to "applied". It now reads (lines 545-546):

"The approach applied in this study provides a theoretical foundation that can be used to predict biogenic NER formation during pesticide degradation experiments."

Some Linguistic Problems or Errors:

1. line 28: add comma, i.e. " for microbial activity, "

Thank you for pointing it out. The comma is added on line 29.

2. lines 56-57: correct sentence as "Recently, a novel approach was suggested for modelling the formation of biogenic residue [16] which can also shed light into the black box of NER."

Thank you for your suggestion. The sentence has been revised and now reads (lines 56-57):

"Recently, a novel approach was suggested for modelling the formation of biogenic residues [15] which can also elucidate the black box of NER."

3. lines 59-60: "but may also be formed by covalent bonding of metabolites (type II NER)" - Covalent bonding of metabolites to what? Why only metabolites, why is covalent bonding not possible for parent compound?

Yes, covalent bonding is possible for both parent compound and metabolites. The sentence was rewritten and now reads (lines 57-60):

"NER may be formed by sequestration or entrapment of parent compounds or metabolites in soils and sediments (type I NER), and also by covalent bonding to soil organic matter (type II NER)"

URL: http://mc.manuscriptcentral.com/sqer 
4. line 63: probably "comprise of all types"

Thank you for your suggestion. The sentence has been revised (line 62): "Apparently, NER are mostly comprised of all types of residues and"

5. lines 94-97: correct sentence as "Thermodynamic Electron Equivalent Model (TEEM2) developed by Perry L. McCarty $[18,24]$ and Expanded Thermodynamic True Yield Prediction Model (ETTYM) by Xiao and VanBriesen $[23,25]$ or their variations have been established and applied $[29,30]$ for the estimation of bacterial growth yield on xenobiotics."

Thank you for your suggestion. The sentence has been revised and the paragraph now reads (lines 93-99): "The Thermodynamic Electron Equivalent Model (TEEM2) developed by Perry L. McCarty [17, 23] and Expanded Thermodynamic True Yield Prediction Model (ETTYM) of Xiao and VanBriesen [22, 24] or their variations have been applied $[28,29]$ for the estimation of bacterial growth yield on xenobiotics. Both models have evolved towards an increased need of knowledge regarding the transformation pathways, metabolic processes and the electron and energy losses associated hereto in order to model specific growth of various organisms."

6. line 98: expression "These models have both been moving" is meaningless in this sentence, maybe "Both models have been moving"

Thank you for your suggestion. The sentence has been revised (lines 96-97):

"Both models have evolved towards an increased need of knowledge regarding the transformation pathways,"

7. lines 104-105: correct text as "potential without the need for information on the pathways as this is rarely known for the majority of chemicals of environmental concern."

Thank you for your suggestion. The sentence has been revised as suggested (lines 102-104):

"In MTB we proposed a simple method to predict just the minimum bacterial growth yield potential without the need for information on the pathways, as this is rarely known for the majority of chemicals of environmental concern."

8. line 106: correct as "the microbial growth and decline are coupled"

Thank you for your suggestion. The sentence has been revised (line 105):

"Furthermore, microbial growth and decline are coupled to the formation of soil organic"

9. lines 110-111: correct text as "to thoroughly compare the recently introduced MTB method with other yield estimation methods"

Thank you for your suggestion. The sentence has been revised as suggested (lines 109-110):

"The objectives of the present study are i) to thoroughly compare the recently introduced MTB method with other yield estimation methods;"

10. line 128: "straightforward"? probably "direct" 
The word has been deleted and the sentence now reads (lines 122-124):

"and combine it with half-reactions of an appropriate electron acceptor (e.g. $\mathrm{O}_{2}, \mathrm{NO}_{3}{ }^{-}, \mathrm{SO}_{4}{ }^{2-}, \mathrm{Fe}^{3+}, \mathrm{Mn}^{4+}$, or even $\mathrm{CO}_{2}$ etc.) allowing for assessment of the bacterial growth yield under a multitude of redox conditions."

11. line 129: Set as new sentence, i.e. "of redox conditions. Here we only look at O2, NO3- and SO42-." Thank you for your suggestion. The sentence has been revised as suggested (lines 124-125):

"of redox conditions. Here we only look at $\mathrm{O}_{2}, \mathrm{NO}_{3}{ }^{-}$, and $\mathrm{SO}_{4}{ }^{2-}$."

12. lines 160-161: correct as "the Gibbs free energy of reaction"

Thank you for your suggestion. The sentence has been revised as suggested. Note that the sentence has been moved from the manuscript to the supplementary information (Line SI 59).

13. lines 237 and 240: There is a mismatch between "(catabolism)." and "where". The sentence is ending (i.e. period) on line 237 and new sentence is starting with the lower case letter on line 240 . Analogous problem on lines 251 and 254.

The periods are removed. Note that the sentence has been moved from the manuscript to the supplementary information.

14. lines 246 or 247: Period is missing at the end of this sentence.

Thank you for the comment. A period has been added. Note that the sentence has been moved from the manuscript to the supplementary information.

15. line 250: "that all the energy"?! probably "that the whole energy"

Thank you for the comment. I have changed the sentence to read (correction in bold):

"The energy balance states that the energy captured by the organism from the redox reaction is used for bacterial growth."

Note that the sentence has been moved from the manuscript to the supplementary information (Line SI 133).

16. lines 310-312: This sentence starts with equation which does not make sense. Also "Where" should be "where" since this is not the beginning of sentence.

The period in line has been removed and "Where" is correctly changed to "where".

Note that the sentence has been moved from the manuscript to the supplementary information.

17. line 322: "Where" should be "where" since this is not the beginning of sentence.

Thank you for your suggestion. The sentence has been revised as suggested.

Note that the sentence has been moved from the manuscript to the supplementary information.

18. lines 342-344: This sentence also starts with equation which does not make sense or period on line 341 must be deleted.

Thank you for pointing this out. The period has been deleted.

Note that the sentence has been moved from the manuscript to the supplementary information.

19. lines 347-349: This sentence does not make sense at all. If electrons are only diverted to the reduction of the terminal electron acceptor (e.g. $\mathrm{O}_{2}$ ) and the synthesis of new cell material, and the electron donor is also the carbon source, the equation reduces to (where $\gamma_{\mathrm{CO} 2}=0$ )

Thank you for bringing this to our attention. The sentence has been changed to: 
"If the electron donor is also the carbon source and the electrons are used only for reduction of the terminal electron acceptor and synthesis of new cell material, the equation reduces to (remember, $\gamma_{\mathrm{CO} 2}=$ $0)^{\prime \prime}$

I hope it is easier to make sense of it now. Note that the sentence has been moved from the manuscript to the supplementary information (Lines SI 226-228).

20. line 363: "oxidized" is US spelling used in this manuscript This has been corrected to "reduced" (line 198) - also see comment 6 under Specific Problems or Errors:

21. line 544: correct "MTB at least."

Since MTB is the method least sensitive to changes in the cell formulation, the sentence has been changed to (lines 365-366):

"While all methods are sensitive to the cell formula used (Table 7), MTB is the method least affected."

22. line 587: delete "experimentally" since it is redundant

Thank you for your suggestion. Yes, it is clearly a pleonasm and it has been deleted (line 405):

"The observed value is typically a net yield accounting only for the formation of new cell"

23. line 594: correct as "prediction methods assume a complete degradation of compound." Thank you for your suggestion. The sentence has been revised on line 412:

"Additionally, the prediction methods assume a complete degradation of the compound."

24. lines 610-611: correct as "other carbon sources, and here the MTB predicted yields are very close to the experimentally determined values."

Thank you for your suggestion. The sentence has been revised as suggested (lines 426-428):

"great care was taken in the experimental setup to minimise confounding factors due to other carbon sources, and here the MTB predicted yields are very close to the experimentally determined values."

25. line 612: correct text as "The observed differences might also be attributed to their high hydrophobicity and"

Thank you for your suggestion. The sentence has been revised as suggested (lines 429-430):

"The observed differences might also be attributed to their high hydrophobicity and limited bioavailability"

26. line 616: correct text as "reactions for PAHs in TEEM2, its errors were higher than for MTB." Thank you for your suggestion. The sentence has been revised as suggested (lines 433-434):

"(putative) oxygenase reactions for PAHs in TEEM2, its errors were higher than for MTB."

27. lines 618-619: correct text as "yield on carbofuran taking oxygenase reactions into account as suggested in [29]."

Thank you for your suggestion. The sentence has been revised ( lines 435-436):

"measured bacterial yield on carbofuran by taking oxygenase reactions into account as suggested in [28]."

28. lines 620-621: correct text as "Under sulphate-reducing conditions the predicted bacterial yields were much lower than the predicted yields under aerobic conditions, which can be expected"

Thank you for your suggestion. The sentence has been revised as suggested (lines 437-439):

"Under sulphate-reducing conditions the predicted bacterial yields were much lower than the predicted yields under aerobic conditions, which can be expected considering the lower"

29. line 623: correct "An interesting observation"

Thank you for your suggestion. The sentence has been revised as suggested (line 440): 
"An interesting observation was that the decrease in yield"

30. lines 626-627: correct text as "the majority of redox reactions might not be sufficient to fuel bacterial growth."

Thank you for your suggestion. The sentence has been revised as suggested (lines 444-445):

"the energy released from the majority of redox reactions might not be sufficient to fuel bacterial growth"

31. line 639: "Where" should be "While"

Thank you for your suggestion. The sentence has been revised as suggested (line 457):

"While ETTYM and TEEM2 both overestimated the yield for oxalate,"

32. line 646: correct text as "reaction, knowledge of the Gibbs energy of formation of chemical is needed." Thank you for your suggestion. The sentence has been revised see comment 6 under Major Problems (lines 464-464):

"All methods are based on the Gibbs energy of reaction and knowledge of the Gibbs energy of formation of the chemical of interest is needed"

33. lines 670-671: correct text as "either due to the low energy associated with the oxidation of substrate (e.g. formate or formaldehyde) or the low energy associated with the reduction of electron acceptor"

Thank you for your suggestion. The sentence has been revised (lines 481-484):

"either due to the low energy associated with the oxidation of substrate (e.g. formate or formaldehyde), or the low energy associated with the reduction of the electron acceptor (e.g. $\mathrm{SO}_{4}{ }^{2-}$ )."

34. lines 685-687: modify this sentence as follows "Results obtained by Eq. (22) are smaller than the measured NER, which confirms this view."

Thank you for your suggestion. The sentence has been revised (lines 499-500). See also comment 15 under Specific Problems or Errors:

"Results obtained by Eq. (4) are smaller than the measured NER, which confirms the results of this equation."

35. lines 687-688: modify this sentence as follows "For daminozide, chemical with the highest predicted yield, calculated biogenic NER and measured NER are almost equal."

Thank you for your suggestion. The sentence has been revised (lines 500-502):

"For daminozide, the chemical with the highest predicted yield, the calculated biogenic NER and measured NER are almost equal. "

36. line 689: modify text as "The inspection of Table 7 gives no significant correlation"

Thank you for your suggestion. The sentence has been revised and now reads (lines 503-504):

"The examination of Table 8 gives no significant correlation between measured total NER and predicted

$X_{\text {biogenic NER }}$ or SOM biogenic NER."

37. lines 690-693: modify this sentence as follows "Such a correlation should not be expected since the processes leading to NER I, II and III are competing and if pesticide is not degraded it can undergo aging, irreversible sorption and covalent binding of parent compound or its metabolites [8]."

Thank you for your suggestion. The sentence has been revised and now reads (lines 504-507):

"Such a correlation should not be expected since the processes leading to NER I, II and III are competing. If a pesticide is not degraded it can undergo aging and irreversible sorption (type I NER) and covalent binding of the parent compound or its metabolites (type II NER) [8]." 
38. line 702: add comma after reference 46

Thank you for pointing this out, see comment 39 below

39. line 704: correct text "stable carbon or nitrogen isotope (13C or 15N)"

Thank you for your suggestions. The sentence has been revised and now reads (lines 517-518)

"the formation of biogenic NER was investigated by tracking the distribution of stable carbon or nitrogen isotope $\left({ }^{13} \mathrm{Cor}^{15} \mathrm{~N}\right)$ in $\mathrm{CO}_{2}$ "

40. line 707: probably "The experimentally determined values"

Thank you for the comment. The sentence now reads (lines 519-521):

"Experiments of this kind are very helpful to discriminate between the various types of NER and to validate our biogenic NER estimation approach."

41. line 709: "although" does not make sense here since both stated results are positive The sentence has been deleted as the paragraph has been revised.

42. lines 710-714: Another example of long and confusing sentence. "together with the release of $\mathrm{CO}_{2}$ " does not make any sense here while expression "to in fact be" is meaningless and cannot be combined with "surmised".

Thank you for the comment. Yes, we agree, the sentence is too long and is barely readable in one breath. The sentence has been tidied up and is now (lines 521-524):

"Shrestha et al. [11] observed that the formation of NER occurred simultaneously with the degradation and release of $\mathrm{CO}_{2}$. This shows the coupling of the formation of NER to microbial activity, and to the growth and decay of biomass."

43. lines 718-719: "dedicated experiments"?! maybe "targeted experiments" Yes, targeted experiments done by dedicated researchers. This has been corrected on line 527-528:

"Before routine application though, further confirmation by targeted experiments is still needed"

44. lines 722-723: correct this sentence as "The MTB method was compared with two widely used bacterial growth yield estimation methods, TEEM2 and ETTYM."

Thank you for your suggestion. The sentence has been revised as suggested (lines 531-532):

"The MTB method was compared with two widely used bacterial growth yield estimation methods, TEEM2 and ETTYM."

45. line 727: correct text as "to electron acceptors other than oxygen,"

Thank you for your suggestion. The sentence has been revised (lines 536-537): "the MTB approach can be expanded to electron acceptors other than oxygen, like sulphate and nitrate."

46. line 730: delete "which is" since it is redundant

Thank you for your suggestion. The sentence has been revised (line 539):

"changes in $Y_{A T P}$, an uncertain parameter."

47. line 730: correct as "are also sensitive to"

Thank you for your suggestion. The sentence has been revised (lines 539-540):

"TEEM2 and ETTYM are also sensitive to changes in the cell formula"

48. line 731-732: correct the first part of this sentence as "All methods were insensitive with respect to the imprecise data on Gibbs energy of formation"

Thank you for your suggestion. The sentence has been revised (lines 540-543):

URL: http://mc.manuscriptcentral.com/sqer 
"All methods showed low sensitivity to variations in the Gibbs energy of formation of the organic chemicals because most of the Gibbs energy of reaction stems from the formation of the oxidation products carbon dioxide and water.

\section{9. line 748: probably "spreadsheet"}

Thank you for pointing this out. This has been corrected (line 556). Apparently my MS Word automatically changes it to "spread sheet."

50. line 749: correct text as "on request from the first author."

This has been corrected. Line 557 now reads:

"on request from the first author."

\section{Other changes}

Other changes made to the manuscript are listed here.

Line 773: "and Figures" deleted.

Lines 817-818 (deleted "anoxic"): "Comparison of bacterial growth yields of organic chemicals of environmental concern under anaerobic conditions in g cell carbon (g substrate carbon) ${ }^{-1}$."

Lines 822-823: "The entries are sorted from low to high predicted yield of MTB under nitrate-reducing conditions."

In sub-section 3.3 Prediction of biogenic NER formation based on the predicted growth yields the following sentence was deleted as it was an unnecessary repetition:

"High $\mathrm{CO}_{2}$ formation as a measure for microbial activity typically resulted in the prediction of a large biogenic NER pool."

To reflect the contributions made by the anonymous reviewers, the acknowledgements now read (lines 550-555): "This research project was financially supported by the Technical University of Denmark and the Helmholtz Centre for Environmental Research UFZ. We thank Fabio Polesel, Carson Odell Lee, and Ulrich Bay Gosewinkel for valuable suggestions and discussions. We also wish to acknowledge the comments and suggestions provided by the anonymous reviewers which helped to improve the manuscript."

After having re-examined the tables, it appears that the values in column $2\left(\mathrm{Y}^{\mathrm{EXP}}\right)$ in Table 6 are incorrectly listed. They have somehow shifted during the transfer from the spreadsheet to the text document. The values in the other columns are correct, hence, the analysis and conclusions made based on Table 6 are all correct and unchanged.

Moreover, wrong values for $Y_{\text {ATP }}(=5)$ and $\mathrm{C}-\mathrm{H}$-bonds $(=6)$ for gluconate have been used. Instead the values should have been $\mathrm{Y}_{\text {ATP }}=10$ and $\mathrm{C}-\mathrm{H}$-bonds $=12$. This has been changed in the supplementary information Table S2 and thus corrected in Table 6 and Table 7.

Additionally, the calculations made for the preparation of Table 7 also contain a minor calculation error. Instead of using $Y_{A T P}=10.5$ for the calculation of the growth yield for TEEM2 and ETTYM methods, a value of $Y_{\text {ATP }}=10.5 \times 0.8=8.4$ has been used. Table 7 has been updated with correctly calculated values. The conclusions drawn on the original erroneous calculations are still valid. 
1

2

3

4

5

6

7

8

9

10

11

12

13

14

15

16

17

18

19

20

21

22

23

24

25

26

27

28

29

30

31

33

34

35

36

37

38

39

40

41

42

43

44

45

46

47

48

49

50

51

52

53

55

56

57

59

60

Consequently, Figure S1 has also been changed to reflect this. The changes do not change any conclusion made. 
1 Supplementary Information

2

3

4 Microbial growth yield estimates from thermodynamics and its

5 importance for degradation of pesticides and formation of biogenic

7 Andreas Libonati Brock ${ }^{\mathrm{a},{ }^{*}}$, Matthias Kästner ${ }^{\mathrm{b}}$, Stefan Trapp ${ }^{\mathrm{a}}$,

18 pages; 4 tables; 1 figure

i) S1. Summary of the methods used to estimate the microbial growth yields.

ii) Table S1. Balanced half-reactions of the simple carbon substrates and the Gibbs free energy of reaction

iii) Table S2. Gibbs free energy of formation, C-H bonds, $Y_{A T P}$,

iv) Table $\mathrm{S} 3$. The relative deviation from the estimated bacterial growth yield estimated under aerobic conditions when assuming a Gibbs free energy of formation of $0 \mathrm{~kJ} \mathrm{~mol}^{-1}$.

v) Figure S1. The effect of cell formula on the yield estimate

vi) References 
31 S1. Summary of the methods used to estimate the microbial growth yields.

\section{A summary of the three methods to estimate the microbial growth yields is provided in} the following.

\section{S1.1 Microbial Turnover to Biomass (MTB)}

The Microbial Turnover to Biomass (MTB) method presented in Trapp et al. [1] was based on the work by Diekert [2] where the maximum bacterial yield is determined from the nutritional value of the substrate $(N)$ combined with the determination of bioavailable electrons from the reaction. The nutritional value describes how much substrate is needed per mass of bacteria [g substrate $(\mathrm{g} \text { biomass })^{-1}$ ]. This is subdivided into a biomass yielding (anabolic) and energy yielding (catabolic) part. The nutritional value is the inverse of the yield, when the yield is defined as gram of cells per gram of substrate

$$
\begin{aligned}
& N=N_{\text {ana }}+N_{\text {cata }}=\frac{1}{Y}=\frac{1}{Y_{\text {ana }}}+\frac{1}{Y_{\text {cata }}} \\
& \text { or } Y=\frac{Y_{\text {ana }} \times Y_{\text {cata }}}{Y_{\text {ana }}+Y_{\text {cata }}}
\end{aligned}
$$

where $Y_{\text {ana }}$ is the anabolic yield, $Y_{\text {cata }}$ is the catabolic yield, and $Y$ is the bacterial growth yield [all in g bacteria dry weight $\left.(\mathrm{dw})(\mathrm{g} \text { substrate })^{-1}\right]$.

\section{Catabolism}

The catabolic yield is determined from calculation of the Gibbs free energy released from the complete oxidation of the compound, the storage of this energy in ATP, and the bacterial growth yield on ATP

$$
Y_{\text {cata }}=\frac{\frac{\Delta G^{0^{\prime}}{ }_{\text {reaction }}}{\Delta G^{0^{\prime}}{ }_{\text {ATP }} / \eta} Y_{A T P}}{M_{S}} \quad\left[\text { g cell dw }\left(\text { g substrate }^{-1}\right]\right.
$$


$55 \Delta G^{0}{ }_{A T P}$ is the Gibbs free energy of hydrolysis of adenosine triphosphate (ATP) [30.53

$\left.56 \mathrm{~kJ} \mathrm{~mol}^{-1}[3]\right]$. Bacteria have approximately $40 \%$ efficiency in the ATP energy gain $(\eta)$

$57[2,4]$. Taking this into account, the energy needed to synthesise one mole of ATP is approximately $-80 \mathrm{~kJ}(\mathrm{~mol} \mathrm{ATP})^{-1} . Y_{A T P}$ is the bacterial yield on ATP [ $\mathrm{g}$ cell $\mathrm{dw}$ (mol

ATP $\left.)^{-1}\right]$ and its estimation is explained later. $\Delta G^{0}{ }_{\text {reaction }}$ is the Gibbs free energy of

60 reaction, $\Delta G^{0^{\prime}}$ reaction $=\Delta G^{0^{\prime}}$ products $-\Delta G^{0^{\prime}}$ reactants, at biological standard state conditions

$61 \quad\left[\mathrm{~kJ} \mathrm{~mol}^{-1}\right]$.

62

63

64

65

66

67

68

69

70

The energy released from the reaction is assumed to not be fully available for the microorganism and thus the concept of bio-available electrons was introduced [1].

The Gibbs free energy of reaction is related to the redox potential $(\Delta E)$ of the reaction through the Nernst equation

$$
\Delta G=-n \times F \times \Delta E
$$

where $n$ is the number of electrons transferred (sum of the change of oxidation status of the carbon atoms in the substrate during oxidation), and $F$ is the Faraday constant $\left[=96,485 \mathrm{C} \mathrm{mol}^{-1}\right]$.

When C-H compounds are oxidised to $\mathrm{CO}_{2}$ and $\mathrm{H}_{2} \mathrm{O}$, the transferred electrons are readily available for energy gain $\left(2 e^{-}\right.$per $\mathrm{C}-\mathrm{H}$ bond). Thus, the number of bioavailable electrons is $n_{b i o} \geq$ no. of $\mathrm{C}$ - $\mathrm{H}$ bonds $\times 2$. Therefore; the minimum bio-available energy can be calculated from the number of C-H bonds.

$$
\Delta G_{\text {bioavailable }}^{0^{\prime}}=\frac{n_{\text {bio }}}{n} \Delta G_{\text {reaction }}^{0^{\prime}}
$$

The "bio-available energy corrected" $Y_{\text {cata }}^{*}$ can then be formulated as

$$
Y_{\text {cata }}^{*}=\frac{\frac{\Delta G_{\text {bioavailable }}^{\prime}}{\left(\Delta G^{\prime}{ }_{A T P}^{\prime} / \eta\right)} Y_{A T P}}{M_{S}}
$$


80 Finally, as $Y_{A T P}$ has been shown to be variable and dependent upon the substrate (and

81 substrate concentration), e.g. [5, 6], a simple set of rules have been proposed in order to 82 define this parameter. The rules are based on the $<\mathrm{CH}_{2} \mathrm{O}>-$ "sugar-structural-similarity" of the compound [1]:

84

- If $<\mathrm{CH}_{2} \mathrm{O}>-<\mathrm{C}_{2} \mathrm{H}_{4} \mathrm{O}_{2}>$ is present in the molecule, or if oxygen is missing, $Y_{\text {ATP }}=5$

$86 \mathrm{~g}$ cell dw $(\mathrm{mol} \mathrm{ATP})^{-1}$

- If $<\mathrm{C}_{3} \mathrm{H}_{6} \mathrm{O}_{3}>-<\mathrm{C}_{4} \mathrm{H}_{8} \mathrm{O}_{4}>$ is present in the molecule, $Y_{A T P}=7.5 \mathrm{~g}$ cell $\mathrm{dw}$ (mol

$$
\text { ATP })^{-1}
$$

- If $<\mathrm{C}_{5} \mathrm{H}_{10} \mathrm{O}_{5}>-<\mathrm{C}_{6} \mathrm{H}_{12} \mathrm{O}_{6}>$ is present, $Y_{A T P}=10 \mathrm{~g}$ cell dw (mol ATP $)^{-1}$

91 Moreover, compounds not containing any "sugar-like" structure are assumed to have a carboxylic groups are not counted [1].

\section{Anabolism}

96 The anabolic yield, $Y_{a n a}$, is calculated from the carbon content in the compound (the

97 carbon source) and in the bacterial cell [2], i.e. how many grams of cell can be produced from the carbon in the compound (only carbon availability is assumed to limit growth)

$$
Y_{\text {ana }}=\frac{n_{C} M_{C}}{\sigma_{C} M_{S}} \quad\left[\mathrm{~g} \text { cell } \mathrm{dw}(\mathrm{g} \text { substrate })^{-1}\right]
$$

100

101 where $\sigma_{c}$ is the fraction of carbon in dry cell (here taken as $\sim 0.53 \mathrm{~g} \mathrm{C}\left(\mathrm{g}\right.$ cell dw) ${ }^{-1}$, with

102 the cell formula $\mathrm{C}_{5} \mathrm{H}_{7} \mathrm{O}_{2} \mathrm{~N}$ [7] but suggested to be $0.5 \mathrm{~g} \mathrm{C}$ (g cell dw) ${ }^{-1}$ in [2]), $M_{C}$ is the 
103

104

molar mass of carbon $\left(12.01 \mathrm{~g} \mathrm{~mol}^{-1}\right), M_{S}$ is the molar mass of the substrate $\left[\mathrm{g} \mathrm{mol}^{-1}\right.$ ], and $n_{c}$ is the number of carbon atoms in the substrate [mol C (mol substrate $\left.)^{-1}\right]$. To convert the yield from $\mathrm{g}$ cell $\mathrm{dw}$ (g substrate) ${ }^{-1}$ to $\mathrm{g}$ cell carbon ( $\mathrm{g}$ substrate carbon $)^{-1}$ the conversion can be determined from

$$
f_{g / c}=\frac{1}{Y_{a n a}}=\frac{\sigma_{C}}{M_{C}} \times \frac{M_{S}}{n_{C}}
$$

where $f_{g / c}$ has the unit (g cell carbon $\left.(\mathrm{g} \text { substrate carbon })^{-1}\right)\left(\mathrm{g} \text { cell dw }(\mathrm{g} \text { substrate })^{-1}\right)^{-1}$.

\section{S1.2 Thermodynamic Electron Equivalent Model 2 (TEEM2)}

In 1965 P. L. McCarty presented a thermodynamic model to estimate the maximal bacterial yield [8]. Since its inception it has been modified and expanded [9]. As the original model was found unable to capture the observed lower yields associated with C1 compounds (i.e. methanol) and for reactions involving oxygenases [4], it was recently modified [7]. The yield is calculated from an energy balance and an electron balance.

\section{Electron balance}

The electron balance states that the electrons provided by the substrate are used either in synthesis of cell material (anabolism) or in energy generation (catabolism)

$$
f_{s}^{0}+f_{e}^{0}=1
$$

where $f_{s}^{0}$ is the fraction of electrons diverted for synthesis and $f_{e}^{0}$ is the fraction of electrons diverted for energy generation (used to reduce the electron acceptor). The bacterial yield is equal to the fraction of electrons that are diverted to cell synthesis and formation of new biomass $\left(f_{s}^{0}\right)$. The yield can be calculated as g cell carbon per $\mathrm{g}$ substrate carbon (which is the very same as mol C per mol C) from the degree of 
128

129

130

reductance of the cell carbon $\left(\gamma_{c}\right)$ and the degree of reductance of the substrate carbon $\left(\gamma_{s}\right)[10]$

$$
Y_{C / C}=f_{S}^{0} \frac{\gamma_{S}}{\gamma_{C}}
$$

\section{Energy balance}

The energy balance states that the energy captured by the organism from the redox reaction is used for bacterial growth

$$
-f_{e}^{0} \epsilon \Delta G_{r}^{0^{\prime}}=f_{s}^{0} \Delta G_{s}^{0 \prime}
$$

where $\Delta G^{0}{ }_{s}$ is the Gibbs free energy for synthesis [kJ mol $\left.{ }^{-1}\right], \Delta G^{0}{ }_{r}$ is the Gibbs free energy released from the redox reaction $\left[\mathrm{kJ} \mathrm{mol}^{-1}\right]$, and $\varepsilon$ is the energy capture efficiency. $\varepsilon$ is a key parameter and is estimated from experimental data. In [7] a best fit between predicted and experimental values was observed when it was set to 0.37 - i.e. $37 \%$ of the energy released from the redox reaction is captured by the bacterium to be used in synthesis. It has generally been found to vary as a function of the growth (is it autotrophic or heterotrophic) $[4,9]$. The Gibbs free energy of reaction is defined as

$$
\Delta G_{r}^{0^{\prime}}=\Delta G_{a}^{0^{\prime}}-\Delta G_{d}^{0^{\prime}}-\frac{q}{p} \Delta G_{x y}^{0^{\prime}}
$$

where the subscript $a$ denotes the electron acceptor while $d$ denotes the electron donor of the redox reaction, $\Delta G^{0}{ }_{x y}$ is the reduction potential of $\mathrm{NADH} / \mathrm{NAD}^{+}$oxidation (equal to $-219.2 \mathrm{~kJ} \mathrm{~mol}^{-1}[7], q$ is the number of oxygenase reactions [oxygenase reactions $\mathrm{mol}^{-}$ $\left.{ }^{1}\right], p$ is the number of electron equivalents (eeq) per mole substrate [eeq $\left.\mathrm{mol}^{-1}\right]$. 
$\Delta G^{0}{ }_{s}$ is given by the Gibbs free energy associated with the transformation of the carbon source (which is often also the electron donor) to an intermediate and the subsequent synthesis of cell material from this intermediate

$$
\Delta G_{s}^{0^{\prime}}=\frac{\Delta G_{f a}^{0}{ }^{\prime}-\Delta G_{d}^{0^{\prime}}}{\epsilon^{m}}+\frac{\Delta G_{i n}^{0}{ }^{\prime}-\Delta G_{f a}^{0}{ }^{\prime}}{\epsilon^{n}}+\frac{\Delta G_{p c}^{0}{ }^{\prime}}{\epsilon}
$$

where $\Delta G^{0}{ }_{f a}$ is the Gibbs free energy of the half-reaction of formaldehyde $\left(\Delta G^{0}{ }_{f a}=\right.$ $46.53 \mathrm{~kJ} \mathrm{eeq}^{-1}$ ), $\Delta G^{0}{ }_{\text {in }}$ is the intermediate (assumed to be acetyl-CoA, a main intermediate in cell synthesis $\left.\left(\Delta G^{0}{ }_{\text {in }}=30.9 \mathrm{~kJ} \mathrm{eeq}^{-1}\right)\right)$,. $m$ is +1 when the electron donor is a $\mathrm{C} 1$ compound, else it is equal to $n . n$ is equal to +1 if $\Delta G_{i n}^{0{ }^{\prime}}-\Delta G_{d}^{0^{\prime}}>0$ (energy is needed); the energy needed to drive the reaction from electron donor to intermediate has to be divided with $\varepsilon$ to take inefficiencies into account. If $\Delta G_{i n}{ }^{\prime}-\Delta G_{d}^{0^{\prime}}<0 n$ is -1 (energy is generated); the energy generated from the reaction is captured with efficiency $\varepsilon$. The efficiency term in synthesis $(\varepsilon)$ is normally taken to be similar to the energy capture efficiency despite not being proven to be identical [11,12]. $\Delta G^{0}{ }_{p c}$ is the Gibbs free energy associated with the synthesis of cell material from the intermediate is given as

$$
\Delta G_{p c}^{0{ }^{\prime}}=\frac{\Delta G^{\circ}{ }_{A T P}}{Y_{A T P} \times 0.9} \times \frac{M_{C}}{\gamma_{c} \sigma_{c}} \quad\left[\mathrm{~kJ} \mathrm{eeq}^{-1}\right]
$$

where $\gamma_{c}$ is the average degree of reductance of the carbon atoms in the cell [eeq (mol carbon) $\left.{ }^{-1}\right], \sigma_{C}$ is the fraction of carbon in the cell [for a cell formula of $\mathrm{C}_{5} \mathrm{H}_{7} \mathrm{O}_{2} \mathrm{~N}: \gamma_{c}=4$ eeq $\mathrm{mol}^{-1}, \sigma_{c}=0.531 \mathrm{~g}$ carbon $\left.(\mathrm{g} \text { cell })^{-1}\right], \Delta G^{0{ }^{\prime}}{ }_{A T P}$ is as previously defined, $Y_{A T P}$ is as previously defined and taken as a constant and equal to $10.5 \mathrm{~g}$ cell dw (mol ATP) ${ }^{-1}$, and 0.9 is the percentage of organic material of a dry cell [g organic material ( $g$ cell dw $)^{-1}$ ]. 
175

\section{S1.3 Expanded Thermodynamic True Yield Prediction Model (ETTYM)}

The Expanded Thermodynamic True Yield Model was presented in [4] and expanded in [11] to account for oxygenase reactions and $\mathrm{pH}$.

To increase the accuracy for the yield prediction on $\mathrm{C} 1$ compounds and substrates with low degrees of reduction, the authors proposed to include a carbon and a nitrogen balance and as a result thereof reformulate the electron and energy balance originally proposed by McCarty $[4,11]$. The nitrogen balance can be ignored if nitrogen is not limiting [11], hence, the yield can be calculated from an energy balance, carbon balance, and electron balance.

\section{Carbon balance}

The carbon balance describes that the carbon is either invested in cell synthesis or into other carbonaceous products. If the only other carbonaceous product is $\mathrm{CO}_{2}$, the equation states that either carbon is incorporated into cell mass or oxidised to $\mathrm{CO}_{2}$

$$
f_{c e l l}+\sum_{i} f_{C S}(i)=1
$$

where $f_{\text {cell }}$ is the bacterial growth yield [g cell carbon (g substrate carbon) ${ }^{-1}$ ], and $f_{C S}(i)$ is the yield of carbonaceous product $i$.

\section{Energy balance}

The energy balance describes the relationship between the Gibbs free energy of cell synthesis and the Gibbs free energy captured from oxidation and reduction of various electron donor-electron acceptor pairs. If there is only one electron donor-electron acceptor pair, the energy balance can be written as 


$$
f_{\text {cell }} \times\left(\frac{\left(\Delta G_{\text {acetate }}-\Delta G_{C S}\right)}{K^{m}}+\frac{\frac{\Delta G_{A T P} \times M_{\text {cell }}}{Y_{A T P} \times 0.9}}{K}\right)=-K \times\left(g(1) \Delta G_{a}-f_{C O 2} \Delta G_{d}\right)
$$

200

where $\Delta G_{\text {acetate }}$ is the Gibbs free energy of acetate reduction $\left(=106.3 \mathrm{~kJ}(\mathrm{~mol} \mathrm{C})^{-1}\right)[11]$

$\Delta G_{C S}$ is the Gibbs free energy of the carbon source, $M_{\text {cell }}$ is the cell mass per mol carbon

$\left(=26.4 \mathrm{~g}\left(\mathrm{molC}^{-1}\right)\right.$ with cell formula $\left.\mathrm{C}_{5} \mathrm{H}_{10} \mathrm{O}_{3} \mathrm{~N}\right), g(1)$ is the number of electrons gained

by the electron acceptor (electron equivalents (eeq) (mol carbon substrate) $\left.)^{-1}\right), f_{\mathrm{CO} 2}$ is the

fraction of carbon oxidised to $\left.\mathrm{CO}_{2}(\mathrm{~mol} \mathrm{C} \text { (mol carbon substrate })^{-1}\right), K$ is the energy

206

efficiency parameter associated with (i) energy capture and storage in ATP and (ii)

207

energy transfer from ATP to cell synthesis $(K=0.41)$ [4]. While these two different

processes have different efficiencies, the values are close enough to lump them into one parameter [4]. $m$ is +1 if $\left(\Delta \mathrm{G}_{\text {acetate }}-\Delta G_{C S}\right)>0$ (energy is needed for transformation

210 of carbon source to acetate) else $m=-1$ (energy is gained from transformation of carbon

211 source to acetate). The other parameters are as previously defined for TEEM2. All half-

212 reactions are written as reductions similarly to TEEM2 and MTB, although $\Delta G_{a}$ is in kJ

$213 \mathrm{eeq}^{-1}, \Delta G_{d}$ is in $\mathrm{kJ}$ (mol substrate carbon) $)^{-1}$.

214

\section{Electron balance}

216 The electron balance states that the electrons coming from the oxidation of the electron

217 donor(s) are equal to the electrons used for reducing electron acceptors: the terminal

218 electron acceptor, nitrogen source different from ammonium, electrons lost in

219 oxygenase reactions; electrons used to reduce or increase the degree of reduction of the carbon source to the same level as the cell [4]

$$
\sum_{i} f_{E D}(i) \times\left(\gamma_{E D}-\gamma(i)\right)=\sum_{j} g(j)
$$


223 where $f_{E D}(i)$ is the fraction of electron donor going to oxidised product $i, \gamma_{E D}$ is the

224 degree of reduction of the electron donor, $\gamma(i)$ is the degree of reduction of oxidised

225 product $i, g(j)$ is the number of electrons sent to electron acceptor $j$.

If the electron donor is also the carbon source and the electrons are used only for

227 reduction of the terminal electron acceptor and synthesis of new cell material, the

228 equation reduces to (remember, $\gamma_{\mathrm{CO} 2}=0$ )

229

$$
f_{\text {CO2 }} \times\left(\gamma_{s}-\gamma_{C O 2}\right)+f_{\text {cell }}\left(\gamma_{s}-\gamma_{x}\right)=f_{C O 2} \times \gamma_{s}+f_{\text {cell }}\left(\gamma_{s}-\gamma_{x}\right)=g(1)(\mathrm{S} 19)
$$

230 where $\gamma_{s}$ is the degree of reduction of the electron donor (carbon source), and $\gamma_{x}$ is the

231 degree of reduction of the cell. 
Table S1. Balanced half-reactions as reductions of the simple carbon substrates and their associated Gibbs free energy of the half-reaction $\left(\Delta G_{r}{ }^{\circ}\right)$ in $\mathrm{kJ} \mathrm{mol}^{-1}$ and $\mathrm{kJ}$ (electron equivalent (eeq) $)^{-1}$ at standard state conditions, except for $\mathrm{H}^{+}\left(=10^{-7} \mathrm{M}\right)$.

\begin{tabular}{|c|c|c|c|}
\hline & Half-reaction & $\Delta G$ & \\
\hline Electron donor & & in $\mathrm{kJ} \mathrm{mol}^{-1}$ & $\mathrm{~kJ} \mathrm{eeq}^{-1}$ \\
\hline Acetate & $2 \mathrm{CO}_{2}+7 \mathrm{H}^{+}+8 \mathrm{e}^{-} \rightleftharpoons \mathrm{C}_{2} \mathrm{H}_{3} \mathrm{O}_{2}^{-}+2 \mathrm{H}_{2} \mathrm{O}$ & 223.4 & 27.9 \\
\hline Citrate & $6 \mathrm{CO}_{2}+15 \mathrm{H}^{+}+18 \mathrm{e}^{-} \rightleftharpoons \mathrm{C}_{6} \mathrm{H}_{5} \mathrm{O}_{7}^{3-}+5 \mathrm{H}_{2} \mathrm{O}$ & 608.1 & 33.8 \\
\hline Formaldehyde & $\mathrm{CO}_{2}+4 \mathrm{H}^{+}+4 \mathrm{e}^{-} \rightleftharpoons \mathrm{CH}_{2} \mathrm{O}+\mathrm{H}_{2} \mathrm{O}$ & 185.8 & 46.5 \\
\hline Formate & $\mathrm{CO}_{2}+\mathrm{H}^{+}+2 \mathrm{e}^{-} \rightleftharpoons \mathrm{CHO}_{2}^{-}$ & 82.8 & 41.4 \\
\hline a-D-Fructose & $6 \mathrm{CO}_{2}+24 \mathrm{H}^{+}+24 \mathrm{e}^{-} \rightleftharpoons \mathrm{C}_{6} \mathrm{H}_{12} \mathrm{O}_{6}+6 \mathrm{H}_{2} \mathrm{O}$ & 982.7 & 40.9 \\
\hline Fumaric acid & $4 \mathrm{CO}_{2}+12 \mathrm{H}^{+}+12 \mathrm{e}^{-} \rightleftharpoons \mathrm{C}_{4} \mathrm{H}_{4} \mathrm{O}_{4}+4 \mathrm{H}_{2} \mathrm{O}$ & 458.8 & 38.2 \\
\hline a-D-Galactose & $6 \mathrm{CO}_{2}+24 \mathrm{H}^{+}+24 \mathrm{e}^{-} \rightleftharpoons \mathrm{C}_{6} \mathrm{H}_{12} \mathrm{O}_{6}+6 \mathrm{H}_{2} \mathrm{O}$ & 974.6 & 40.6 \\
\hline Gluconate & $12 \mathrm{CO}_{2}+42 \mathrm{H}^{+}+44 \mathrm{e}^{-} \rightleftharpoons \mathrm{C}_{12} \mathrm{H}_{22} \mathrm{O}_{14}^{2-}+10 \mathrm{H}_{2} \mathrm{O}$ & 3151 & 71.6 \\
\hline a-D-Glucose & $6 \mathrm{CO}_{2}+24 \mathrm{H}^{+}+24 \mathrm{e}^{-} \rightleftharpoons \mathrm{C}_{6} \mathrm{H}_{12} \mathrm{O}_{6}+6 \mathrm{H}_{2} \mathrm{O}$ & 980.9 & 40.9 \\
\hline Glycerol & $3 \mathrm{CO}_{2}+14 \mathrm{H}^{+}+14 \mathrm{e}^{-} \rightleftharpoons \mathrm{C}_{3} \mathrm{H}_{8} \mathrm{O}_{3}+3 \mathrm{H}_{2} \mathrm{O}$ & 540.3 & 38.6 \\
\hline Glycine & $2 \mathrm{CO}_{2}+\mathrm{NH}_{3}+6 \mathrm{H}^{+}+6 \mathrm{e}^{-} \rightleftharpoons \mathrm{C}_{2} \mathrm{H}_{5} \mathrm{NO}_{2}+2 \mathrm{H}_{2} \mathrm{O}$ & 208.7 & 34.8 \\
\hline Glyoxylate & $2 \mathrm{CO}_{2}+3 \mathrm{H}^{+}+4 \mathrm{e}^{-} \rightleftharpoons \mathrm{C}_{2} \mathrm{HO}_{3}^{-}+\mathrm{H}_{2} \mathrm{O}$ & 210.9 & 52.7 \\
\hline Lactate & $3 \mathrm{CO}_{2}+11 \mathrm{H}^{+}+12 \mathrm{e}^{-} \rightleftharpoons \mathrm{C}_{3} \mathrm{H}_{5} \mathrm{O}_{3}^{-}+3 \mathrm{H}_{2} \mathrm{O}$ & 391.4 & 32.6 \\
\hline a-Lactose & $12 \mathrm{CO}_{2}+48 \mathrm{H}^{+}+48 \mathrm{e}^{-} \rightleftharpoons \mathrm{C}_{12} \mathrm{H}_{22} \mathrm{O}_{11}+13 \mathrm{H}_{2} \mathrm{O}$ & 2044 & 42.6 \\
\hline Malate & $4 \mathrm{CO}_{2}+10 \mathrm{H}^{+}+12 \mathrm{e}^{-} \rightleftharpoons \mathrm{C}_{4} \mathrm{H}_{4} \mathrm{O}_{5}^{2-}+3 \mathrm{H}_{2} \mathrm{O}$ & 418.2 & 34.9 \\
\hline Malonate & $3 \mathrm{CO}_{2}+6 \mathrm{H}^{+}+8 \mathrm{e}^{-} \rightleftharpoons \mathrm{C}_{3} \mathrm{H}_{2} \mathrm{O}_{4}^{2-}+2 \mathrm{H}_{2} \mathrm{O}$ & 269.4 & 33.7 \\
\hline Mannitol & $6 \mathrm{CO}_{2}+26 \mathrm{H}^{+}+26 \mathrm{e}^{-} \rightleftharpoons \mathrm{C}_{6} \mathrm{H}_{14} \mathrm{O}_{6}+6 \mathrm{H}_{2} \mathrm{O}$ & 1035 & 39.8 \\
\hline Oxalate & $2 \mathrm{CO}_{2}+2 \mathrm{e}^{-} \rightleftharpoons \mathrm{C}_{2} \mathrm{O}_{4}^{2-}$ & 114.0 & 57.0 \\
\hline Phenol & $6 \mathrm{CO}_{2}+28 \mathrm{H}^{+}+28 \mathrm{e}^{-} \rightleftharpoons \mathrm{C}_{6} \mathrm{H}_{6} \mathrm{O}+11 \mathrm{H}_{2} \mathrm{O}$ & 799.1 & 28.5 \\
\hline Phenylacetic acid & $8 \mathrm{CO}_{2}+36 \mathrm{H}^{+}+36 \mathrm{e}^{-} \rightleftharpoons \mathrm{C}_{8} \mathrm{H}_{8} \mathrm{O}_{2}+14 \mathrm{H}_{2} \mathrm{O}$ & 1131 & 31.4 \\
\hline Propionate & $3 \mathrm{CO}_{2}+13 \mathrm{H}^{+}+14 \mathrm{e}^{-} \rightleftharpoons \mathrm{C}_{3} \mathrm{H}_{5} \mathrm{O}_{2}^{-}+4 \mathrm{H}_{2} \mathrm{O}$ & 390.7 & 27.9 \\
\hline Pyruvate & $3 \mathrm{CO}_{2}+9 \mathrm{H}^{+}+10 \mathrm{e}^{-} \rightleftharpoons \mathrm{C}_{3} \mathrm{H}_{3} \mathrm{O}_{3}^{-}+3 \mathrm{H}_{2} \mathrm{O}$ & 354.8 & 35.5 \\
\hline Sorbitol & $6 \mathrm{CO}_{2}+26 \mathrm{H}^{+}+26 \mathrm{e}^{-} \rightleftharpoons \mathrm{C}_{6} \mathrm{H}_{14} \mathrm{O}_{6}+6 \mathrm{H}_{2} \mathrm{O}$ & 1035 & 39.8 \\
\hline
\end{tabular}




\begin{tabular}{|l|c|r|r|}
\hline Succinate & $4 \mathrm{CO}_{2}+12 \mathrm{H}^{+}+14 \mathrm{e}^{-} \rightleftharpoons \mathrm{C}_{4} \mathrm{H}_{4} \mathrm{O}_{4}^{-}+4 \mathrm{H}_{2} \mathrm{O}$ & 415.7 & 29.7 \\
\hline Tartrate & $4 \mathrm{CO}_{2}+8 \mathrm{H}^{+}+10 \mathrm{e}^{-} \rightleftharpoons \mathrm{C}_{4} \mathrm{H}_{4} \mathrm{O}_{6}^{2-}+2 \mathrm{H}_{2} \mathrm{O}$ & 583.9 & 58.4 \\
\hline Xylose & $5 \mathrm{CO}_{2}+20 \mathrm{H}^{+}+20 \mathrm{e}^{-} \rightleftharpoons \mathrm{C}_{5} \mathrm{H}_{10} \mathrm{O}_{5}+5 \mathrm{H}_{2} \mathrm{O}$ & 1231 & 61.5 \\
\hline
\end{tabular}


Table S2. Gibbs free energy of formation in $\mathrm{kJ} \mathrm{mol}^{-1}\left(\Delta G_{f}^{\circ}\right)$, number of carbon-hydrogen bonds, $Y_{A T P}$ in

$237 \mathrm{~g}$ dry weight $(\mathrm{mol} \mathrm{ATP})^{-1}$, number of (putative) oxygenase reactions $\left(t^{\text {oxy }}\right)$, chemical structure, and degree of reductance $\left(\gamma_{s}\right)$ of the simple carbon substrates used in the comparison.

\begin{tabular}{|c|c|c|c|c|c|c|c|}
\hline Name & Structure & $\Delta G_{f}^{\circ}{ }^{\prime}$ & C-H bonds & $Y_{A T P}$ & $t_{o x y}$ & $\gamma_{s}$ & Reference \\
\hline Acetate & $\mathrm{C}_{2} \mathrm{H}_{3} \mathrm{O}_{2}^{-}$ & -369.4 & 3 & 5 & 0 & 4 & [13] \\
\hline Citrate & $\mathrm{C}_{6} \mathrm{H}_{5} \mathrm{O}_{7}^{3-}$ & -1168.3 & 4 & 5 & 0 & 3 & [13] \\
\hline Formaldehyde & $\mathrm{CH}_{2} \mathrm{O}$ & -130.5 & 2 & 5 & 0 & 4 & [13] \\
\hline Formate & $\mathrm{CHO}_{2}^{-}$ & -351.0 & 1 & 5 & 0 & 2 & [13] \\
\hline a-D-Fructose & $\mathrm{C}_{6} \mathrm{H}_{12} \mathrm{O}_{6}$ & $\begin{array}{l}-915.4 \\
\end{array}$ & 7 & 10 & 0 & 4 & [13] \\
\hline Fumaric acid & $\mathrm{C}_{4} \mathrm{H}_{4} \mathrm{O}_{4}$ & -647.1 & 2 & 5 & 0 & 3 & [13] \\
\hline a-D-Galactose & $\mathrm{C}_{6} \mathrm{H}_{12} \mathrm{O}_{6}$ & -923.5 & 7 & 10 & 0 & 4 & [13] \\
\hline Gluconate & $\mathrm{C}_{12} \mathrm{H}_{22} \mathrm{O}_{14}{ }^{2-}$ & -880.2 & 12 & 10 & 0 & 3.7 & [14] \\
\hline a-D-Glucose & $\mathrm{C}_{6} \mathrm{H}_{12} \mathrm{O}_{6}$ & -917.2 & 7 & 10 & 0 & 4 & [13] \\
\hline Glycerol & $\mathrm{C}_{3} \mathrm{H}_{8} \mathrm{O}_{3}$ & -488.5 & 5 & 7.5 & 0 & 4.7 & [13] \\
\hline Glycine & $\mathrm{C}_{2} \mathrm{H}_{5} \mathrm{NO}_{2}$ & -370.8 & 2 & 5 & 0 & 3 & [13] \\
\hline Glyoxylate & $\mathrm{C}_{2} \mathrm{HO}_{3}^{-}$ & -459.6 & 1 & 5 & 0 & 2 & [13] \\
\hline Lactate & $\mathrm{C}_{3} \mathrm{H}_{5} \mathrm{O}_{3}^{-}$ & -517.8 & 4 & 5 & 0 & 4 & [13] \\
\hline a-Lactose & $\mathrm{C}_{12} \mathrm{H}_{22} \mathrm{O}_{11}$ & -1515.2 & 14 & 5 & 0 & 4 & [13] \\
\hline Malate & $\mathrm{C}_{4} \mathrm{H}_{4} \mathrm{O}_{5}^{2-}$ & -845.1 & 3 & 5 & 0 & 3 & [13] \\
\hline Malonate & $\mathrm{C}_{3} \mathrm{H}_{2} \mathrm{O}_{4}{ }^{2-}$ & -677.6 & 2 & 5 & 0 & 2.7 & [14] \\
\hline Mannitol & $\mathrm{C}_{6} \mathrm{H}_{14} \mathrm{O}_{6}$ & -942.6 & 8 & 5 & 0 & 4.3 & [13] \\
\hline Oxalate & $\mathrm{C}_{2} \mathrm{O}_{4}{ }^{2-}$ & -674.0 & 0 & 5 & 0 & 1 & [13] \\
\hline Phenol & $\mathrm{C}_{6} \mathrm{H}_{6} \mathrm{O}$ & -72.8 & 5 & 5 & 2 & 4.7 & [14] \\
\hline Phenylacetic acid & $\mathrm{C}_{8} \mathrm{H}_{8} \mathrm{O}_{2}$ & -136.9 & 7 & 5 & 2 & 4.5 & [14] \\
\hline Propionate & $\mathrm{C}_{3} \mathrm{H}_{5} \mathrm{O}^{-2}$ & -361.1 & 5 & 5 & 0 & 4.7 & [13] \\
\hline Pyruvate & $\mathrm{C}_{3} \mathrm{H}_{3} \mathrm{O}_{3}^{-}$ & -474.6 & 3 & 5 & 0 & 3.3 & [13] \\
\hline Sorbitol & $\mathrm{C}_{6} \mathrm{H}_{14} \mathrm{O}_{6}$ & -942.7 & 8 & 5 & 0 & 4.3 & [13] \\
\hline Succinate & $\mathrm{C}_{4} \mathrm{H}_{4} \mathrm{O}_{4}^{-2}$ & -690.2 & 4 & 5 & 0 & 3.5 & [13] \\
\hline Tartrate & $\mathrm{C}_{4} \mathrm{H}_{4} \mathrm{O}_{6}^{-2}$ & -747.5 & 2 & 5 & 0 & 2.5 & [14] \\
\hline
\end{tabular}


1

2

3

4

5

6

7

8

9

10

11

12

13

14

15

16

17

18

19

20

21

22

23

24

25

26

27

28

29

30

31

32

33

34

35

36

37

38

39

40

41

42

43

44

45

46

47

48

49

50

51

52

53

55

56

57

60

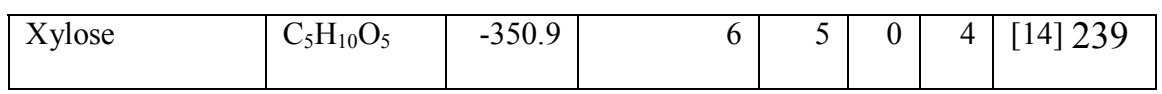


Table S3. The relative deviation from the estimated bacterial growth yield estimated under aerobic

241 conditions when assuming a Gibbs free energy of formation of $0 \mathrm{~kJ} \mathrm{~mol}^{-1}$. The deviation is computed

242 relative to the yield estimated with the Gibbs free energy of formation reported in Table 3. The mean

243 absolute deviation is computed. MTB has the lowest mean average deviation.

\begin{tabular}{|c|c|c|c|}
\hline & MTB & TEEM2 & ETTYM \\
\hline $2,4-\mathrm{D}$ & $5 \%$ & $7 \%$ & $7 \%$ \\
\hline 2,4-DB & $1 \%$ & $1 \%$ & $1 \%$ \\
\hline Acetamiprid & $-10 \%$ & $-27 \%$ & $-21 \%$ \\
\hline Acetochlor & $1 \%$ & $2 \%$ & $2 \%$ \\
\hline Alachlor & $-4 \%$ & $-8 \%$ & $-8 \%$ \\
\hline Anthracene & $-7 \%$ & $-25 \%$ & $-9 \%$ \\
\hline Atrazine & $-11 \%$ & $-27 \%$ & $-22 \%$ \\
\hline Azoxystrobin & $-3 \%$ & $-5 \%$ & $-5 \%$ \\
\hline Benalaxyl & $-4 \%$ & $-8 \%$ & $-7 \%$ \\
\hline Benzene & $-3 \%$ & $-15 \%$ & $-4 \%$ \\
\hline Benzoate & $2 \%$ & $4 \%$ & $3 \%$ \\
\hline Bifenazate & 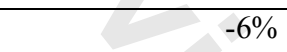 & $-10 \%$ & $-10 \%$ \\
\hline Carbofuran & $3 \%$ & $5 \%$ & $4 \%$ \\
\hline Chlorothalonil & 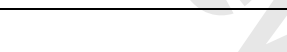 & $-6 \%$ & $-8 \%$ \\
\hline Chlorpropham & $-7 \%$ & $-11 \%$ & $-11 \%$ \\
\hline Cypermethrin & $-4 \%$ & $-6 \%$ & $-6 \%$ \\
\hline Daminozide & $0 \%$ & $0 \%$ & $0 \%$ \\
\hline DDT & $-6 \%$ & $-8 \%$ & $-8 \%$ \\
\hline Desmedipham & $-8 \%$ & $-12 \%$ & $-12 \%$ \\
\hline Dicamba & $5 \%$ & $7 \%$ & $7 \%$ \\
\hline Ethylenediaminetetraacetate (EDTA) & $18 \%$ & $39 \%$ & $30 \%$ \\
\hline Famoxadone & $-6 \%$ & $-9 \%$ & $-8 \%$ \\
\hline Glyphosate & $20 \%$ & $52 \%$ & $52 \%$ \\
\hline Iprodione & $-5 \%$ & $-7 \%$ & $-7 \%$ \\
\hline
\end{tabular}




\begin{tabular}{|c|c|c|c|}
\hline MCPA & $2 \%$ & $2 \%$ & $2 \%$ \\
\hline MCPB & $0 \%$ & $0 \%$ & $0 \%$ \\
\hline Mecoprop (MCPP) & $0 \%$ & $0 \%$ & $0 \%$ \\
\hline Metalaxyl-M & $-3 \%$ & $-5 \%$ & $-5 \%$ \\
\hline Metamitron & $-7 \%$ & $-18 \%$ & $-14 \%$ \\
\hline Milbemectin & $-3 \%$ & $-6 \%$ & $-6 \%$ \\
\hline Naphthalene & $-6 \%$ & $-25 \%$ & $-10 \%$ \\
\hline Nitrilotriacetate (NTA) & $23 \%$ & $49 \%$ & $44 \%$ \\
\hline Paraquat & $-8 \%$ & $-27 \%$ & $-14 \%$ \\
\hline Pendimethalin & $-7 \%$ & $-13 \%$ & $-13 \%$ \\
\hline Phenanthrene & $-7 \%$ & $-25 \%$ & $-9 \%$ \\
\hline Phenmedipham & $-8 \%$ & $-11 \%$ & $-12 \%$ \\
\hline Propyzamide & $-4 \%$ & $-6 \%$ & $-7 \%$ \\
\hline Pymetrozine & $-12 \%$ & $-27 \%$ & $-24 \%$ \\
\hline Pyrene & $-3 \%$ & $-12 \%$ & $-5 \%$ \\
\hline Mean absolute deviation & $6 \% \pm 5 \%$ & $14 \% \pm 13$ & $11 \% \pm 11 \%$ \\
\hline
\end{tabular}


246 Figure S1. The effect of cell formula on the yield estimate. Top: Microbial Turnover to Biomass (MTB)

247 method; middle: Thermodynamic Electron Equivalent Method 2 (TEEM2); bottom: Expanded

248 Thermodynamic True Yield Prediction Method (ETTYM). Left: The effect of the carbon content $\left(\sigma_{c}\right)$;

249 and right: the effect of degree of reductance $\left(\gamma_{c}\right)$ are shown depending on the chosen cell formula. For

250 ETTYM, the standard cell formula is $\mathrm{C}_{5} \mathrm{H}_{10} \mathrm{O}_{3} \mathrm{~N}$; for TEEM2 and MTB it is $\mathrm{C}_{5} \mathrm{H}_{7} \mathrm{O}_{2} \mathrm{~N}$. $\bullet: \mathrm{C}_{5} \mathrm{H}_{7} \mathrm{O}_{2} \mathrm{~N}\left(\sigma_{c}=\right.$

$\left.\left.\left.2510.53 \mathrm{gC}(\mathrm{g} \text { cell dry weight })^{-1}\right), \gamma_{c}=4\right), \circ: \mathrm{C}_{5} \mathrm{H}_{10} \mathrm{O}_{3} \mathrm{~N}\left(\sigma_{c}=0.45 \mathrm{gC}(\mathrm{g} \text { cell dry weight })^{-1}\right), \gamma_{c}=4.2\right) ; \boldsymbol{\nabla}$ :

252

$\left.\mathrm{C}_{5} \mathrm{H}_{8.33} \mathrm{O}_{0.8} \mathrm{~N}\left(\sigma_{c}=0.63 \mathrm{gC}(\mathrm{g} \text { cell dry weight })^{-1}\right), \gamma_{c}=4.74\right) ; \Delta: \mathrm{C}_{4.1} \mathrm{H}_{6.8} \mathrm{O}_{2.2} \mathrm{~N}\left(\sigma_{c}=0.47 \mathrm{gC}(\mathrm{g}\right.$ cell dry

253 weight $\left.)^{-1}\right), \gamma_{c}=3.85$ ). The compounds used can be found in Table S2.
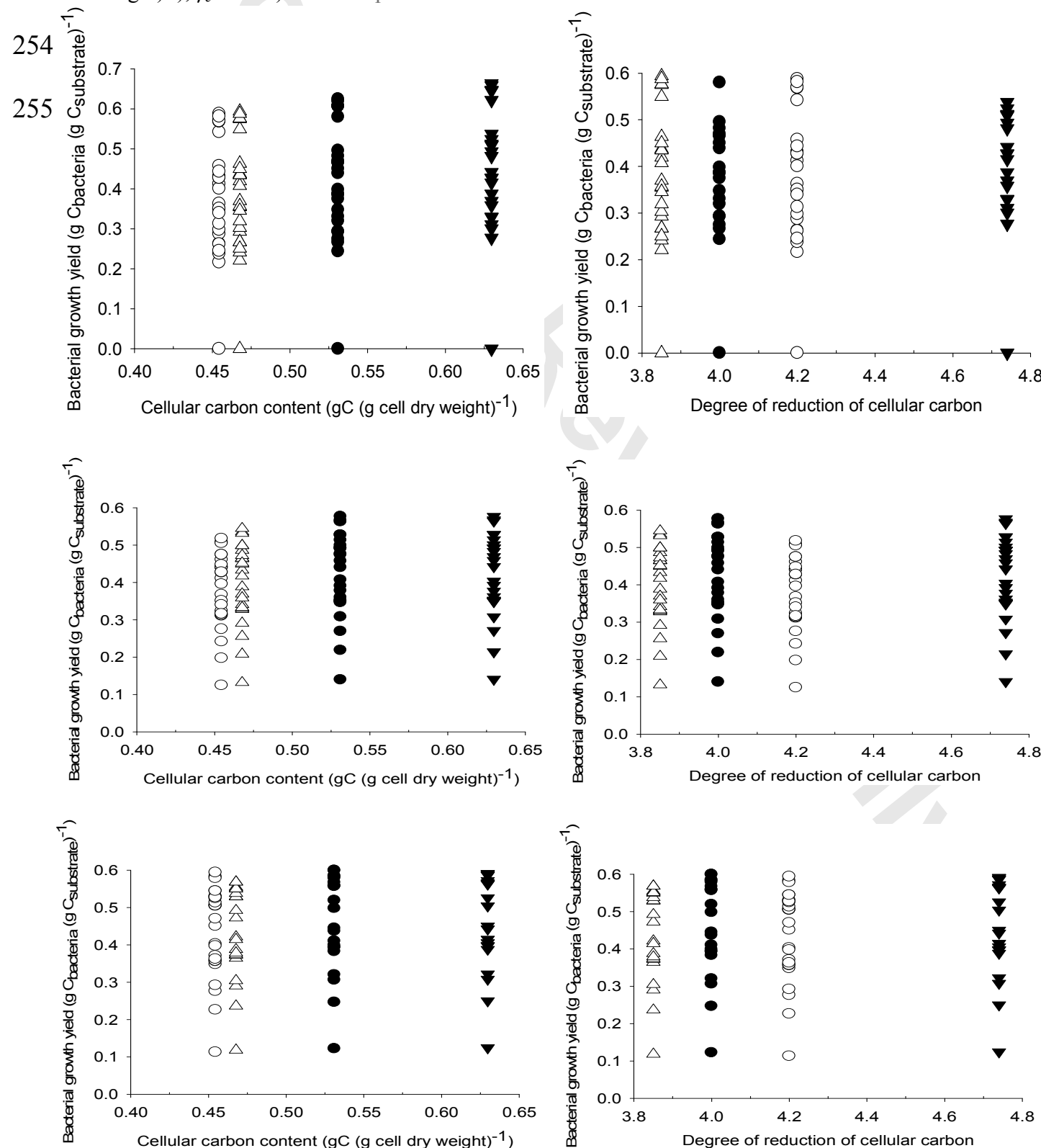

URL: http://mc.manuscriptcentral.com/sqer 


\section{References}

[1] S. Trapp, A. Libonati Brock, K. Nowak and M. Kästner, Prediction of the formation of biogenic non-extractable residues during degradation of environmental chemicals from biomass yields, Environ. Sci. Technol. (2017), Submitted for publication

[2] G. Diekert, Grundmechanismen des Stoffwechsels und der Energiegewinnung, in Umweltbiotechnologie, J.C.G. Ottow and W. Bidlingmaier, eds., Fischer Verlag, Stuttgart, Germany, 1997; pp. 1-38.

[3] K. Burton, Energy of adenosine triphosphate. Nature 181 (1958), pp. 1594-1595.

[4] J. Xiao, and J.M. VanBriesen, Expanded thermodynamic model for microbial true yield prediction, Biotechnol. Bioeng 93 (2006), pp. 110-121.

[5] J.J. Heijnen, and J.P. Dijken, In search of a thermodynamic description of biomass yields for the chemotrophic growth of microorgansims, Biotechnol Bioeng 39 (1992), pp. 833-852

[6] D. W. Tempest and O.M. Neijssel, The Status of $Y_{\text {atp }}$ and Maintenance Energy as Biologically Interpretable Phenomena. Ann. Rev. Microbiol., 38 (1984), pp. 459486.

[7] P.L. McCarty, Thermodynamic Electron Equivalents Model for bacterial yield prediction: Modifications and comparative evaluations, Biotechnol. Bioeng 97 (2007), pp. 377-388.

[8] P.L. McCarty, Thermodynamics of biological synthesis and growth, Intl. J. Air Water Poll. 9 (1965), pp. 621-639.

[9] B.E. Rittmann, P.L. McCarty, Environmental biotechnology: principles and applications. McGraw-Hill: New York, NY, 2001.

[10] J.M. VanBriesen, Thermodynamic yield predictions for biodegradation through oxygenase activation reactions, Biodegradation 12 (2001), pp. 265-281.

[11] J. Xiao, and J.M. VanBriesen, Expanded thermodynamic true yield prediction model: adjustments and limitations, Biodegradation 19 (2008), pp. 99-127.

[12] J.M. VanBriesen, Evaluation of methods to predict bacterial yield using thermodynamics, Biodegradation 13 (2002), pp. 171-190.

[13] R.K. Thauer, K. Jungermann, and K. Decker, Energy conservation in chemotrophic anaerobic bacteria, Bacteriol. Rev. 41 (1977), pp. 100-180. 
290 [14] A. Flamholz, E. Noor, A. Bar-Even, and R. Milo, eQuilibrator - the biochemical thermodynamics calculator, Nucleic Acids Res. 40 (2012), pp. 770-775. 